\title{
Efeito de não linearidades estruturais na resposta aeroelástica de aerofólios
}

Dissertação apresentada à Escola de Engenharia de São Carlos da Universidade de São Paulo, como parte dos requisitos para a obtenção do título de Mestre em Engenharia Mecânica.

Área de concentração: Aeronaves

ESTE EXEMPLAR TRATA-SE DA VERSÃO CORRIGIDA.

A VERSÃO ORIGINAL ENCONTRASE DISPONÍVEL JUNTO AO DEPARTAMENTO DE ENGENHARIA MECANICA DA EESC-USP.

Orientador: Prof. Associado Flávio Donizeti Marques

Coorientador: Dr. Rui Marcos Grombone de Vasconcellos

São Carlos 
AUTORIZO A REPRODUÇÃO TOTAL OU PARCIAL DESTE TRABALHO, POR QUALQUER MEIO CONVENCIONAL OU ELETRÔNICO, PARA FINS DE ESTUDO E PESQUISA, DESDE QUE CITADA A FONTE.

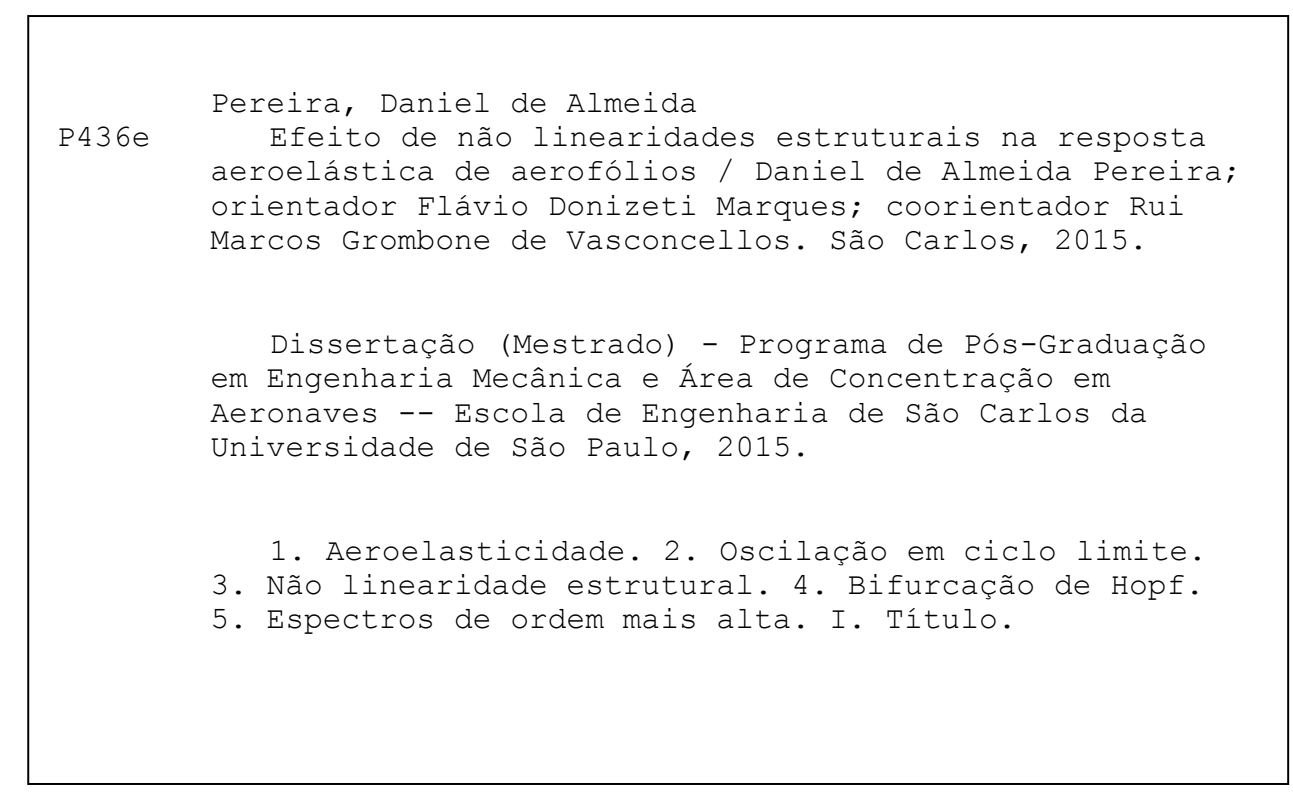




\section{FOLHA DE JULGAMENTO}

Candidato: Engenheiro DANIEL. DE ALMEIDA PEREIRA.

Título da dissertação: "Efeito de não linearidades estruturais na resposta aeroelástica de aerofólios".

Data da defesa: 04/08/2015

Comissão Julgadora:

Resultado:

Prof. Dr. Rui Marcos Grombone de Vasconcellos (Orientador)

APROVADO

(Universidade Estadual Paulista "Júlio de Mesquita Filho"/UNESP - São João da Boa Vista)

Prof. Associado Carlos Dias Maciel

(Escola de Engenharia de São Carlos/EESC)

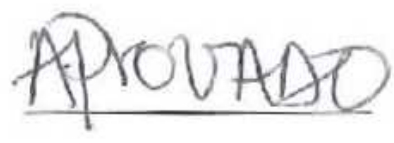

Prof. Dr. Domingos Alves Rade

APAOVADO

(Instituto Tecnológico de Aeronáutica/ITA)

Coordenador do Programa de Pós-Graduação em Engenheira Mecânica: Prof. Associado Gherhardt Ribatski

Presidente da Comissão de Pós-Graduação:

Prof. Associado Paulo César Lima Segantine 
"À minha família." 
"Só existem dois dias no ano que nada pode ser feito. Um se chama ontem e o outro se chama amanhã, portanto hoje é o dia certo para amar, acreditar, fazer e principalmente viver".

Dalai Lama 


\section{Agradecimentos}

Primeiramente eu gostaria de agradecer toda a minha família, cada um sabe o carinho e amor que tenho por vocês e o quão são importantes na minha vida. Vocês me deram e dão forças para seguir em frente e enfrentar qualquer desafio. Em especial, ao meu pai João Afonso que sempre me inspirou força e determinação para vencer todos os obstáculos e a minha mãe Eliana que é a minha fortaleza e meu exemplo de coragem para sempre dizer a verdade e seguir em frente. Sem o amor e carinho de vocês dois nada disso seria possível. Quero agradecer também a minha avó materna Mariana que sempre esteve presente na minha vida demostrando muito carinho e amor, e a minha avó paterna Maria, que sempre estará presente entre nós, a qual dedico este trabalho em sua memória.

Em especial agradeço ao meu orientador Prof. Flávio D. Marques, o qual considero um grande amigo. Sem a sua sabedoria, paciência e as incontáveis discussões e debates nada disso teria acontecido. Quero frisar aqui a sua honestidade e o valor da sua palavra.

Quero agradecer aos importantes comentários dados pelo Prof. Rui M. G. Vasconcellos que foi meu coorientador e que vem me ajudando desde a época da graduação.

Também quero agradecer a minha namorada Juliana que esteve presente durante todos os momentos que precisei e me apoiou e auxiliou em todas as minha decisões, seu carinho e amor foram muito importantes para a elaboração desse trabalho.

I want to thank Dr. Muhammad R. Hajj by the scientific contributions and by the hospitality that he received me at Virginia Tech. I am very grateful to my good friend and co-worker Mohamed Zakaria and his family, they were awesome with me. I thank all the students and staff at Virginia Tech that I had the pleasure of meeting. I also want to thank especially Trei 
Green and Chris Dauphin, who received me in their home and much more than this, they became my great friends. I hope to see you one day here in Brazil. Obrigado também ao meu amigo americano Matthew Nuar que tem alma de brasileiro.

Não poderia deixar de agradecer a todos os funcionários da USP, em especial Claudinho, Mazé, Gisele, João, Fábio Galo, Paulo, entre outros que fizeram parte dessa etapa da minha vida. A todos os meus amigos da pós-graduação da Eng. Aeronáutica com os quais passei momentos valiosos, em especial ao Marcel que me ajudou muito me hospedando na etapa final desse trabalho.

A todos os meus amigos da república BML, que fazem e fizeram parte de grandes momentos da minha vida. Ao meu grande amigo e irmão Eric Eduardo, obrigado por essa grande amizade. E a todos os outros grandes amigos, em especial ao Germano, Murillo e Vicente. Agradeço também ao meu amigo Sr. Anísio e família, com o qual vivo aprendendo o valor da humildade. Obrigado também ao Abrahao, a Jô e família que sempre me receberam como um filho. E, finalmente, agradeço a tia Márcia que é um dos grandes exemplos de pessoas que possuem luz própria a qual muito admiro e me espelho.

Agradeço a CAPES (Coordenação de Aperfeiçoamento de Pessoal de Nível Superior) pela suporte financeiro dado essa a pesquisa através da bolsa concedida, cujo número do processo é 0011/07-0.

Agradeço principalmente a Deus pela sua luz que guia meus passos. 


\section{Conteúdo}

Resumo $\quad$ xi

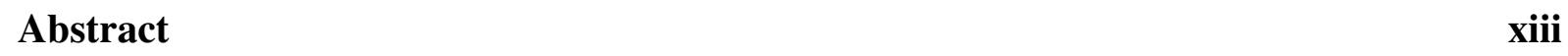

Lista de Símbolos $\quad$ xv

1 INTRODUÇÃO 1

1.1 Não linearidades em sistemas aeroelásticos . . . . . . . . . . . . . . . . . 10

1.2 Técnicas de identificação e análise de séries temporais. . . . . . . . . . . . 15

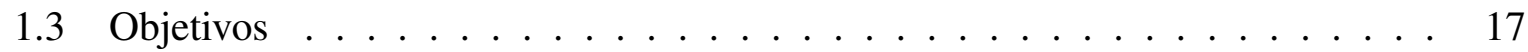

1.4 Organização da dissertação . . . . . . . . . . . . . . . . . . . 17

2 MODELO AEROELÁSTICO 19

2.1 Introdução . . . . . . . . . . . . . . . . . . . . . . . . . 19

2.2 Modelo matemático . . . . . . . . . . . . . . . . . . . . . . . . . . 19

2.2.1 Aerodinâmica não estacionária . . . . . . . . . . . . . . . . . . . 24

2.2.2 Representação das equações de movimento no espaço de estados . . . . 28

2.2.3 Representação das não linearidades estruturais . . . . . . . . . . . . . 30

2.3 Modelo experimental . . . . . . . . . . . . . . . . . . 32 
$3 \quad$ ANÁLISE DE SÉRIES TEMPORAIS 37

3.1 Introdução . . . . . . . . . . . . . . . . . . . . . 37

3.2 Análise da bifurcação de Hopf . . . . . . . . . . . . . . . . . . . 37

3.3 Reconstrução do espaço de estados . . . . . . . . . . . . . . . . . 38

3.4 Espectros de ordem mais alta . . . . . . . . . . . . . . . . . . . 42

4 RESULTADOS

4.1 Introdução . . . . . . . . . . . . . . . . . . . . . . . . . . . 49

4.2 Determinação dos parâmetros do sistema . . . . . . . . . . . . . . . . . . . 49

4.3 Análise através das séries temporais . . . . . . . . . . . . . . 56

4.4 Bifurcações de Hopf . . . . . . . . . . . . . . . . . . . . . . . . . 61

4.4.1 Influência da não linearidade de enrijecimento . . . . . . . . . . . 61

4.4.2 Influência da não linearidade de folga . . . . . . . . . . . . . 63

4.4.3 Bifurcações subcríticas versus supercríticas . . . . . . . . . . . . 65

4.5 Análise por espectros de ordem mais alta . . . . . . . . . . . . . . . . . . 69

5 CONCLUSÃO

A Funções T de Theodorsen $\quad 79$

$\begin{array}{lr}\text { Bibliografia } & 81\end{array}$ 


\section{Resumo}

Pereira, D.A. (2015). Efeito de não linearidades estruturais na resposta aeroelástica de aerofólios. São Carlos, 2015. Dissertação (Mestrado) - Escola de Engenharia de São Carlos, Universidade de São Paulo.

A aeroelasticidade estuda a interação mútua entre os efeitos aerodinâmicos e estruturais. É sabido que essa relação muitas vezes se comporta de maneira não linear, causando diversos problemas, tais como flutter, oscilações em ciclo limite, bifurcações e caos. Tais fenômenos são difíceis de serem diagnosticados, podendo causar problemas graves à estrutura das aeronaves e também inviabilizar as suas operações. Dentre as principais fontes de não linearidades em sistemas aeroelásticos, pode-se citar as de origem aerodinâmica e estrutural. As de origem estrutural, por sua vez, podem ter caráter distribuído ou concentrado. Sabe-se que os efeitos estruturais concentrados denominados enrijecimento e folga são os de maior impacto na aeroelasticidade não linear. Desse modo, o objetivo desse trabalho é estudar a interação não linear entre duas não linearidades estruturais, ou seja, o enrijecimento associado à rigidez em torção e a folga presente nas articulações das superfícies de controle de seções típicas aeroelásticas. Experimentos em túnel de vento são realizados utilizando um dispositivo que permite variar a intensidade do efeito de enrijecimento e do tamanho da folga na articulação da superfície de comando. O modelo numérico de seção típica aeroelástica também é utilizado e validado com dados experimentais. Análises por meio de diagramas de bifurcação de Hopf e técnicas baseadas em espectros de potência são utilizadas. Todas as respostas aeroelásticas foram caracterizadas através de ferramentas de análise nos domínios do tempo e da frequência, como técnica de reconstrução de espaço de estados e os espectros de alta ordem (HOS), os quais são importantes na identificação dos tipos de acoplamentos não lineares. Resultados indicam que a combinação dos efeitos de enrijecimento e folga são responsáveis pelo comportamento subcrítico das bifurcações de Hopf e que a intensidade do enrijecimento tem influência direta nas amplitudes de ciclo limite.

Palavras chave: Aeroelasticidade, oscilação em ciclo limite, não linearidade estrutural, bifurcação de Hopf, espectros de alta ordem. 


\section{Abstract}

Pereira, D.A. (2015). Effect of structural nonlinearities in the aeroelastic response of airfoils. São Carlos, 2015. Dissertação (Mestrado) - Escola de Engenharia de São Carlos, Universidade de São Paulo.

Aeroelasticity is the field of engineering that deals with the mutual interaction between the aerodynamic and structural dynamics effects. It is known that this relationship often shows nonlinear behavior, causing various problems such as flutter, limit cycle oscillations, bifurcations and chaos. Such phenomena are difficult to predict and can cause serious problems to the aircraft structure and also they can jeopardize their operations. The unsteady aerodynamic and structural dynamics provide the main sources of nonlinearities in aeroelastic systems. Structural nonlinearities can be treated as distributed or concentrated effects. It is know that the nonlinear concentrated structural effects referred as hardening and freeplay have a significant impact on nonlinear aeroelasticity. The objective of this work is to analyze an aeroelastic system under the influence of combined structural nonlinearities, i.e., the hardening nonlinearity in the pitch airfoil motion and the freeplay nonlinearity in the control surface hinge. Wind tunnel experiments are carried out using one device that allows to vary the intensity of the hardening effect and the size of the freeplay gap in the control surface hinge. The numerical model of the typical aeroelastic section is also used and validated with experimental data. All aeroelastic responses are characterized by analytical tools in time and frequency domains. It was used the state space reconstruction technique and the higher order spectral analysis (HOS) to identify types of nonlinear couplings. The results indicate that the combination of hardening and freeplay effects are responsible for inducing the subcritical behavior on the Hopf bifurcations and that the intensity of the stiffness has a direct influence on the limit cycle amplitudes.

Keywords: Aeroelasticity, limit cycle oscillation, structural nonlinearities, Hopf bifurcation, higher order spectral analysis. 


\section{Lista de Símbolos}

\begin{tabular}{|c|c|}
\hline$a$ & distância adimensional entre o EE e a corda média; \\
\hline$b$ & semicorda do aerofólio; \\
\hline$c$ & distância adimensional entre o EE da SC e a corda média; \\
\hline$C(k)$ & função de Theodorsen; \\
\hline$c_{i}(i=0,2 \cdots 4)$ & constantes da aproximação de Sears; \\
\hline$d_{i, j}$ & elementos que compõe a matriz de amortecimento; \\
\hline$E_{p}$ & energia potencial; \\
\hline$F(\alpha)$ & não linearidade do tipo enrijecimento presente em torção; \\
\hline$F(\beta)$ & não linearidade do tipo folga presente na SC; \\
\hline$h$ & movimento de flexão (plunge); \\
\hline$I_{\alpha}$ & momento de inercia da asa em relação ao EE da mesma; \\
\hline$I_{\beta}$ & momento de inercia da SC em relação ao EE da mesma; \\
\hline$k$ & frequência reduzida; \\
\hline$k_{h}, k_{\alpha}, k_{\beta}$ & rigidez de flexão, de torção e da SC respectivamente; \\
\hline$L^{N C}$ & termo não circulatório da sustentação; \\
\hline$L^{C}$ & termo circulatório da sustentação; \\
\hline$L(t)$ & força de sustentação; \\
\hline$L$ & função de Lagrange; \\
\hline$M_{\alpha}^{N C}$ & termo não circulatório do momento aerodinâmico da asa; \\
\hline$M_{\beta}^{N C}$ & termo não circulatório do momento aerodinâmico da SC; \\
\hline$M_{\alpha}^{C}$ & termo circulatório do momento aerodinâmico da asa; \\
\hline$M_{\beta}^{C}$ & termo circulatório do momento aerodinâmico da SC; \\
\hline
\end{tabular}




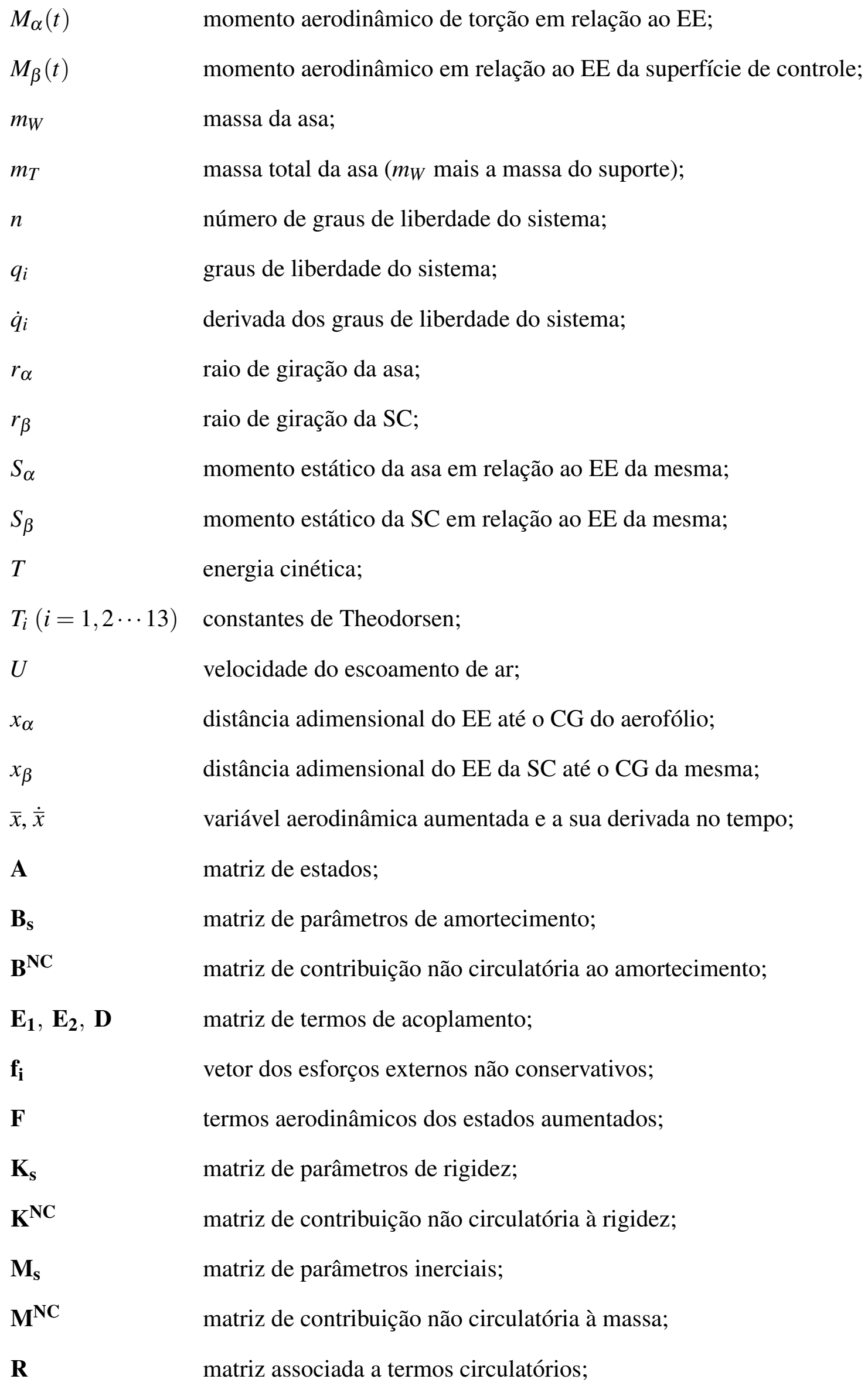




$\begin{array}{ll}\mathbf{S}_{\mathbf{1}}, \mathbf{S}_{\mathbf{2}}, \mathbf{S}_{\mathbf{3}} & \text { vetores associados aos termos circulatórios; } \\ \mathbf{X} & \text { vetor de estados; } \\ \alpha & \text { movimento de torção (pitch); } \\ \beta & \text { movimento da superfície de controle; } \\ \mu_{e} & \text { razão entre a massa total e a massa da asa; } \\ \xi(t) & \text { razão entre o deslocamento de flexão e a semi corda; } \\ \rho & \text { densidade do ar; } \\ \sigma & \text { variável de integração; } \\ \tau & \text { tempo adimensional; } \\ \phi(\tau) & \text { função de Wagner; } \\ \omega_{h}, \omega_{\alpha}, \omega_{\beta} & \text { frequência natural de flexão, de torção e da SC respectivamente; } \\ \Omega_{\text {exp }} & \text { frequência fundamental experimental; } \\ \Omega_{\text {num }} & \text { frequência fundamental numérica. }\end{array}$

\section{Acrônimos:}

CFD

CG

EE

HOS

LCO

RMS

RP

SC computational fluid dynamics;

centro de gravidade;

eixo elástico;

higher order spectral analysis;

limit cycle oscillation ou oscilações em ciclo limite;

root mean square ou valor eficaz;

razão de polinômios;

superfície de controle ou superfície de comando. 


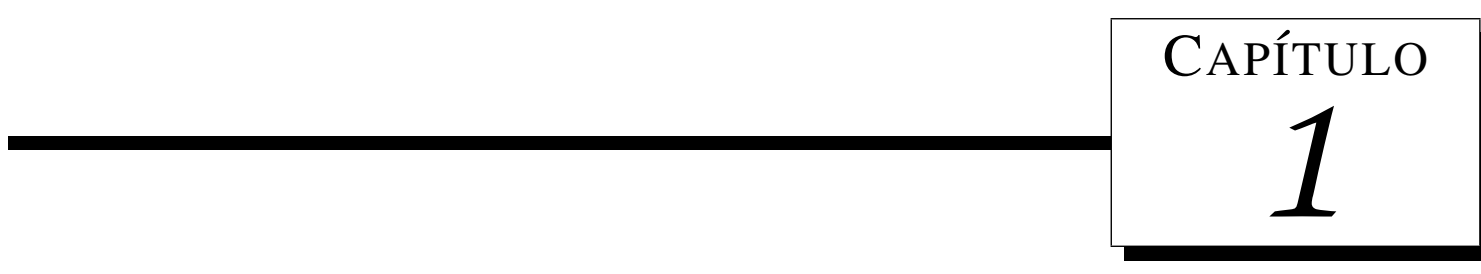

\section{INTRODUÇÃO}

Aeroelasticidade é um termo na engenharia aeronáutica que se refere ao campo de estudo que compreende a interação entre as deformações elásticas de uma estrutura e o efeito das forças aerodinâmicas vindas do escoamento de ar. A natureza interdisciplinar desse campo é melhor ilustrada através da Figura 1.1, que se originou nos anos 40 com o Prof. A. R. Collar (COLLAR, 1946). A Figura 1.1 mostra um triângulo formado pela ligação entre três principais disciplinas: aerodinâmica (A), dinâmica (I) e elasticidade (E). A aerodinâmica clássica estuda as forças que atuam em um corpo sob o escoamento de ar. A elasticidade estuda o comportamento de corpos sólidos que se deformam ao serem submetidos a ações de forças externas, e a dinâmica estuda os efeitos das forças inerciais sobre os corpos e como eles se comportam e interagem entre si ao longo do tempo. Os fenômenos associados a esses três campos podem interagir entre eles criando outras quatro subaéreas de estudos: mecânica de voo (MV), dinâmica estrutural (DE), aeroelasticidade estática (AE) e aeroelasticidade dinâmica (AD). O campo de mecânica de voo envolve a interação entre a aerodinâmica e a dinâmica das aeronaves, sendo uma importante disciplina em todas as fases de projetos de aeronaves. Os outros três campos têm em comum a área regida pelas forças elásticas e são formados pela relação: (i) entre elasticidade e dinâmica, chamado de dinâmica estrutural. (ii) entre aerodinâmica e elasticidade, chamado de aeroelasticidade estática. (iii) entre os três, chamada de aeroelasticidade dinâmica (HODGES; PIERCE, 2011). 


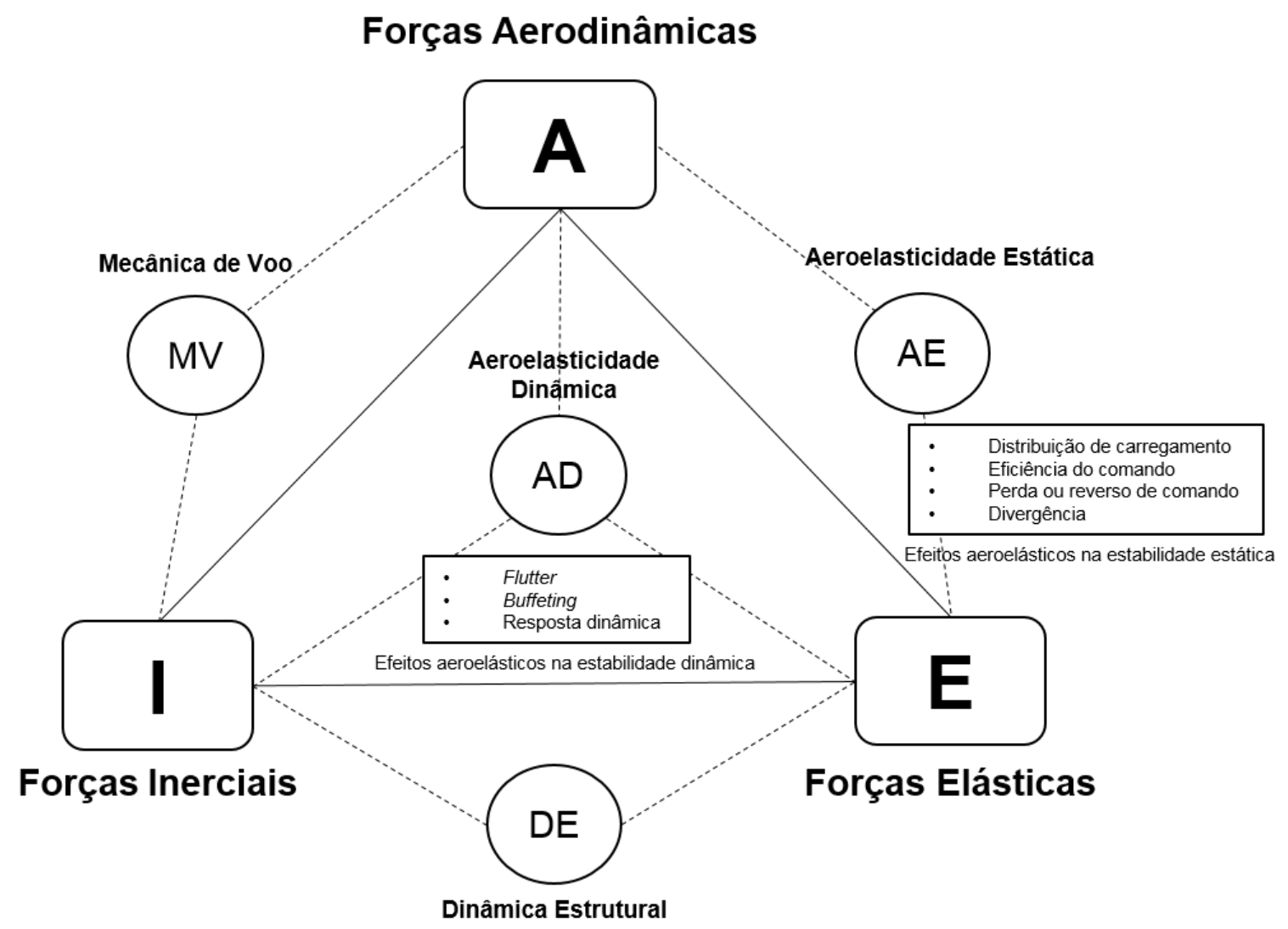

Figura 1.1: Campo de estudo da aeroelasticidade baseado no triângulo de Collar (COLLAR, 1946).

A aeroelasticidade estática estuda os fenômenos e os problemas associadas com o comportamento estático e a estabilidade de um sistema aeroelástico no estado de equilíbrio. Os principais fenômenos são:

- Divergência. É um fenômeno relacionado a instabilidade estática. O aumento da sustentação deve-se ao aumento no ângulo de ataque das asas. Se a pressão dinâmica do escoamento for suficientemente alta, o efeito aerodinâmico se torna mais forte que o efeito das forças restauradoras elásticas, levando ao aumento instável do ângulo de ataque o que pode levar ao colapso da estrutura da aeronave. Caso essa velocidade não seja crítica a asa permanece estaticamente deformada.

- Perda ou reversão de comando. Quando a superfície de comando é acionada positivamente e negativamente espera-se que ocorra um aumento e uma diminuição da sustentação, respectivamente. Contudo, devido ao arqueamento do aerofólio, nessas 
condições há sempre geração de um momento aerodinâmico negativo, antagônico à deflexão da superfície de comando. Desse modo, há condições nas quais essa parcela tornase suficientemente grande, gerando um efeito aeroelástico contrário ao esperado.

- Distribuição de carregamento. Devido ao efeito aeroelástico, a distribuição da sustentação da asa tende a aumentar em intensidade ao longo da semi-envergadura, sendo que quanto mais próximo da ponta da asa, maior será a sustentação (ver Figura 1.2).

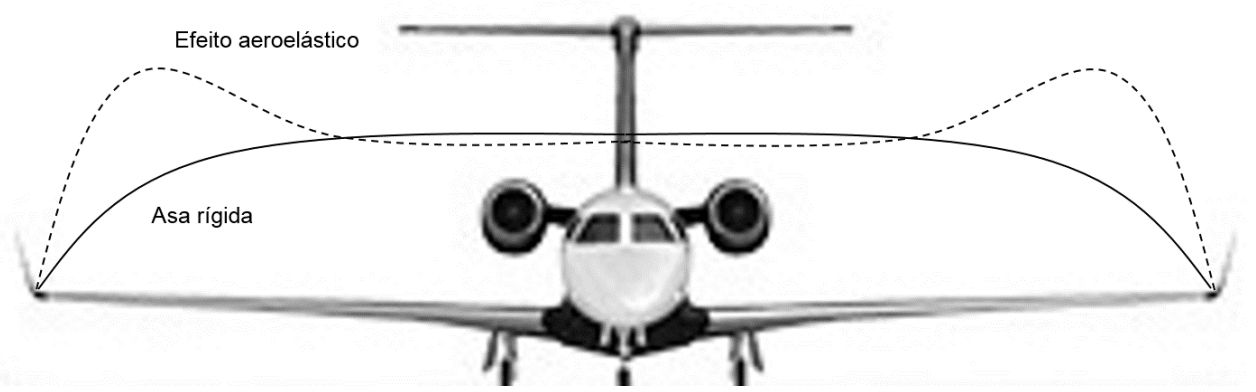

Figura 1.2: Efeito aeroelástico na distribuição do carregamento aerodinâmico.

A aeroelasticidade dinâmica estuda o efeito combinado das forças aerodinâmicas, inerciais e elásticas no sistema, sendo considerada um campo multidisciplinar de estudo da engenharia aeronáutica que trabalha os problemas de interação mútua entre dinâmica estrutural (forças inerciais e elásticas) e escoamento aerodinâmico não-estacionário (BISPLINGHOFF; ASHLEY; HALFMAN, 1996). Os principais fenômenos associados são:

- Flutter. É um fenômeno relacionado à instabilidade dinâmica. Sistemas dinâmicos estruturais possuem amortecimento estrutural que pode ser medido quando não há forças aerodinâmicas agindo no dispositivo. Quando a velocidade do ar é aumentada, o amortecimento aumenta devido à parcela de amortecimento vinda da aerodinâmica. Contudo, quando a velocidade do escoamento atinge um determinado valor, o amortecimento passa a diminuir rapidamente. Desse modo, há um ponto chamado de velocidade crítica de flutter onde o amortecimento resultante é zero e o dispositivo, ao receber uma força externa, fica instável, com oscilações autoexcitadas. Acima dessa velocidade, qualquer perturbação externa poderá causar oscilações com amplitude crescendo exponencialmente, o que pode levar o dispositivo a uma falha catastrófica. 
- Buffeting. É uma vibração instável de alta frequência caracterizada por oscilações transientes induzidas pela esteira aerodinâmica de um componente em outro, como exemplo tem-se o efeito da esteira da asa induzindo vibrações no profundor.

- Resposta dinâmica de uma aeronave. Refere-se à capacidade da aeronave de se manter estável quando está sob efeito de ventos e rajadas. Toda aeronave deve ser projetada para recuperar a estabilidade dinâmica, ou seja, o sistema deve ser estável em qualquer condição de voo, mesmo que para isso ele necessite de controle ativo, também conhecido como aeroservoelasticidade.

O primeiro caso de flutter documentado da história aconteceu em 1916, com a aeronave Handley Page O/400 (Figura 1.3 (a)) que sofreu violentas oscilações de cauda como resultado do acoplamento do modo de torção da fuselagem com o modo de rotação antissimétrico do profundor. Durante a Primeira Guerra mundial foi feito um grande esforço a fim de entender e prever os efeitos aeroelásticos. Como resultado o número de acidentes relacionados aos problemas aeroelásticos diminuíram de 146 no período de 1933-1945 para sete entre 1960 e 1972 (HENSHAW et al., 2007). Nessa época, Frazer (1929) compilou um documento clássico na área que ficou conhecido como "The Flutter Bible", no qual os tratamentos descritos para a análise e prevenção dos problemas de vibrações na engenharia aeronáutica lançaram as bases para as técnicas em uso hoje. Novos problemas aeroelásticos surgiram com as aeronaves que voavam em voo transônico. Em 1944 durante os testes de voo da aeronave P-80 (primeira aeronave a atingir Mach 0,7, ver Figura 1.3 (b)), os pilotos da NACA reportaram oscilações autoexcitadas do aileron em torno da sua dobradiça de fixação. De 1947 a 1956, ocorreram mais 21 incidentes de flutter envolvendo oscilações constantes em superfície de controle durante voos transônicos. Os caças F-100 e F-111 apresentaram esse mesmo efeito no leme (aeronaves que atingem Mach $\geq 1$, ver Figura 1.3 (c) e 1.3 (d), respectivamente). Hoje, voos em regime transônico ainda são considerados os mais críticos do ponto de vista aeroelástico (DOWELL, 2014). O fenômeno de flutter de painel, que aparece mais frequentemente em determinados regimes de voos transônicos e supersônicos, é uma instabilidade dinâmica autoexcitada que ocorre 
em placas finas e cascas dos componentes de um veículo aeroespacial, levando o dispositivo a apresentar oscilações em ciclo limite (do inglês, limit cycle oscillation, LCO) com grandes deslocamentos transversais que podem causar falha por fadiga estrutural (FUNG, 1963; DOWELL, 1970). Dispositivos externos também afetam os problemas de estabilidade aeroelásticos. Sete problemas de flutter foram documentados entre 1947 e 1956 envolvendo o pilone e o motor das aeronaves. Mais detalhes da história dos problemas aeroelásticos podem ser encontrado em Garrick e Reed-III (1981).

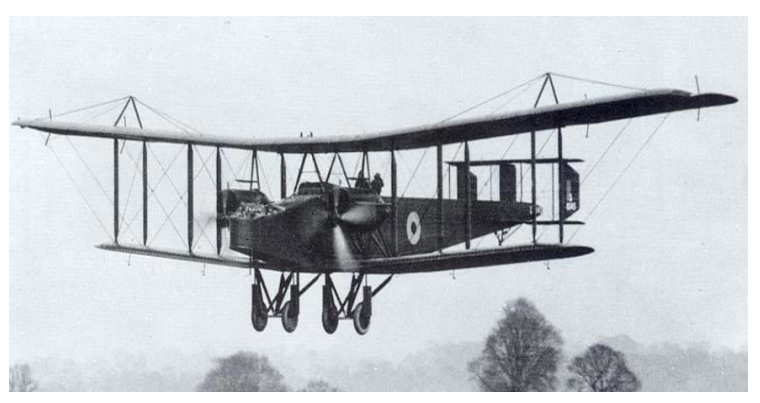

(a) Handley Page $\mathrm{O} / 400$

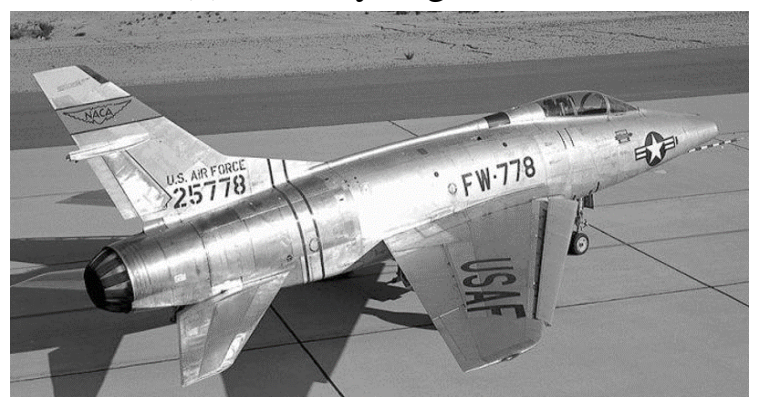

(c) F-100

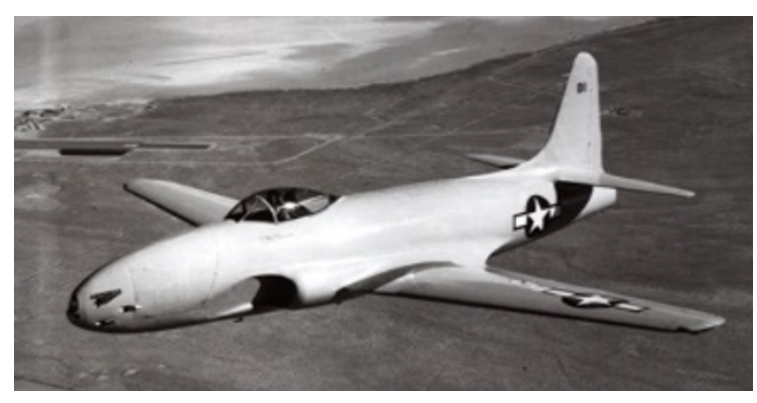

(b) P-80

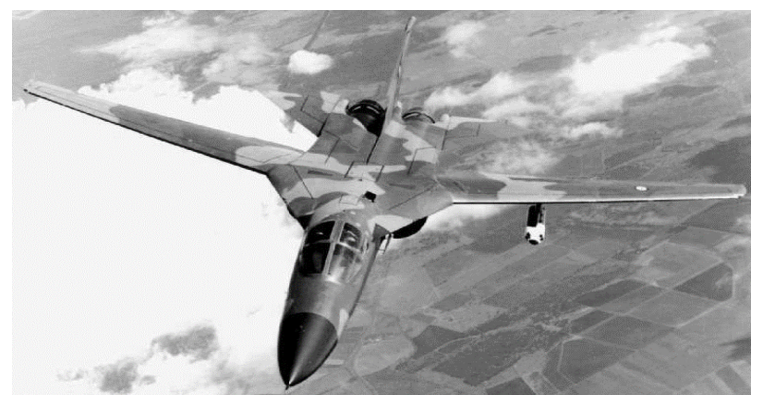

(d) F-111

Figura 1.3: Aeronaves que apresentaram fenômenos aeroelásticos indesejados (fonte: en.wikipedia.org).

Problemas com dispositivos externos que são anexados às aeronaves representam grandes desafios, particularmente devido às muitas configurações de dispositivos que um avião pode transportar. Certas combinações de acessórios externos carregados pelas aeronaves militares modernas e movimentos aerodinâmicos das ondas de choque no F-14, F-16, F-18 e B-1 (ver Figuras 1.4 (a) até (d), respectivamente) produzem oscilações em ciclo limite em determinados regimes de voo. Embora essas oscilações sejam caracterizadas quase que a maioria por oscilações periódicas com amplitude limitada, testes em voo demonstraram que essa amplitude pode diminuir ou aumentar devido às forças aerodinâmicas que são funções do ângulo de ataque e da velocidade da aeronave. Desse modo, pode-se concluir que a aeroelasticidade tem 
um papel importante no desenvolvimento e projeto das aeronaves. Nota-se que a maioria dos incidentes reportados têm ocorrido com aviões militares, uma vez que eles tendem a atingir condições mais críticas do envelope de voo. Contudo, a utilização de asa finas, estabilizadores horizontais, estabilizadores verticais móveis, configurações de cauda em T, materiais mais leves e estruturas mais complexas aumentaram a probabilidade de ocorrência do flutter em aeronaves comerciais e também militares (LIVNE, 2003; LIVNE; WEISSHAAR, 2003; HODGES; PIERCE, 2011).

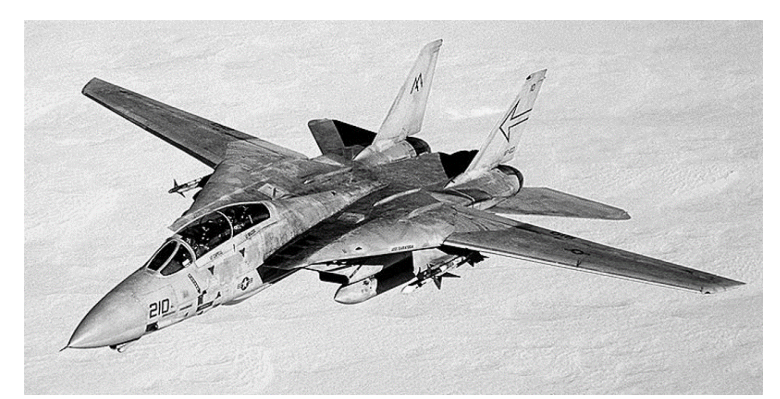

(a) F-14

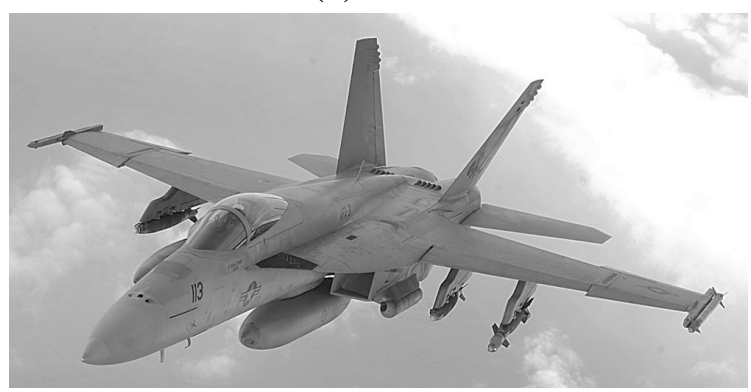

(c) F-18

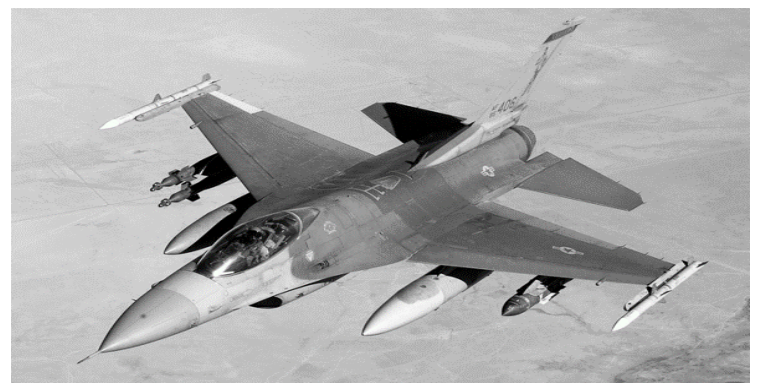

(b) F-16

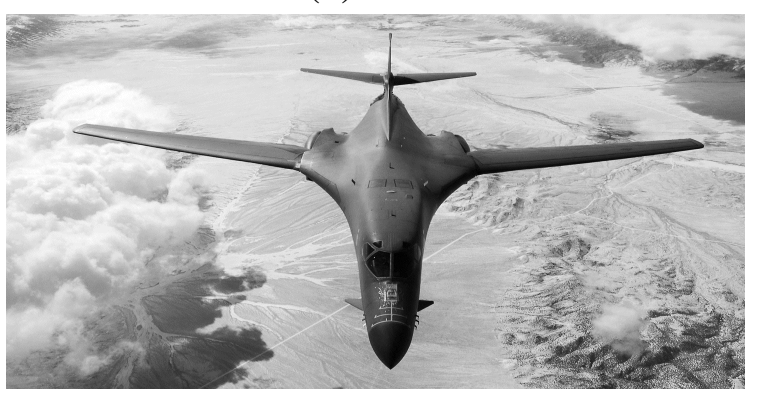

(d) B-1

Figura 1.4: Aeronaves militares modernas que apresentaram fenômenos aeroelásticos em determinados regimes de voo (fonte: en.wikipedia.org).

Os efeitos aeroelásticos podem alterar completamente o desempenho das aeronaves. Por exemplo, eles determinam se as superfícies de controle exercem as suas funções corretamente ou se apresentam o comportamento de reversão ou perda de controle. Os fenômenos aeroelásticos aumentam a fadiga estrutural, geram vibrações inaceitáveis para os passageiros e tripulações e podem até mesmo levar à destruição completa da aeronave. Desse modo, está claro que estudos nessa área tem grande importância prática e consequência direta em muitas outras áreas da tecnologia aeroespacial. Sabe-se que previsões precisas dos fenômenos aeroelásticos são complexas (DOWELL; EDWARDS; STRGANAC, 2003). Hoje, as aeronaves passam por análises aeroelásticas sofisticadas através de modelos computacionais para assegurar que estão 
livres de flutter dentro do envelope de operação. Esses resultados numéricos são frequentemente verificados por ensaios de flutter em túnel de vento e testes de vibração em solo. A análise de flutter em voo é a verificação final das previsões numéricas; ela representa uma tarefa cara e perigosa, contudo é a maneira mais segura de demonstrar que a aeronave estará livre de flutter dentro de uma margem de segurança (SILVA et al., 2005). De fato, com os recentes avanços em materiais e estruturas, e com os modelos computacionais melhores, os engenheiros estão agora tentando usar a aeroelasticidade de uma forma positiva para conseguir projetos mais adequados, aumentando ainda mais a busca por modelos computacionais que descrevem essas dinâmicas complexas (FRIEDMANN, 1999; DOWELL; TANG, 2002; XIANG; YAN; LI, 2014).

Sistemas aeroelásticos são inerentemente não lineares, portanto sujeitos aos comportamentos como bifurcações, oscilações em ciclo limite e caos (SHETA et al., 2002). Esses comportamentos, cujas origens estão tanto na dinâmica estrutural quanto no carregamento aerodinâmico não-estacionário, podem impossibilitar a previsão das respostas obtidas e produzir grandes efeitos destrutivos (DOWELL et al., 1995). Por exemplo, o fenômeno de flutter na presença de não linearidades passa a se manifestar de maneira diferente do previsto em modelos lineares. Nesse caso, oscilações em ciclo limite e comportamento caótico podem ser associados a esse fenômeno. Modelos lineares com elevada margem de segurança são utilizados devido à dificuldade, ao alto custo e ao tempo necessário para o desenvolvimento de modelos mais complexos que levem em consideração os efeitos não lineares. Análises lineares da resposta dinâmico-estrutural e modelos com baixa fidelidade para o escoamento aerodinâmico falham na determinação do comportamento das oscilações em ciclo limite dos sistemas com não linearidades, aumentando, assim, o apelo por modelos não lineares empíricos que resolvam determinados problemas, mas que juntos possam ajudar a determinar margens de segurança mais precisas para as aeronaves.

Em geral, modelos lineares utilizados em projetos possuem margens de segurança conservadoras para garantir estabilidade às aeronaves mesmo sob a influência de efeitos não lineares (HENSHAW et al., 2007). Isso implica em aeronaves mais pesadas e mais rígidas projetadas para garantir contra falhas aeroelásticas. Em alguns casos são colocados limites no envelope 
de operação para evitar condições potencialmente perigosas. Esse tipo de análise mais conservadora no geral diminuiu drasticamente o número de acidentes nos últimos anos. Contudo, com os novos apelos para a aviação global como a diminuição da poluição, a emissão de ruídos e o aumento do desempenho das aeronaves, todas as áreas tiveram um grande avanço, como os materiais compósitos, sistema de controle sofisticados, entre outros. Devido à inter-relação disciplinar, a aeroelasticidade torna-se uma importante ferramenta de estudo. Os modelos matemáticos devem ser melhorados e os fenômenos antes evitados através da linearização devem ser entendidos por uma série de razões (HENSHAW et al., 2007):

1. As análises computacionais de flutter com modelos lineares não são suficientemente precisas para sistemas não lineares. Os fenômenos não lineares podem fazer as aeronaves atuarem em regiões fora do envelope de voo previsto numericamente, como ocorre com o fenômeno de oscilações instáveis antes da velocidade crítica de flutter. Desse modo, quando há não linearidade envolvida também não há nenhuma indicação da verdadeira precisão alcançada pelo modelo computacional, necessitando, assim, de experimentos e modelos que levem em consideração dinâmicas complexas.

2. Projetos mais leves e eficientes estruturalmente são alcançados através da otimização estrutural, reduzindo assim a rigidez e aumentando a probabilidade de encontrar flutter, o que restringe o envelope de operação das aeronaves, comprometendo o seu desempenho.

3. Atualmente, a utilização de sistemas de controle tem aumentado o efeito indesejado dos fenômenos aeroservoelásticos. Os controles de voo ativos permitem que as aeronaves atinjam regiões críticas do envelope de voo. Essas aeronaves, ao invés de operarem em regiões onde a aerodinâmica é bem representada com modelos lineares, sofrem grandes efeitos não lineares dificultando as previsões do seu comportamento.

4. Melhorias nos sistemas de controle ativo podem aumentar o carregamento aerodinâmico ao qual a aeronave está sujeita durante a sua operação, o que pode fazer com que apresente 
problemas estruturais como perda de propriedades mecânicas ou ainda o aparecimento de folgas, além do aumento do custo de manutenção.

5. As aeronaves futuras podem apresentar configurações complexas com superfícies móveis que alteram toda a configuração e formato da aeronave, como exemplo dos conceitos: flapping wings e morphing wings (BARBARINO et al., 2011). Nesse caso, métodos comparativos de dados experimentais e modelos numéricos são inexistentes, representando um apelo para novos experimentos sobre fenômenos não lineares. Outra possibilidade é que esses novos dispositivos necessitem dos efeitos não lineares para voarem, o que de fato pode ser encontrado na natureza.

Sendo assim, são necessárias novas aproximações para a previsão e modelagem dos fenômenos aeroelásticos não lineares, uma vez que o objetivo é reduzir os custos, os riscos e melhorar a eficiência da aeronave. Isso também é válido não apenas para novos modelos, mas também para as aeronaves que podem passar por atualizações (no caso de aviões militares quando equipados com novas armas), onde a recertificação é necessária. Além disso, o crescente avanço em todas as áreas aeronáuticas, em um futuro próximo, o estudo e investigação de não linearidades farão parte da rotina dos projetos aeronáuticos. Desse modo, há um apelo muito grande no estudo sobre as não linearidades aeroelásticas. Uma forma de comprovar isso é observando o número crescente de artigos científicos voltados para essa área. A Figura 1.5 apresenta um levantamento sobre artigos científicos publicados em um período de 1990-2014 relativos às palavras chaves: "aeroelasticity" e "nonlinearities", restritas à área de engenharia. Aqui foi utilizada a base Web of Science ${ }^{T M}$ (Thomson Reuters ${ }^{T M}$ - webofscience.com). Desse modo, observa-se claramente um aumento expressivo do número de publicações, comprovando assim que a aeroelasticidade não linear é um tema muito atual de grande importância dentro da área aeronáutica. 


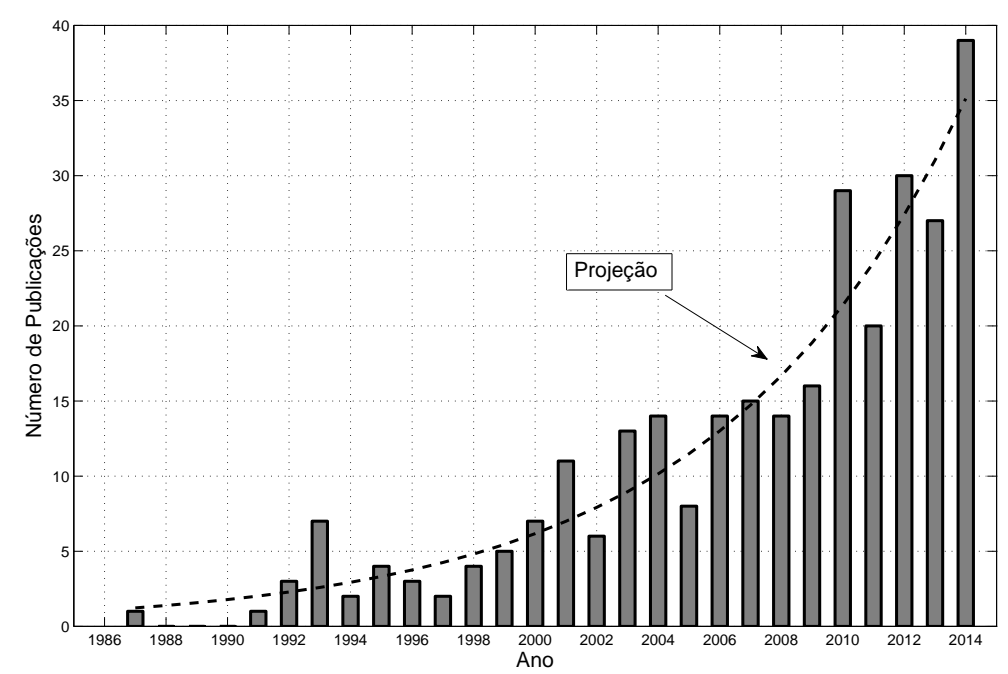

Figura 1.5: Número de publicações relacionadas ao campo da aeroelasticidade não linear (Web of Science TM $^{T \text { Thomson Reuters). }}$

\subsection{Não linearidades em sistemas aeroelásticos}

Não linearidades têm gerado oscilações em ciclo limite em diversos projetos de aeronaves militares. Várias experiências com LCOs têm sido documentadas pelo centro de teste em voo da força aérea americana localizado em Eglin Air Force Base, Florida, EUA (DOWELL; EDWARDS; STRGANAC, 2003). A grande maioria desses trabalhos referem-se à aeronave F16, que apresentou oscilações em ciclo limite para diversas regiões do envelope de voo devido à adição de dispositivos externos possuindo não linearidade estrutural (DENEGRI; CUTCHINS, 1997; CHEN; SARHADDI; LIU, 1998; DENEGRI, 2000; DENEGRI; JOHNSON, 2001). Há muitas outras aeronaves que apresentaram LCOs como por exemplo o F-18, o B-1 e B-2, devido aos efeitos aerodinâmicos não lineares dos movimentos das ondas de choque e separação da camada limite. Entretanto, há a possibilidade de não linearidades estruturais envolvendo a rigidez, o amortecimento ou a folga terem também exercido influência (DOBBS; MILLER; STEVENSON, 1985; CUNNINGHAM; ATLEE; GEURTS, 1997; HARTWICH et al., 2001).

As principais fontes físicas de não linearidades em problemas aeroelásticos estão no escoamento aerodinâmico ou na dinâmica da estrutural. Não linearidades aerodinâmicas são relacionadas aos efeitos de compressibilidade ou viscosos. Em regime transônico, o movimento 
de ondas de choque no caso não estacionário é um exemplo onde a aerodinâmica não linear está presente. Em condições de baixa velocidade, escoamentos com separação também apresentam comportamento não linear importante (DOWELL, 1990). Não linearidades com origem no comportamento dinâmico-estrutural podem ser devido às grandes deformações, às característica particulares dos materiais ou por problemas de junções. As não linearidades estruturais podem ser classificadas como sendo distribuídas ou concentradas. No caso de não linearidades distribuídas, seus efeitos são considerados contínuos ao longo de uma estrutura, enquanto que as concentradas se restringem a efeitos localizados (DOWELL, 2014).

Os efeitos não lineares concentrados podem ser incorporados aos modelos aeroelásticos através das forças ou momentos de restauração elástica representados por modelos de molas. A Figura 1.6 mostra algumas representações para não linearidades típicas encontradas nos sistemas dinâmicos. Os tipos mais comuns de não linearidades concentradas são as associadas à rigidez, representáveis por função polinomial, como o efeito de enrijecimento e amolecimento, ao amortecimento não linear, à folga (freeplay), à fricção, à histerese, entre outros (WORDEN; TOMLINSON, 2001). Se, para os altos níveis de excitação, o esforço de restauração elástico é maior do que o esperado para um sistema linear, esses sistemas são referidos como tendo uma característica de enrijecimento (do inglês, hardening). Contudo, se para altos níveis de excitação o esforço de restauração é menor que o esperado para comportamentos lineares, tais sistemas possuem uma característica de amolecimento (do inglês, softening) (O’NEIL; STRGANAC, 1998).

As não linearidades estruturais vêm sendo estudadas há muito tempo. Zhao e Yang (1990) demonstraram o aparecimento de caos em sistemas com não linearidade do tipo estrutural concentrada na rigidez em torção de um aerofólio, cuja curva de enrijecimento é representada por uma função cúbica. Eles determinaram que o caos ocorre para certas posições do eixo elástico quando a velocidade é maior que a velocidade linear de flutter. Tang e Dowell (1992) estudaram o fenômeno de flutter para um modelo de hélice de helicóptero apresentando não linearidade do tipo folga na rigidez de arfagem. Eles analisaram três combinações diferentes entre a estrutura linear e não linear com a aerodinâmica linear e não linear, concluindo que essas não linearida- 


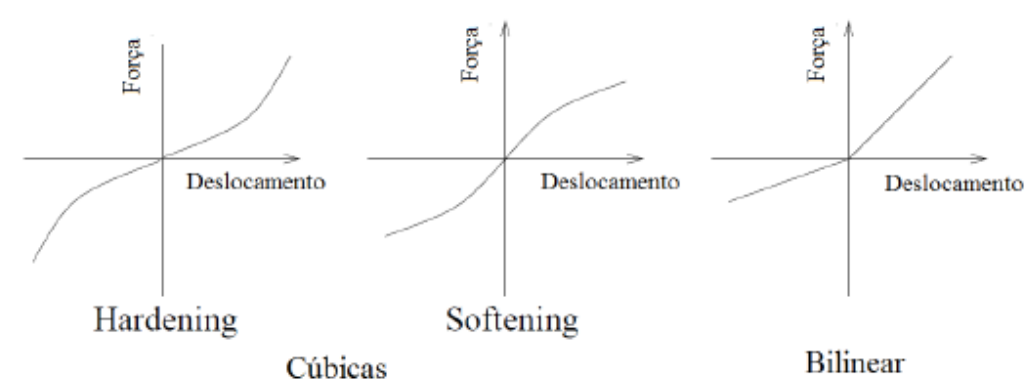

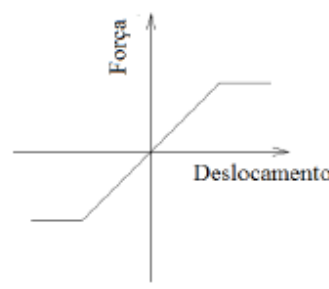

Saturação

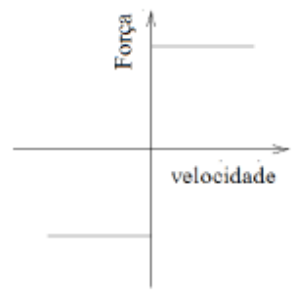

Fricção

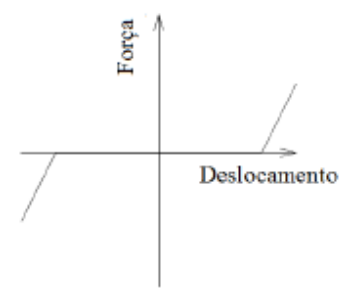

Folga ou Freeplay

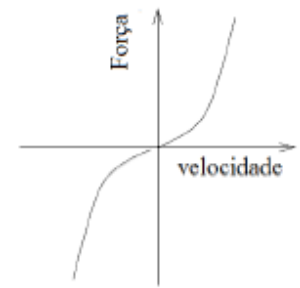

Amortecimento não linear

Figura 1.6: Tipos de não linearidades concentradas (WORDEN; TOMLINSON, 2001).

des exercem efeitos combinados na dinâmica do sistema, gerando LCOs e caos. Já Kousen e Bendiksen (1994) introduziram o efeito não linear da folga em uma seção típica com dois graus de liberdade para regime de escoamento transônico. Price, Alighanbari e Lee (1995) analisaram respostas caóticas para sistemas com rigidez não linear concentrada do tipo bilinear e cúbica. Eles demostraram que, de fato, há aparecimento de comportamento caótico devido ao efeito de enrijecimento, caracterizando onde ocorreram as possíveis transições das oscilações em ciclo limite para o caos. O’Neil e Strganac (1998) desenvolveram um modelo experimental que fornece medidas diretas de respostas aeroelásticas não lineares de seção típica quando a rigidez em arfagem e flexão é do tipo enrijecimento cúbico. O dispositivo permite movimento de arfagem e flexão de uma seção típica, onde ambos movimentos são definidos por molas de tração. Neste caso, o dispositivo permite a variação da intensidade da rigidez em flexão e arfagem levando ao comportamento mais ou menos enrijecido.Virgin, Dowell e Conner (1999), Tang, Kholodar e 
Dowell (2000) e Trickey, Virgin e Dowell (2002) observaram movimentos caóticos em modelos experimentais com não linearidade do tipo folga na superfície de comando de um aerofólio. Beran et al. (2004) investigaram oscilações em ciclo limite através de uma asa representada por uma viga em balanço com um pilone conectado apresentando não linearidades estruturais e aerodinâmicas sob escoamento transônico. Eles utilizaram análises por bifurcações para caracterizar as respostas não lineares e concluíram que a previsão dos resultados estão relacionados com todas as não linearidades envolvidas no sistema. Dowell, Thomas e Hall (2004) aprofundaram os estudos do efeito das não linearidades aerodinâmicas sob o regime transônico de uma seção típica com a não linearidade estrutural do tipo folga na superfície de controle. Vasconcellos et al. (2012) e Vasconcellos et al. (2014) apresentaram um estudo sobre os diferentes métodos com validação experimental para aproximação numérica da não linearidade estrutural do tipo folga. Li, Guo e Xiang (2012) investigaram a origem do caos em uma seção típica com dois graus de liberdade em sistemas com diferentes não linearidades representadas por razão de polinômios. Vasconcellos, Marques e Pereira (2013) mostraram que a combinação de não linearidade cúbica assimétrica (enrijecimento com pré-carga) na mola de arfagem com efeito de estol leva a um cenário complexo de oscilações aeroelásticas não lineares, no qual ocorre um acoplamento das frequências naturais que se acentua com o aumento da velocidade do escoamento, podendo levar a cenários com comportamentos caóticos.

Sabe-se que o comportamento do sistema está diretamente relacionado com as não linearidades envolvidas. Desse modo, muitos trabalhos vêm sendo realizados na aeroelasticidade não linear, principalmente com as não linearidades estruturais concentradas como o efeito de enrijecimento e de folga (DOWELL; EDWARDS; STRGANAC, 2003). Na presença de folga o sistema apresenta comportamento subcrítico da bifurcação de Hopf. A Figura 1.7 representa os diagramas de bifurcação clássico para o comportamento supercrítico e subcrítico, respectivamente, os quais são dados pela relação da amplitude de ciclo limite pela velocidade do ar. No geral, se um sistema depende da condição inicial e possui diferentes soluções quando a velocidade do escoamento está aumentando e diminuindo próximo à velocidade crítica de $f l u t$ ter, a bifurcação é chamada subcrítica e as oscilações em ciclo limite podem existir abaixo da 
velocidade de flutter. Nesse caso considera-se o LCO como sendo instável (representado pela linha tracejada na Figura 1.7). Entretanto, se o sistema é independente da condição inicial e a sua estabilidade muda somente depois da velocidade de flutter, a bifurcação é chamada de supercrítica e o sistema apresenta somente LCOs estáveis (representado pela linha sólida na Figura 1.7). Em algumas condições esse efeito é desejável uma vez que sem ele o LCO pode ser substituído por um flutter catastrófico (DOWELL; EDWARDS; STRGANAC, 2003).
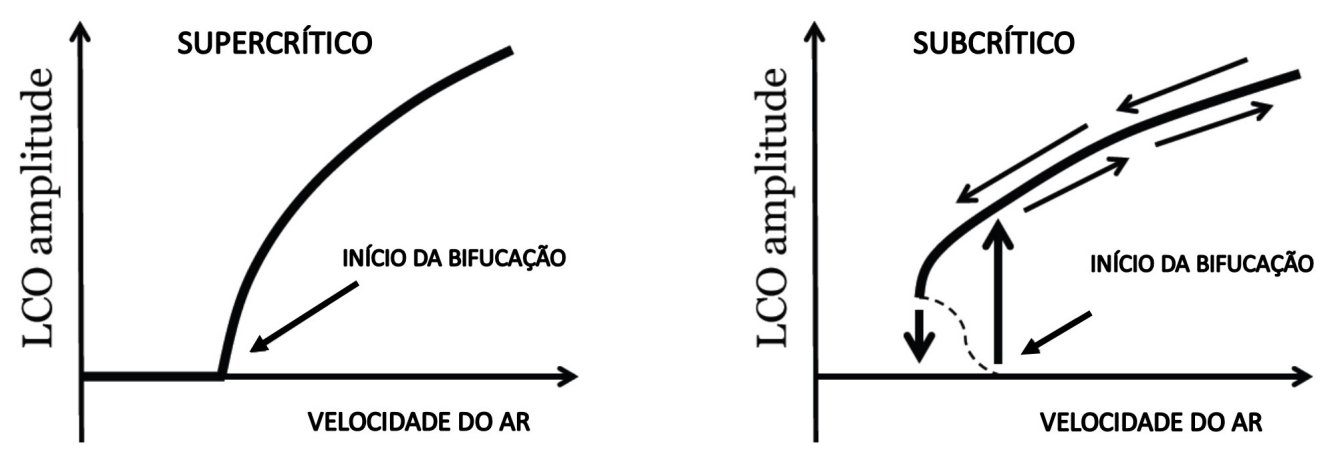

Figura 1.7: Formas supercrítica e subcrítica da bifurcação de Hopf.

As análises de bifurcação são usadas para indicar mudanças quantitativas e qualitativas no comportamento do sistema tais como o número ou o tipo de soluções sob a variação de um ou mais parâmetros (NAYFEH; BALACHANDRAN, 1995). Alighanbari e Price (1996) analisaram através dos diagramas de bifurcação as respostas de um aerofólio com dois graus de liberdade e não linearidade do tipo folga na rigidez de arfagem; eles utilizaram a aproximação por razão de polinômio de terceira ordem para a folga estrutural. Os diagramas de bifurcação apresentaram comportamento estável, instável e caos, dependendo das regiões onde a folga exerce menos ou mais influência. Lee, Jiang e Wong (1999) realizaram investigações analíticas de sistemas aeroelásticos com não linearidade cúbica, representativo do efeito de enrijecimento. Eles examinaram os efeitos da variação dos parâmetros lineares do sistema no envelope da velocidade de flutter, através da bifurcação de Hopf. Abdelkefi et al. (2012) analisaram, através das bifurcações de Hopf, as mudanças no comportamento do sistema variando a intensidade das não linearidades estruturais de enrijecimento. Mostrou-se que a estabilidade do sistema está relacionada com a influência que o acoplamento não linear tem. Liu, Chen e Chen (2012) ana- 
lisaram o efeito da não linearidade de histerese na dinâmica do sistema através dos diagramas de bifurcações.

Muitos estudos foram feitos sobre a análise da não linearidade de enrijecimento e é de conhecimento que essa não linearidade é responsável pelo aparecimento de oscilações em ciclo limite. Sabe-se também que quanto maior a intensidade desse efeito, maior será o controle sobre as amplitudes das vibrações. Já a folga também é responsável pelo aparecimento de LCOs. Contudo, ela sempre induz ao sistema o aparecimento de efeitos subcríticos. Embora sejam conhecidos os efeitos dessas duas não linearidades, carecem de pesquisas sobre o efeito que elas exercem uma na outra alterando o comportamento do sistema. Logo, é imprescindível estudar o comportamento dinâmico de dispositivos aeronáuticos através de experimentos. Os resultados experimentais ajudam a interpretar melhor o fenômeno que está ocorrendo e validar modelos matemáticos para futuras análises. Desse modo, é importante utilizar ferramentas para analisar os resultados experimentais obtidos, na grande maioria são utilizadas ferramentas de análises de séries temporais.

\subsection{Técnicas de identificação e análise de séries temporais.}

Uma série temporal é uma sequência de pontos, tipicamente formados por medidas sucessivas de um mesmo experimento durante um intervalo de tempo. Métodos para análise de séries temporais podem ser divididos em duas classes: métodos no domínio da frequência e métodos no domínio do tempo. Como é inevitável a presença de ruídos nos sinais experimentais é necessária a utilização de filtros adequados para se obter séries temporais de boa qualidade, já que os ruídos podem tornar as análises mais difíceis. Com as séries temporais é possível resgatar características fundamentais do sistema através de um conjunto discreto de variáveis, usando ferramentas como as reconstruções do espaço de estados e análise espectral (BENDAT; PIERSOL, 2011).

Normalmente não se medem todas as variáveis de estado do sistema como a velocidade e o deslocamento, obtendo somente as séries temporais para uma delas. A técnica de reconstrução 
do espaço de estados é usada para extrair informações da dinâmica do sistema presentes em variáveis de estados que não foram medidas experimentalmente. O uso de técnicas de reconstrução do espaço de estados através de séries temporais é uma forma conveniente de analisar os fenômenos aeroelásticos não lineares. Uma vantagem dessa abordagem é que para sistemas aeroelásticos complexos com efeitos não lineares significativos, torna-se mais fácil fazer a análise através de poucas medidas dinâmicas durante um experimento (MARQUES et al., 2006; SIMONI, 2008) . A técnica tem base no teorema de imersão (do ingles, Takens' embedding theorem) de Takens (1981) e Mañé (1981), segundo o qual é possível reconstruir um espaço de fases $m$-dimensional similar ao espaço de fases original (preservando os invariantes geométricos do sistema, tais como os expoentes de Lyapunov) já que toda série temporal guarda informações sobre todos os estados não observáveis. Para isso, o sinal deve ser filtrado, uma vez que o teorema tem como uma de suas principais premissas a necessidade da ausência de ruído no sinal para sua correta aplicação. Os resultados apresentados em Marques e Vasconcellos (2009) mostraram que o uso da técnica de métodos por coordenadas defasadas para reconstrução do espaço de estados conseguem representar bem o comportamento dinâmico complexo do sistema devido à presença de não linearidades, servindo de base para comparar resultados experimentais e computacionais.

As análises espectrais proporcionam uma forma rápida e eficiente de identificar as componentes de um sinal. A partir de um sinal estacionário com comprimento finito as análises espectrais descrevem como se distribui a energia e potência sobre as frequências do sistema. A análise espectral encontra aplicações em diversos campos. No monitoramento de vibração, o conteúdo espectral dos sinais medidos dão informações sobre o desgaste e outras características lineares de sistemas mecânicos sob estudo (SMITH, 2003; STOICA; MOSES, 2005). Nesse contexto, a transformada rápida de Fourier (do ingles, fast fourier transform -FFT) pode ser usada para determinar as frequências presentes no sinal para um intervalo de tempo definido. Uma outra ferramenta para análise no domínio da frequência são os espectros de ordem mais alta (do ingles, higher-order spectral, HOS) que são transformadas de Fourier das funções de correlação de ordem mais alta, com os quais é possível acessar mais informações entre 
as frequências do sistema, mostrando, assim, se elas possuem ou não determinados tipos de acoplamentos não lineares. Por exemplo, o bispectro (medida de terceira ordem) é sensível a acoplamentos quadráticos, o trispectro, a acoplamentos cúbicos e assim por diante (NAYFEH; BALACHANDRAN, 1995).

\subsection{Objetivos}

Esse trabalho faz um estudo experimental e computacional do comportamento aeroelástico de aerofólios com não linearidades estruturais concentradas. No caso do modelo computacional foi utilizada uma seção típica com três graus de liberdade: flexão (do inglês, plunge), torção (do inglês, pitch) e deflexão da superfície de comando (do inglês, control surface). A rigidez de torção e a rigidez da superfície de comando apresentam não linearidades estruturais concentradas do tipo enrijecimento e do tipo folga, respectivamente. Já a curva de rigidez em flexão é linear. Todas as respostas são obtidas no domínio do tempo. A dinâmica do sistema aeroelástico é caracterizada através das bifurcações de Hopf. As frequências do sistema e os tipos de não linearidades foram identificados utilizando espectros de potência e espectros de ordem mais alta, respectivamente. Os objetivos desse trabalho são: (a) o estudo dos efeitos que as não linearidades de enrijecimento e de folga exercem no sistema aeroelástico, através da variação da intensidade das suas curvas de momento restaurador e (b) a análise do comportamento não linear do aerofólio quando há a combinação dessas duas não linearidades estruturais.

\subsection{Organização da dissertação}

No Capítulo 1, são discutidos, primeiramente, os fundamentos da aeroelasticidade, a história dos problemas de flutter na aviação e a relevância do estudo das não linearidades. Segue-se com a discussão sobre algumas ferramentas de análise de séries temporais que serão utilizadas nesse trabalho, bem como os objetivos esperados e contribuições aqui presentes.

No Capítulo 2 é explicado com detalhes o modelo computacional. O objetivo dessa seção é explicar os fenômenos físicos envolvidos bem como a capacidade de representação do modelo 
computacional, suas aproximações e limitações. Na sequência, é apresentado o modelo experimental com todos os detalhes, com mais atenção para os dispositivos responsáveis por gerar as não linearidades estruturais.

O Capítulo 3 apresenta com detalhes as ferramentas de análise por séries temporais conhecidas como reconstrução de estados pelo método das coordenadas defasadas. Nele também são apresentados os fundamentos básico da análise no domínio da frequência por espectros de ordem mais alta. Essas ferramentas são aplicadas aos resultados computacionais e experimentais com o intuito de caracterizar e identificar as respostas aeroelásticas apresentando duas não linearidades combinadas.

No Capítulo 4, primeiramente é discutida a caracterização da dinâmica estrutural do experimento. Em seguida são feitas análises computacionais e experimentais para o sistema aeroelástico apresentando efeito não linear estrutural do tipo enrijecimento e do tipo folga, presentes na curva de rigidez do movimento de arfagem e na superfície de comando. Segue-se com a reconstrução de estados pelo método das coordenadas defasadas, com o estudo do efeito no diagrama de bifurcação, e, por fim, as não linearidades presentes no experimento são identificadas usando os espectros de ordem mais alta.

O Capítulo 5 se refere à conclusão e à discussão sobre os trabalhos futuros. Nesse capítulo, explicam-se com detalhes os resultados mais importantes de uma maneira clara e discutir quais objetivos foram alcançados. 


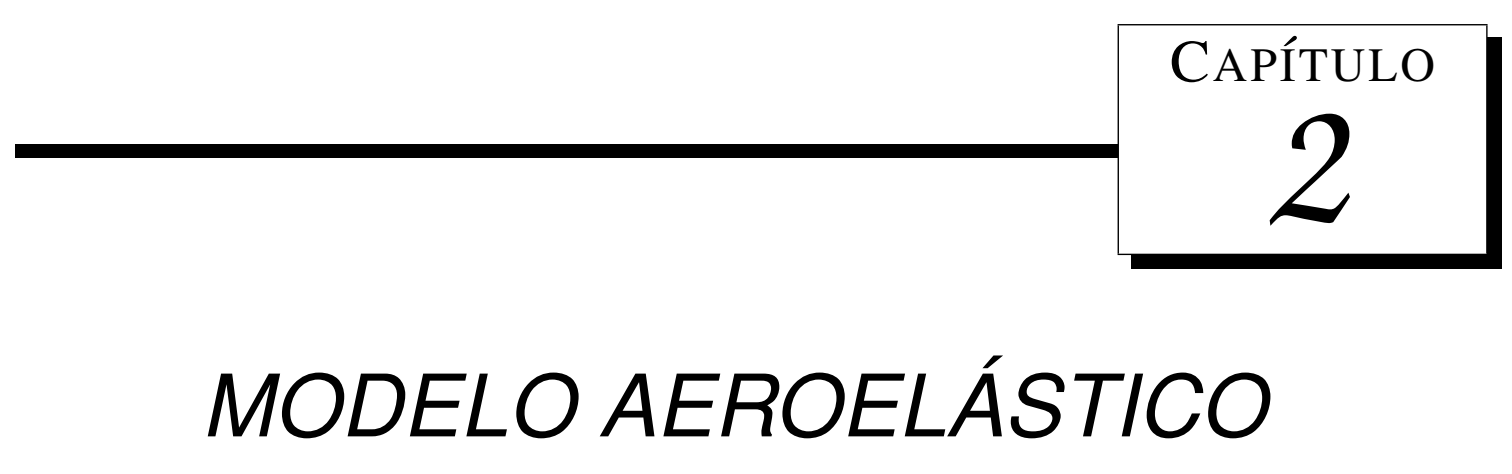

\subsection{Introdução}

Nesse capítulo, são descritos com detalhes (i) a física envolvida no sistema aeroelástico, (ii) o modelo computacional e suas características, (iii) as aproximações para as curvas que representam as não linearidades de enrijecimento e folga e (iv) as equações resultantes no espaço de estados e, finalmente, (v) o modelo experimental, com mais atenção para os dispositivos responsáveis por gerar as não linearidades estruturais.

\subsection{Modelo matemático}

O modelo numérico desenvolvido nesse trabalho segue o princípio do sistema aeroelástico com três graus de liberdade, cuja formação se dá pela relação entre a dinâmica estrutural e a aerodinâmica não-estacionária de um determinado sistema mecânico. As matrizes estruturais da seção típica apresentada pela Figura 2.1 são desenvolvidas através das equações de movimento (FUNG, 1993; BISPLINGHOFF; ASHLEY; HALFMAN, 1996). As equações aerodinâmicas seguem os desenvolvimentos do método clássico de Theodorsen (1935) com aproximações para movimentos arbitrários.

As variáveis do deslocamento de flexão, de torção e da superfície de controle estão representadas na Figura 2.1 por $h, \alpha$ e $\beta$, respectivamente, e são medidas em relação ao eixo elástico, 


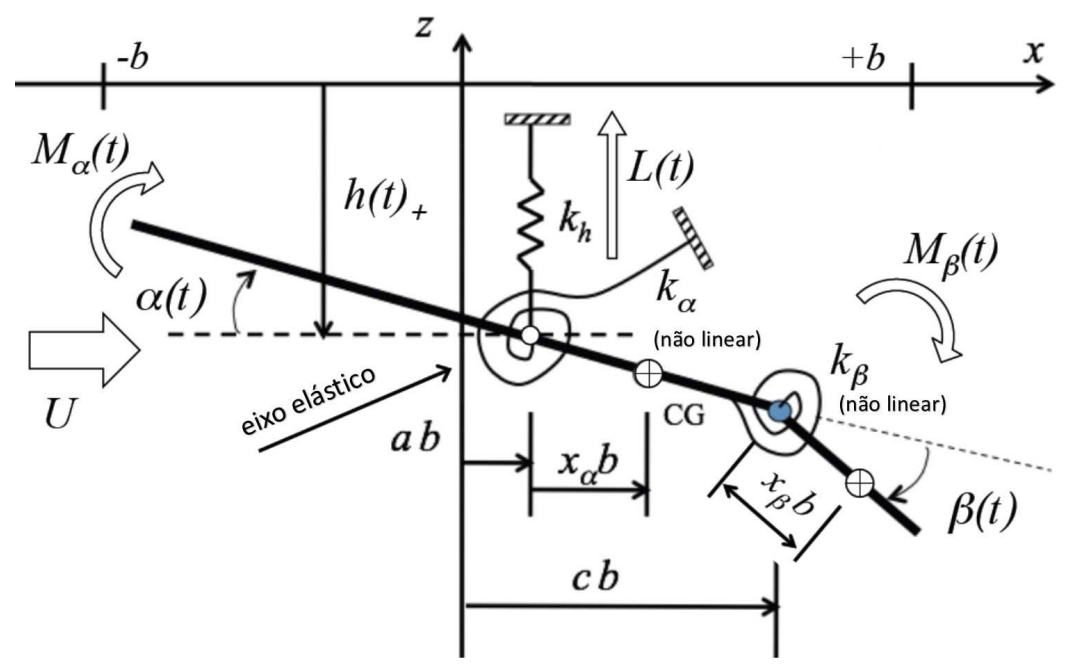

Figura 2.1: Seção típica aeroelástica.

considerando o sistema de referência do deslocamento do aerofólio sendo positivo para baixo e o no sentido horário.

Na Figura 2.1, a variável $b$ representa o comprimento da semicorda, $a b$ representa a distância entre o eixo elástico (EE) e a corda média, $c b$ representa a distância entre a corda média e o eixo de articulação da superfície de controle (SC), $U$ é a velocidade do ar, $x_{\alpha}$ e $x_{\beta}$ são as distâncias adimensionais do eixo elástico até o centro gravitacional (CG) e da superfície de controle até o seu CG, respectivamente, $k_{h}, k_{\alpha}$, e $k_{\beta}$ representam a rigidez de flexão, de torção e da articulação da SC, respectivamente, sendo as duas últimas não lineares, $L(t)$ é a força de sustentação, $M_{\alpha}(t)$ e $M_{\beta}(t)$ são os momentos aerodinâmicos medidos em relação ao EE e ao eixo de rotação da SC, respectivamente.

As equações de movimento para a seção típica são desenvolvidas a partir da equação de Lagrange,

$$
\frac{d}{d t}\left(\frac{\partial L}{\partial \dot{\mathbf{q}}_{\mathbf{i}}}\right)-\frac{\partial L}{\partial \mathbf{q}_{\mathbf{i}}}=\mathbf{f}_{\mathbf{i}} \quad(i=1,2, \ldots, n),
$$

onde $n$ é o numero de graus de liberdade do sistema, $\mathbf{q}_{\mathbf{i}}$ são os deslocamentos em flexão, torção e da superfície de controle, representados por $h, \alpha$ e $\beta$, respectivamente. As velocidades são representadas por $\dot{\mathbf{q}}_{\mathbf{i}}$, sendo $\dot{h}, \dot{\alpha}$ e $\dot{\beta}$ as velocidades dos respectivos deslocamentos dos três graus de liberdade. Já $\mathbf{f}_{\mathbf{i}}$ representa os esforços não conservativos aplicados à seção típica, ou 
seja, a força de sustentação e os momentos aerodinâmicos. Por fim, $L$ é a Função de Lagrange definida como a energia cinética menos a energia potencial:

$$
L=T-E_{p}
$$

onde $T$ é a energia cinética e $E_{p}$ a energia potencial.

A expressão para a energia cinética é dada por

$$
T=\frac{1}{2} \int\|\dot{\vec{r}}\| d m
$$

onde $\dot{\vec{r}}$ é a velocidade generalizada de um ponto na superfície da seção típica, chamado de $\dot{\overrightarrow{r_{1}}}$ para o aerofólio e $\dot{\overrightarrow{r_{2}}}$ para a superfície de comando. As Figuras 2.2 (a) e (b) apresentam os vetores da posição do aerofólio e da SC em relação a uma origem fixa, respectivamente. A

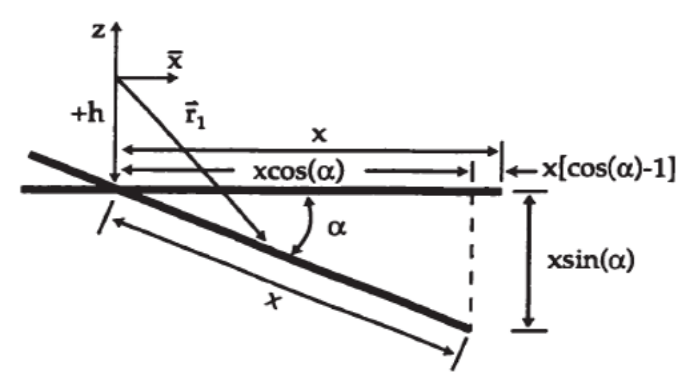

(a) Posição do aerofólio $\left(\overrightarrow{r_{1}}\right)$

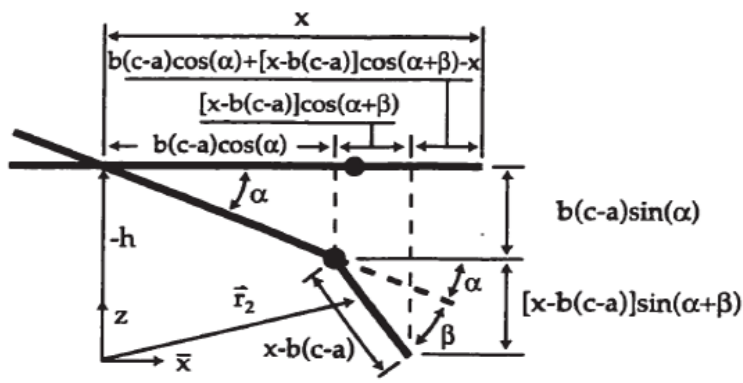

(b) Posição da SC $\left(\overrightarrow{r_{2}}\right)$

Figura 2.2: Representação dos vetores de velocidade de um ponto na superfície da seção típica (TRICKEY, 2000).

partir da geometria presente na Figura 2.2 (a) e (b), os vetores de posição são dados por

$$
\begin{aligned}
& \vec{r}_{1}=x[\cos (\alpha)-1] \hat{i}+[-h-x \sin (\alpha)] \hat{k}, \\
& \overrightarrow{r_{2}}=[b(c-a) \cos (\alpha)+[x-b(c-a)] \cos (\alpha+\beta)-x] \hat{i}+ \\
& {[-h-b(c-a) \sin (\alpha)-[x-b(c-a)] \sin (\alpha+\beta)] \hat{k},}
\end{aligned}
$$

onde $\hat{i}$ e $\hat{k}$ representam os vetores unitário na direção $x$ e $z$, respectivamente.

Derivando as Equações (2.4) e (2.5) para achar a velocidade e assumindo como aproximação pequenos deslocamentos do aerofólio onde $\cos (\alpha)$ é igual a 1 e $\operatorname{sen}(\alpha)$ é igual a $\alpha$, observa-se que a equação resultante contém apenas a parcela referente ao eixo $\hat{k}$, cujos vetores são dados 
por

$$
\begin{gathered}
\dot{\overrightarrow{r_{1}}}=[-\dot{h}-x \dot{\alpha}] \hat{k} \\
\dot{\overrightarrow{r_{2}}}=[-\dot{h}-x \dot{\alpha}-[x-b(c-a)] \dot{\beta}] \hat{k} .
\end{gathered}
$$

Essa primeira aproximação do modelo matemático é consistente uma vez que no desenvolvimento da teoria para a aerodinâmica não estacionária também há a aproximação para ângulos pequenos. Substituindo os valores das Equações (2.6) e (2.7) na Equação (2.3) e aplicando as relações descritas em (TRICKEY, 2000), obtém-se a expressão final para a energia cinética do aerofólio e da superfície de comando, dada por:

$$
T=\frac{1}{2} m_{T} \dot{h}^{2}+S_{\alpha} \dot{\alpha} \dot{h}+S_{\beta} \dot{\beta} \dot{h}+\frac{1}{2} I_{\alpha} \dot{\alpha}^{2}+\frac{1}{2} I_{\beta} \dot{\beta}^{2}+\left[I_{\beta}+b(c-a) S_{\beta}\right] \dot{\alpha} \dot{\beta}
$$

onde $m_{T}$ representa a massa total que está se movimentando na direção em $Z$ (ver Figura 2.1), ela é obtida pela soma da massa da asa com as massas dos suportes de fixação e rigidez dos três graus de liberdade. A distância do eixo elástico ao vínculo da superfície de controle é representado por $(c-a), S_{\alpha}$ e $S_{\beta}$ são os momentos estáticos, $I_{\alpha}$ e $I_{\beta}$ são os momentos de inércia em relação ao EE e ao vínculo da SC, respectivamente.

A expressão para a energia potencial é dada pela energia potencial elástica acumulada pelas molas de flexão, torção e da articulação da SC, cujo valor é

$$
E_{p}=\frac{1}{2} k_{h} h^{2}+\frac{1}{2} k_{\alpha} \alpha^{2}+\frac{1}{2} k_{\beta} \beta^{2}
$$

onde $k_{h}, k_{\alpha}$ e $k_{\beta}$ representam a rigidez dos vínculos para os três graus de liberdade.

O vetor dos esforços não conservativos para a seção típica é:

$$
\mathbf{f}_{\mathbf{i}}=\left[\begin{array}{lll}
-L(t) & M_{\alpha}(t) & M_{\beta}(t)
\end{array}\right]^{T},
$$

onde $L(t)$ é a força de sustentação resultante na asa, $M_{\alpha}(t)$ é o momento aerodinâmico medido em relação ao eixo elástico e $M_{\beta}(t)$ representa o momento aerodinâmico medido em relação à superfície de controle.

Aplicando as Equações (2.8) a (2.10) na equação de Lagrange (Eq.( 2.1)) para cada grau 
de liberdade, encontram-se as equações de movimento:

$$
\begin{gathered}
m_{T} \ddot{h}(t)+S_{\alpha} \ddot{\alpha}(t)+S_{\beta} \ddot{\beta}(t)+k_{h} h(t)=-L(t), \\
S_{\alpha} \ddot{h}(t)+I_{\alpha} \ddot{\alpha}(t)+\left[I_{\beta}+b(c-a) S_{\beta}\right] \ddot{\beta}(t)+k_{\alpha} \alpha(t)=M_{\alpha}(t) \\
S_{\beta} \ddot{h}(t)+I_{\beta} \ddot{\beta}(t)+\left[I_{\beta}+b(c-a) S_{\beta}\right] \ddot{\alpha}(t)+k_{\beta} \beta(t)=M_{\beta}(t) .
\end{gathered}
$$

Por conveniência, adimensionaliza-se a Equação (2.11) dividindo-a por $\left(\frac{1}{m_{W} b}\right)$ e as Equações (2.12) e (2.13) dividindo-as por $\left(\frac{1}{m_{W} b^{2}}\right)$, onde $m_{W}$ representa a massa da asa.

$$
\begin{gathered}
\mu_{e}\left(\frac{\ddot{h}(t)}{b}\right)+x_{\alpha} \ddot{\alpha}(t)+x_{\beta} \ddot{\beta}(t)+\omega_{h}^{2}\left(\frac{h(t)}{b}\right)=\frac{-L(t)}{m_{W} b} \\
x_{\alpha}\left(\frac{\ddot{h}(t)}{b}\right)+r_{\alpha}^{2} \ddot{\alpha}(t)+\left[r_{\beta}^{2}+x_{\beta}(c-a)\right] \ddot{\beta}(t)+r_{\alpha}^{2} \omega_{\alpha}^{2} \alpha(t)=\frac{M_{\alpha}(t)}{m_{W} b^{2}} \\
x_{\beta}\left(\frac{\ddot{h}(t)}{b}\right)+\left[r_{\beta}{ }^{2}+x_{\beta}(c-a)\right] \ddot{\alpha}(t)+r_{\beta}^{2} \ddot{\beta}(t)+r_{\beta}{ }^{2} \omega_{\beta}{ }^{2} \beta(t)=\frac{M_{\beta}(t)}{m_{W} b^{2}}
\end{gathered}
$$

sendo,

$$
x_{\alpha}=\frac{S_{\alpha}}{m_{W} b}, x_{\beta}=\frac{S_{\beta}}{m_{W} b}, r_{\alpha}^{2}=\frac{I_{\alpha}}{m_{W} b^{2}}, r_{\beta}^{2}=\frac{I_{\beta}}{m_{W} b^{2}}, \omega_{h}^{2}=\frac{k_{h}}{m_{W}}, \omega_{\alpha}^{2}=\frac{k_{\alpha}}{I_{\alpha}}, \omega_{\beta}^{2}=\frac{k_{\beta}}{I_{\beta}},
$$

onde $x_{\alpha}$ é a distância entre o eixo elástico e o CG do aerofólio (ver Figura 2.1), $x_{\beta}$ é a distância entre a articulação da SC e o CG da mesma, $r_{\alpha}$ e $r_{\beta}$ são os raios de giração do aerofólio e da superfície de controle, respectivamente, $\mu_{e}=\frac{m_{T}}{m_{W}}$ e $\omega_{h}, \omega_{\alpha}$ e $\omega_{\beta}$ são as frequências naturais de flexão, torção e de rotação da SC, respectivamente.

Adicionam-se os fatores de amortecimento às Equações (2.14) até (2.16), sendo $d_{i, j}$ os elementos que compõe a matriz de amortecimento, a qual é obtida pela combinação das matrizes de massa e rigidez conhecida como amortecimento de Rayleigh (CLOUGH; PENZIEN, 2003). Além disso, as não linearidades estruturais do tipo enrijecimento e folga são obtidas introduzindo-se uma função $F(\alpha)$ e $F(\beta)$ que multiplicam os fatores de rigidez $k_{\alpha}$ e $k_{\beta}$, respectivamente. Desse modo, fazendo a substituição $\xi(t)=\frac{h(t)}{b}$, as equações do movimento para a seção aeroelástica típica final tornam-se: 


$$
\begin{array}{cc} 
& {\left[\begin{array}{ccc}
\mu_{e} & x_{\alpha} & x_{\beta} \\
x_{\alpha} & r_{\alpha}^{2} & {\left[r_{\beta}^{2}+(c-a) x_{\beta}\right]} \\
x_{\beta} & {\left[r_{\beta}^{2}+(c-a) x_{\beta}\right]} & r_{\beta}^{2}
\end{array}\right]\left\{\begin{array}{c}
\ddot{\xi}(t) \\
\ddot{\alpha}(t) \\
\ddot{\beta}(t)
\end{array}\right\}+} \\
{\left[\begin{array}{cccc}
\omega_{h}^{2} & {\left[\begin{array}{ccc}
d_{1,1} & d_{1,2} & d_{1,3} \\
d_{2,1} & d_{2,2} & d_{2,3} \\
d_{3,1} & d_{3,2} & d_{3,3}
\end{array}\right]\left\{\begin{array}{c}
\dot{\xi}(t) \\
\dot{\alpha}(t) \\
\dot{\beta}(t)
\end{array}\right\}+} \\
0 & r_{\alpha}^{2} \omega_{\alpha}^{2} \frac{F(\alpha)}{\alpha(t)} & 0 \\
0 & 0 & r_{\beta}^{2} \omega_{\beta}^{2} \frac{F(\beta)}{\beta(t)}
\end{array}\right]\left\{\begin{array}{c}
\xi(t) \\
\alpha(t) \\
\beta(t)
\end{array}\right\}=\left(\frac{1}{b^{2} m_{W}}\right)\left\{\begin{array}{c}
-b L(t) \\
M_{\alpha}(t) \\
M_{\beta}(t)
\end{array}\right\} .}
\end{array}
$$

\subsubsection{Aerodinâmica não estacionária}

Os carregamentos aerodinâmicos $L(t), M_{\alpha}(t)$ e $M_{\beta}(t)$ são obtidos integrando a diferença da distribuição de pressão em torno do aerofólio, como mostrado na Equação (2.18).

$$
L(t) \equiv \int_{-(1+a) b}^{(1-a) b} \Delta p x d x, \quad M_{\alpha}(t) \equiv \int_{-(1+a) b}^{(1-a) b} \Delta p x d x, \quad M_{\beta}(t) \equiv \int_{(c-a) b}^{(1-a) b} \Delta p x d x .
$$

Desse modo, o problema se resume a achar a distribuição de pressão. Existem diversas ferramentas computacionais que podem ser utilizadas para o cálculo da pressão distribuída. Por exemplo, os modelos computacionais que desenvolvem as equações de Navier-Stokes ou a aproximação dessas equações para um fluido ideal (equação de Euler) calculam a distribuição de pressão tridimensional completa através de simulações numéricas (FOX; MCDONALD; PRITCHARD, 1985). Nesses casos, os resultados podem demorar muito tempo para serem computados. Assim, a alternativa é assumir algumas simplificações na dinâmica dos fluidos para que a aproximação analítica possa ser usada. As Equações (2.19) e (2.20) representam as equações aproximadas para um fluido bidimensional, assumindo que o escoamento seja irrota- 
cional (Equação 2.19), incompressível (Equação 2.20).

$$
\nabla \times \vec{V}=0 \rightarrow \vec{V}=\nabla \phi
$$

onde $\vec{V}$ é o vetor velocidade, $\nabla$ é o operador gradiente e $\phi$ é o potencial de velocidades.

$$
\nabla^{2} \phi=0
$$

onde $\nabla^{2}$ é o operador laplaciano.

Com as aproximações das Equações (2.19) e (2.20), a pressão pode ser obtida através da Equação (2.21), que representa a equação não estacionária de Bernoulli para pequenas perturbações no fluido.

$$
p=-\rho_{\infty}\left[\frac{\partial \phi}{\partial t}+U_{\infty} \frac{\partial \phi}{\partial x}\right]
$$

A Tabela 2.1 apresenta uma relação de alguns modelos utilizados para aerodinâmica não estacionária, onde $k=\frac{\omega b}{U}$ é a frequência reduzida do sistema e $\alpha$ representa o ângulo de ataque. Na primeira coluna, na qual a frequência reduzida é menor que 0,1 , utiliza-se a aproximação para aerodinâmica quase-estacionária. Para movimentos oscilatórios onde a frequência reduzida é maior que 0,1 , utilizam-se os modelos presentes na segunda coluna da Tabela 2.1. Estes modelos não consideram a influência da separação da camada limite, ou seja, não consideram influências aerodinâmicas não lineares $\left(\alpha<20^{\circ}\right)$. Já a terceira coluna apresenta os modelos usados para oscilações com ângulo de ataque altos e alguns desafios enfrentados por esses

\begin{tabular}{|c|c|c|}
\hline $\mathrm{k}<0,1$ & $\mathrm{k}>0,1$ e $\alpha<20^{\circ}$ & $\mathrm{k}>0,1$ e $\alpha>20^{\circ}$ \\
\hline & Bidimensional: & Tri/ Bidimensional \\
\hline & - Peters (PETERS, 2008) & - Modelos numéricos para solução de Euler \\
\hline Aerodinâmica & - Theodorsen (THEODORSEN, 1935) & - Dinâmica dos fluidos computacional (CFD) \\
\hline \multirow{3}{*}{ Quase-estacionária } & Tridimensional: & Desafios \\
\hline & - Reissner (REISSNER, 1947) & - Aerodinâmica não linear \\
\hline & $\begin{array}{l}\text { - Método de malha de vórtices } \\
\text { (KATZ; PLOTKIN, 2006) }\end{array}$ & - Custo computacional \\
\hline
\end{tabular}
modelos.

Tabela 2.1: Comparação de alguns modelos para aerodinâmica não estacionária.

O modelo escolhido nesse trabalho para o cálculo dos carregamentos aerodinâmicos não estacionários foi o proposto por Theodorsen (1935) com aproximações para movimentos ar- 
bitrários de um aerofólio até ângulos de ataque de $20^{\circ}$ onde não há influência da aerodinâmica não linear. O método de Theodorsen está detalhado em Trickey (2000), Vasconcellos (2012), Vasconcellos et al. (2012, 2014). Conforme explicado acima, o modelo aerodinâmico de Theodorsen (1935) obtém uma solução analítica para a distribuição de pressão em torno de um seção típica bidimensional, assumindo que o escoamento seja potencial, incompressível e irrotacional.

Considera-se o campo potencial do fluido como a soma das potências referentes ao aerofólio (parte não circulatória) e do potencial referente ao padrão de vórtices sobre o aerofólio e ao longo da esteira (parte circulatória). Em outras palavras, o modelo analítico considera a influência do aerofólio, a condição de Kutta, na qual a pressão finita tende a zero no bordo de fuga, e a influência da esteira. Desso modo, a sustentação e os momentos aerodinâmicos são dados por

$$
\begin{gathered}
L(t)=L^{N C}+L^{C}, \\
M_{\alpha}(t)=M_{\alpha}^{N C}+M_{\alpha}^{C}, \\
M_{\beta}(t)=M_{\beta}^{N C}+M_{\beta}^{C},
\end{gathered}
$$

onde os termos não circulatórios são,

$$
\begin{aligned}
& L^{N C}=\pi \rho b^{2}\left[\ddot{h}+U \dot{\alpha}-b a \ddot{\alpha}-\frac{U}{\pi} T_{4} \dot{\beta}-\frac{b}{\pi} T_{1} \ddot{\beta}\right] \\
& M_{\alpha}^{N C}=\pi \rho b^{2}\left\{b a \ddot{h}-U b\left(\frac{1}{2}-a\right) \dot{\alpha}-b^{2}\left(\frac{1}{8}+a^{2}\right) \ddot{\alpha}-\frac{U^{2}}{\pi}\left(T_{4}+T_{10}\right) \beta+\right. \\
& \left.\frac{U b}{\pi}\left[-T_{1}+T_{8}+(c-a) T_{4}-\frac{1}{2} T_{11}\right] \dot{\beta}+\frac{b^{2}}{\pi}\left[T_{7}+(c-a) T_{1}\right] \ddot{\beta}\right\}, \\
& M_{\beta}^{N C}=\pi \rho b^{2}\left\{\frac{b}{\pi} T_{1} \ddot{h}+\frac{U b}{\pi}\left[2 T_{9}+T_{1}-\left(a-\frac{1}{2}\right) T_{4}\right] \dot{\alpha}-\right. \\
& \left.\frac{2 b^{2}}{\pi} T_{13} \ddot{\alpha}-\frac{U^{2}}{\pi^{2}}\left(T_{5}-T_{4} T_{10}\right) \beta+\frac{U b T_{4} T_{11}}{2 \pi^{2}} \dot{\beta}+\frac{b^{2} T_{3}}{\pi^{2}} \ddot{\beta}\right\},
\end{aligned}
$$

e os termos circulatórios são,

$$
\begin{gathered}
L^{C}=2 \pi \rho U b C(k) f(t), \\
M_{\alpha}^{C}=2 \pi \rho b^{2}\left(a+\frac{1}{2}\right) C(k) f(t),
\end{gathered}
$$




$$
M_{\beta}^{C}=-\rho U b^{2} T_{12} C(k) f(t)
$$

onde $C(k)$ é chamada função de Theodorsen,

$$
f(t)=U \alpha+\dot{h}+\dot{\alpha} b\left(\frac{1}{2}-a\right)+\frac{U}{\pi} T_{10} \beta+\frac{b}{2 \pi} T_{11} \dot{\beta}
$$

é o termo quase-estacionário e os termos $T_{i}$ (para $i=1,2, \cdots$ ) são conhecidos como constantes de Theodorsen (THEODORSEN, 1935).

Os carregamentos aerodinâmicos dados pelas Eqs. (2.22), (2.23) e (2.24) são dependentes da função de Theodorsen $C(k)$, onde $k=\frac{\omega b}{U}$ é a frequência reduzida de movimentos harmônicos. Entretanto, para considerar a dinâmica de movimentos arbitrários aos quais o aerofólio estará sujeito, manipula-se a função de Theodorsen utilizando a integral de convolução de Duhamel no domínio do tempo e a função de Wagner, a qual leva em consideração a resposta da sustentação de um aerofólio a entrada degrau como sendo a superposição de soluções elementares (LI; GUO; XIANG, 2010). Desse modo, o termo de sustentação circulatório pode ser obtido segundo:

$$
C(k) f(t)=f(0) \phi(\tau)+\int_{0}^{\tau} \frac{\partial f(\sigma)}{\partial \sigma} \phi(\tau-\sigma) d \sigma
$$

onde $\sigma$ é a variável de integração, $\tau=\frac{t U}{b}$ é o tempo adimensional e $\phi(\tau)$ é a função de Wagner, para a qual, através da aproximação de Sears (1940), tem-se

$$
\phi(\tau) \approx c_{0}-c_{1} e^{-c_{2} \tau}-c_{3} e^{-c_{4} \tau}
$$

onde $c_{0}=1,0, c_{1}=0,165, c_{2}=0,0455, c_{3}=0,335$ and $c_{4}=0,3$.

Substituindo a Eq. (2.33) na Eq. (2.32) e usando a integração por partes, a função de Theodorsen $C(k)$ e o termo quase estacionário $f(t)$ podem ser escritos como

$$
C(k) f(t)=\left(c_{0}-c_{1}-c_{3}\right) f(t)+c_{2} c_{4}\left(c_{1}+c_{3}\right) \bar{x}+\left(c_{1} c_{2}+c_{3} c_{4}\right) \dot{\bar{x}}
$$

onde $\bar{x}$ and $\dot{\bar{x}}$ são variáveis aerodinâmicas aumentadas no espaço de estados.

Substituindo a Eq. (2.34) nas Eqs. (2.28), (2.29) e (2.30), obtêm-se os valores dos carregamentos aerodinâmicos. Mais detalhes para o cálculo do modelo aerodinâmico não estacionário 
podem ser encontrados em Lee, Gong e Wong (1997), Lee, Liu e Chung (2005), Li, Guo e Xiang (2010).

\subsubsection{Representação das equações de movimento no espaço de estados}

As equações de movimento do sistema aeroelástico são equações diferenciais de segunda ordem. Elas podem ser resolvidas através do método de Runge Kutta de $4^{a}$ ordem, o qual faz parte de uma família importante de métodos iterativos implícitos e explícitos para a resolução numérica (aproximação) de soluções de equações diferenciais ordinárias. Para resolver as equações diferenciais o sistema deverá estar representado no espaço de estados. Desse modo, com a introdução das variáveis aumentadas $\bar{x}$ e $\dot{\bar{x}}$ e reagrupando os termos da Eq. 2.17, obtém-se a equação de movimento final do aerofólio,

$$
\left(\mathbf{M}_{\mathbf{s}}-\mathbf{M}^{N C}\right) \ddot{\mathbf{x}}+\left(\mathbf{B}_{\mathbf{s}}-\mathbf{B}^{N C}-\frac{1}{2} \mathbf{R S}_{\mathbf{2}}\right) \dot{\mathbf{x}}+\left(\mathbf{K}_{\mathbf{s}}-\mathbf{K}^{N C}-\frac{1}{2} \mathbf{R S}_{\mathbf{1}}\right) \mathbf{x}-\mathbf{R S}_{\mathbf{3}} \mathbf{x}_{\mathbf{a}}=0
$$

onde $\mathbf{x}=[\xi \alpha \beta]^{T}, \mathbf{x}_{\mathbf{a}}=[\bar{x} \dot{\bar{x}}]^{T} \mathrm{e}$

$$
\begin{gathered}
\mathbf{M}_{\mathbf{s}}=\left[\begin{array}{ccc}
\mu_{e} & x_{\alpha} & x_{\beta} \\
x_{\alpha} & r_{\alpha}^{2} & {\left[r_{\beta}^{2}+(c-a) x_{\beta}\right]} \\
x_{\beta} & {\left[r_{\beta}^{2}+(c-a) x_{\beta}\right]} & r_{\beta}^{2}
\end{array}\right], \\
\mathbf{B}_{\mathbf{s}}=\left[\begin{array}{ccc}
d_{1,1} & d_{1,2} & d_{1,3} \\
d_{2,1} & d_{2,2} & d_{2,3} \\
d_{3,1} & d_{3,2} & d_{3,3}
\end{array}\right] \\
\mathbf{K}_{\mathbf{s}}=\left[\begin{array}{ccc}
\omega_{h}^{2} & 0 & 0 \\
0 & r_{\alpha}^{2} \omega_{\alpha}^{2} \frac{F(\alpha)}{\alpha(t)} & 0 \\
0 & 0 & r_{\beta}^{2} \omega_{\beta}^{2} \frac{F(\beta)}{\beta(t)}
\end{array}\right]
\end{gathered}
$$

onde $\mathbf{M}_{\mathbf{s}}, \mathbf{B}_{\mathbf{s}}$ e $\mathbf{K}_{\mathbf{s}}$ são as matrizes da dinâmica estrutural (Equação (2.17)).

As matrizes $\mathbf{M}^{N C}, \mathbf{B}^{N C}, \mathbf{K}^{N C}, \mathbf{R}, \mathbf{S}_{\mathbf{1}}, \mathbf{S}_{\mathbf{2}}$ e $\mathbf{S}_{\mathbf{3}}$ têm origem na aproximação para aerodinâmica não estacionária de Theodorsen (1935), dadas por 


$$
\begin{aligned}
& \mathbf{M}^{N C}=-\frac{\rho}{m_{W}}\left[\begin{array}{ccc}
\pi b^{2} & -\pi a b^{2} & -T_{1} b^{2} \\
-\pi a b^{2} & \pi b^{2}\left(\frac{1}{8}+a^{2}\right) & -\left[T_{7}+(c-a) T_{1}\right] b^{2} \\
-T_{1} b^{2} & 2 T_{13} b^{2} & \frac{-T_{3} b^{2}}{\pi}
\end{array}\right] \\
& \mathbf{B}^{N C}=-\frac{\rho U b}{m_{W}}\left[\begin{array}{ccc}
0 & \pi & -T_{4} \\
0 & \pi\left(\frac{1}{2}-a\right) & {\left[T_{1}-T_{8}-(c-a) T_{4}+\frac{T_{11}}{2}\right]} \\
0 & {\left[-2 T_{9}-T_{1}+T_{4}\left(a-\frac{1}{2}\right)\right]} & \frac{\left(-T_{4} T_{11}\right)}{2 \pi}
\end{array}\right] \\
& \mathbf{K}^{N C}=-\frac{\rho}{m_{W}}\left[\begin{array}{ccc}
0 & 0 & 0 \\
0 & 0 & \left(T_{4}+T_{10} U^{2}\right) \\
0 & 0 & \frac{\left(T_{5}-T_{4} T_{10}\right) U^{2}}{\pi}
\end{array}\right] \\
& \mathbf{R}=\frac{1}{m_{W}}\left[\begin{array}{lll}
-2 \pi \rho U & 2 \pi \rho U\left(a+\frac{1}{2}\right) & -\rho U T_{12}
\end{array}\right]^{T}, \\
& \mathbf{S}_{\mathbf{1}}=\left[\begin{array}{ccc}
0 & U & \frac{T_{10} U}{\pi}
\end{array}\right] \\
& \mathbf{S}_{\mathbf{2}}=\left[\begin{array}{lll}
b & b\left(\frac{1}{2}-a\right) & \frac{b T_{11}}{2 \pi}
\end{array}\right] \\
& \mathbf{S}_{\mathbf{3}}=\left[\begin{array}{ll}
\frac{c_{2} c_{4}\left(c_{1}+c_{3}\right) U^{2}}{b} & \left(c_{1} c_{2}+c_{3} c_{4}\right) U
\end{array}\right] .
\end{aligned}
$$

$\mathrm{Na}$ forma de espaço de estados a Eq. 2.35 é dada por

$$
\dot{\mathbf{X}}=\mathbf{A X}
$$

onde, $\mathbf{X}=\left[\begin{array}{llllllll}\xi & \alpha & \beta & \dot{\xi} & \dot{\alpha} & \dot{\beta} & \bar{x} & \dot{\bar{x}}\end{array}\right]^{T} \mathrm{e}$ 


$$
\mathbf{A}=\left[\begin{array}{ccc}
\mathbf{0} & \mathbf{I} & \mathbf{0} \\
-\mathbf{M}_{\mathbf{t}}^{-1} \mathbf{K}_{\mathbf{t}} & -\mathbf{M}_{\mathbf{t}}^{-1} \mathbf{B}_{\mathbf{t}} & -\mathbf{M}_{\mathbf{t}}^{-1} \mathbf{D} \\
\mathbf{E}_{\mathbf{1}} & \mathbf{E}_{2} & \mathbf{F}
\end{array}\right]
$$

sendo,

$$
\begin{gathered}
\mathbf{M}_{\mathbf{t}}=\left(\mathbf{M}_{\mathbf{s}}-\mathbf{M}^{N C}\right), \mathbf{B}_{\mathbf{t}}=\left(\mathbf{B}_{\mathbf{s}}-\mathbf{B}^{N C}-\frac{1}{2} \mathbf{R S}_{\mathbf{2}}\right), \mathbf{K}_{\mathbf{t}}=\left(\mathbf{K}_{\mathbf{s}}-\mathbf{K}^{N C}-\frac{1}{2} \mathbf{R S}_{\mathbf{1}}\right), \mathbf{D}=\mathbf{R S}_{\mathbf{3}}, \\
\mathbf{E}_{\mathbf{1}}=\left[\begin{array}{ccc}
0 & 0 & 0 \\
\frac{U}{b} & \frac{U T_{10}}{\pi b} & 0
\end{array}\right], \\
\mathbf{E}_{\mathbf{2}}=\left[\begin{array}{ccc}
0 & 0 & 0 \\
\left(\frac{1}{2}-a\right) & \frac{T_{11}}{2 \pi} & 1
\end{array}\right], \\
\mathbf{F}=\left[\begin{array}{cc}
0 & 1 \\
\frac{-c_{2} c_{4} U^{2}}{b^{2}} & \frac{-\left(c_{2}+c_{4}\right) U}{b}
\end{array}\right] .
\end{gathered}
$$

\subsubsection{Representação das não linearidades estruturais}

Os efeitos não lineares concentrados foram incorporados ao modelo aeroelástico através das forças ou momentos de restauração elástica $F(\alpha)$ e $F(\beta)$ aplicados à matriz de rigidez $\mathbf{K}_{\mathbf{s}}$ (ver Eq. (2.17)). Para cada iteração no tempo, calcula-se o valor da influência não linear utilizando os resultados dos deslocamentos da iteração anterior, desse modo resolveu-se a equação diferencial numericamente como sendo linear, com os efeitos das forças não lineares alterando os módulos das curvas de rigidez. Nesse trabalho foram considerados duas não linearidades estruturais aplicadas cada uma a um respectivo grau de liberdade, considerando: $(i)$ para o movimento de torção somente a não linearidade do tipo enrijecimento, $(i i)$ para o movimento da superfície de controle somente a não linearidade do tipo folga. A Figura 2.3 (a) apresenta o efeito não linear de enrijecimento da curva de momento restaurador para o deslocamento em torção $(\alpha)$ 
em comparação com uma rigidez linear, observa-se que quanto maior o ângulo de ataque maior será o momento de restauração. A Figura 2.3 (b) apresenta o efeito de folga em comparação com uma rigidez linear, observa-se que a rigidez é zero entre os intervalos de $-\delta \mathrm{a}+\delta$.

A função não linear de enrijecimento foi obtida usando a aproximação por razão de polinômios (RP) (do inglês, rational polynomials approximation, utilizado em Li, Guo e Xiang (2012)), através de medidas experimentais da curva de restauração elástica do momento de torção. A aproximação por RP usada nesse trabalho segue a seguinte equação,

$$
F(\alpha)=\frac{a_{3} \alpha^{3}+a_{2} \alpha^{2}+a_{1} \alpha+a_{0}}{b_{2} \alpha^{2}+b_{1} \alpha+b_{0}}
$$

onde $a_{0}$ até $a_{3}$ e $b_{0}$ até $b_{2}$ são coeficientes reais obtidos numericamente utilizando dados experimentais.

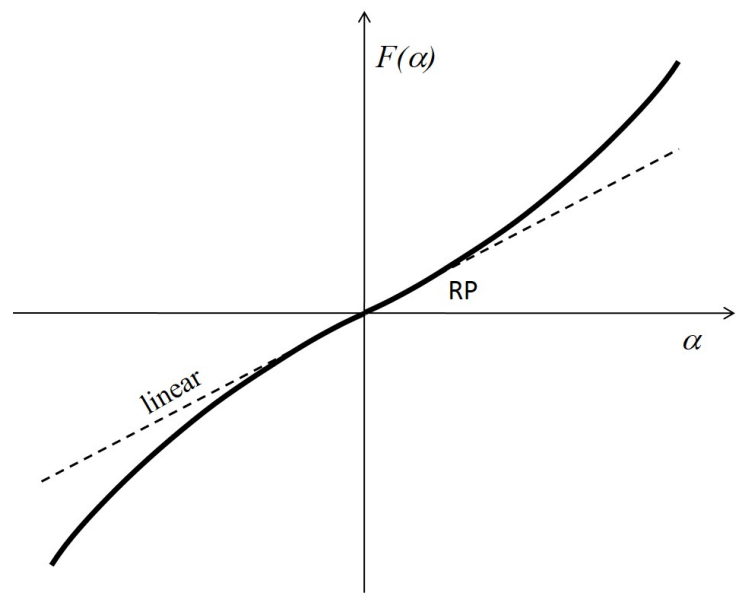

(a) Representação do enrijecimento

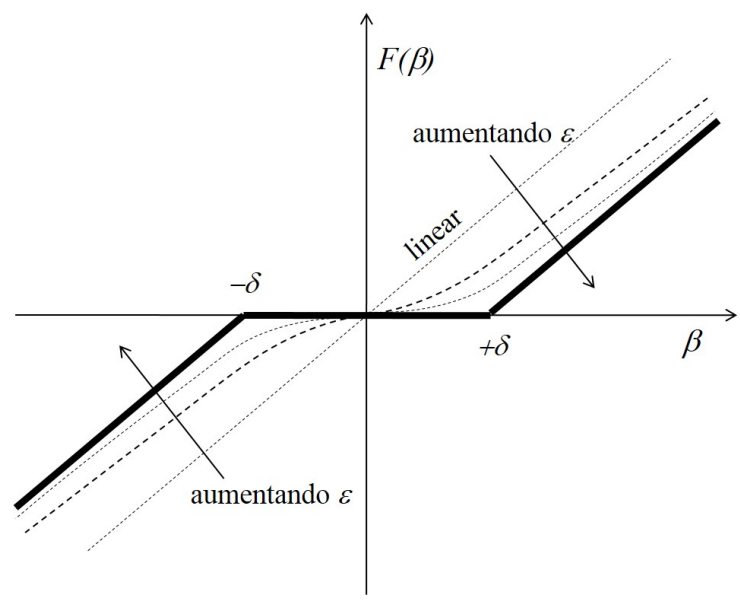

(b) Representação da folga

Figura 2.3: Representação do efeito não linear de enrijecimento aplicado em torção e do efeito não linear de folga aplicado na superfície de controle.

Para a função não linear de folga aplicada ao momento restaurador da superfície de controle, foi utilizada uma aproximação por combinações de tangentes hiperbólicas conforme proposto e validado por (VASCONCELLOS et al., 2014). Essa função é dada por:

$$
\mathbf{F}(\beta)=\frac{1}{2}[1-\tanh (\varepsilon(\beta+\delta))](\beta+\delta)+\frac{1}{2}[1+\tanh (\varepsilon(\beta-\delta))](\beta-\delta),
$$

onde $\delta$ representa a fronteira positiva e negativa da folga, cujo comprimento é de $2 \delta$, e $\varepsilon$ é o coeficiente responsável por suavizar a função, na qual para valores mais altos de $\varepsilon$ a desconti- 
nuidade é melhor representada (Figura 2.3(b)).

\subsection{Modelo experimental}

O dispositivo experimental é baseado no modelo testado por Vasconcellos (2012) no Laboratório de Aeroelasticidade da EESC/USP, o qual consiste em reproduzir o comportamento bidimensional de uma seção aeroelástica típica que permite movimentos de torção (pitch), de flexão (plunge) e rotação da superfície de controle (sistema com três graus de liberdade). Ele é formado por uma asa com o perfil NACA 0012, 250 $\mathrm{mm}$ de corda e $700 \mathrm{~mm}$ de envergadura fixada em uma suspensão elástica que permite os movimentos nos três graus de liberdade. A Figura 2.3(a) mostra uma ilustração do conjunto asa, suspensão e suporte. O ensaio foi feito com um túnel de vento tipo soprador (circuito aberto) que permite velocidade de escoamento de ar máxima de aproximadamente $25 \mathrm{~m} / \mathrm{s}$, possuindo um bocal de saída de seção quadrada de dimensões $500 \times 500 \mathrm{~mm}$, ilustrado na Figura 2.3(b).

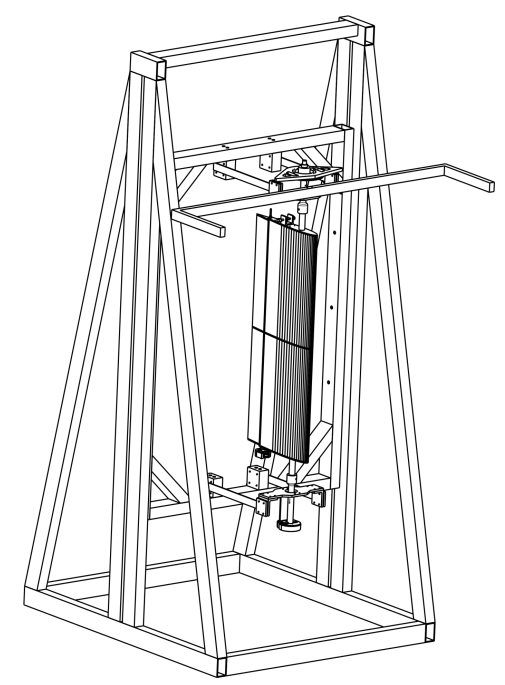

(a) Asa e suportes

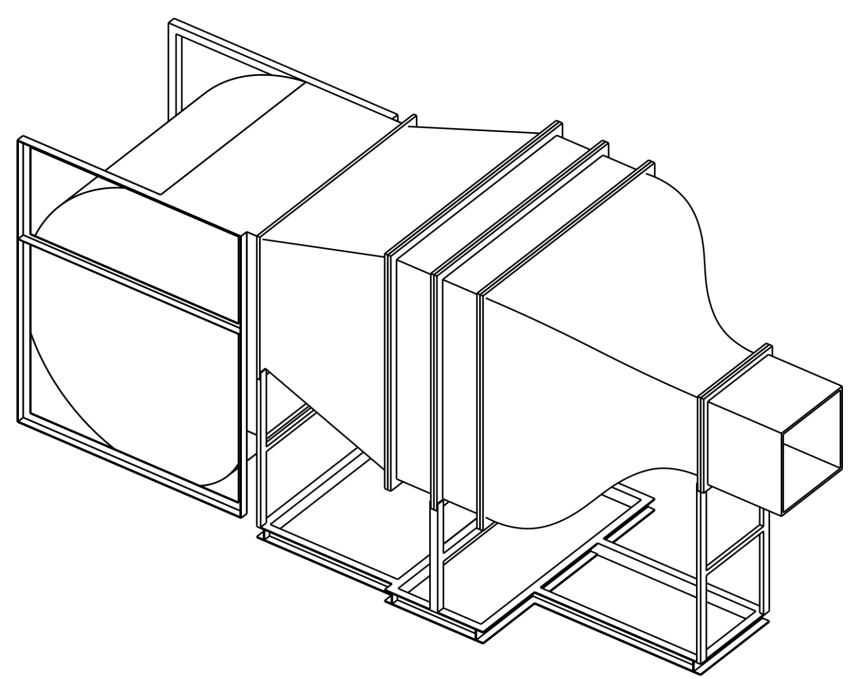

(b) Túnel de vento de seção aberta

Figura 2.4: Desenho mostrando a vista isométrica (a) do dispositivo completo e (b) do túnel de vento.

A Figura 2.5 mostra detalhadamente os dispositivos experimentais. Durante as análises foram utilizados um barômetro, um anemômetro conectado a um tubo de pitot e um sistema de aquisição de dados conhecido como dSPACE ${ }^{\circledR}$, o qual é ligado em conjunto com um modelo 
no Simulink ${ }^{\circledR}$. Os sinais são coletados nos três graus de liberdade utilizando sensores (tipo encoder) ópticos.

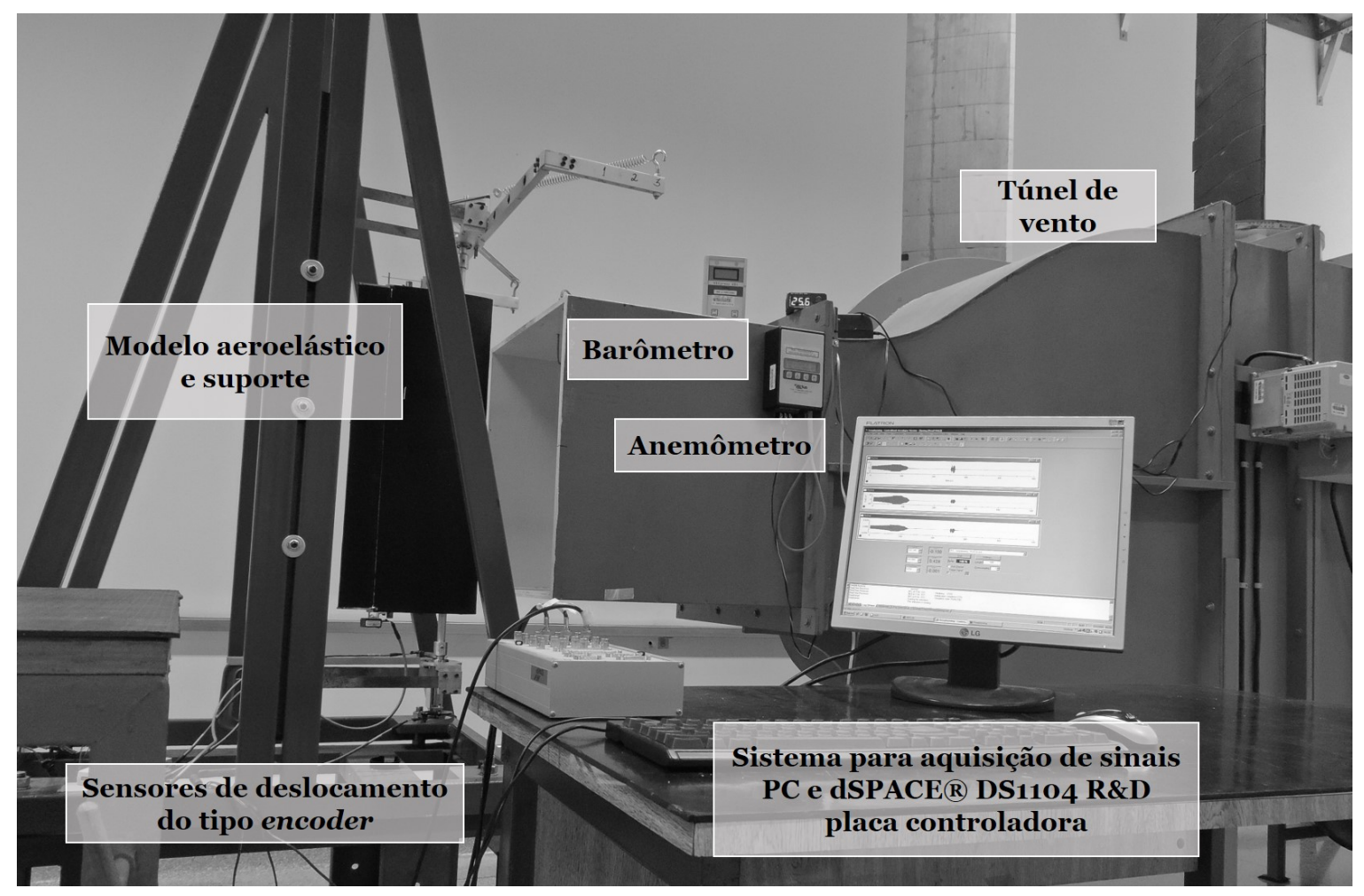

Figura 2.5: Dispositivos experimentais.

O modelo aeroelástico é formado por uma asa rígida montada ao longo de sua envergadura feita de isopor convencional revestida com fibra de vidro e epóxi, os quais são responsáveis pela rigidez estrutural. A asa é construída em duas semi-envergaduras e três placas de alumínio anexadas a ela, uma central e duas externas que servem para acoplar o dispositivo responsável pela rigidez torcional da superfície de controle. Esse dispositivo é responsável pelo controle dos batentes da rigidez da articulação da SC, permitindo variar os parâmetros $-\delta$ e $+\delta$ presentes na Equação (2.47) da não linearidade do tipo folga (ver Figure 2.6). Tanto a asa quanto a SC são suportadas por microrrolamentos fixos a elas, contendo um eixo principal de alumínio, o qual está conectado através de rolamentos e flanges à placa que permite o deslocamento angular.

A Figura 2.6 apresenta com detalhes todos os componentes presentes na asa, responsáveis por aproximá-la à seção típica. A rigidez em plunge e a união da asa com a estrutura são dadas por quatro vigas feitas de aço mola, duas em cima e duas em baixo. A rigidez em pitch é 


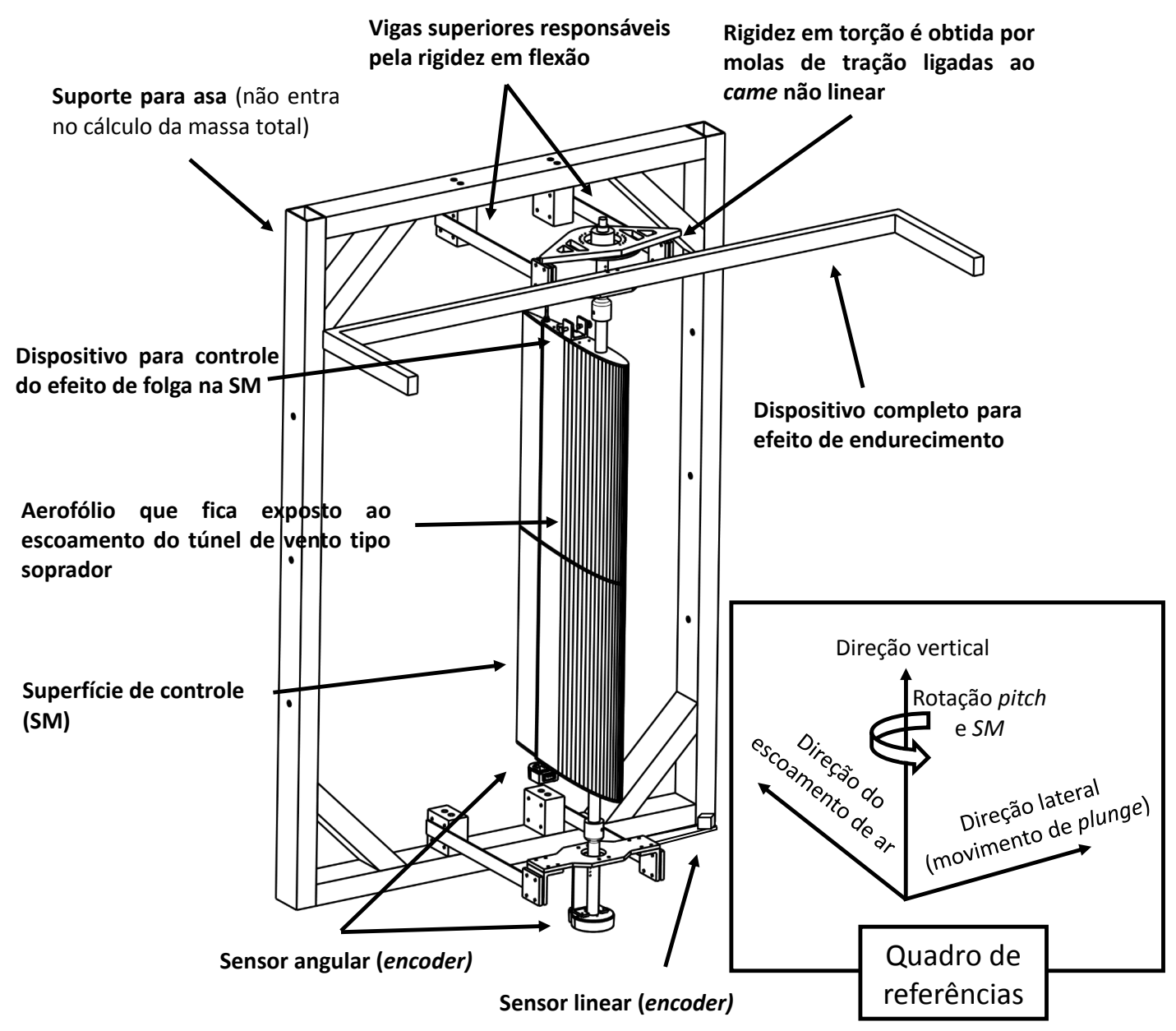

Figura 2.6: Modelo aeroelástico experimental com detalhes.

dada por um dispositivo composto por três partes: um came não linear, duas molas de tração lineares conectadas à ele (ver Figura 2.8) e um suporte conectado à asa e às molas de tração, o qual permite variar o tamanho inicial das molas de tração, criando assim diferentes intensidades de enrijecimento. Observa-se também a presença dos sensores angulares de deslocamento em pitch, da superfície de controle e do sensor de deslocamento linear em plunge. O quadro de referências mostra a direções dos movimentos do aerofólio e do escoamento de ar.

A Figura 2.7 mostra o dispositivo desenvolvido nesse trabalho. Observa-se que o efeito não linear é gerado através das duas aletas presas num círculo, o qual foi chamado nesse trabalho de came. Se o dispositivo fosse uma circunferência, a deformação resultante em uma mola, 
quando a asa possui um ângulo de torção, seria igual ao deslocamento sofrido pela outra mola, resultando numa força de rigidez linear contrária ao movimento. Contudo, com o came não linear, a mola que está sofrendo deformação na direção do deslocamento em torção terá um deslocamento maior proporcional a curva da aleta, resultando em uma rigidez não linear. A intensidade da rigidez (inclinação da curva não linear) é dada pela deformação inicial de cada mola.

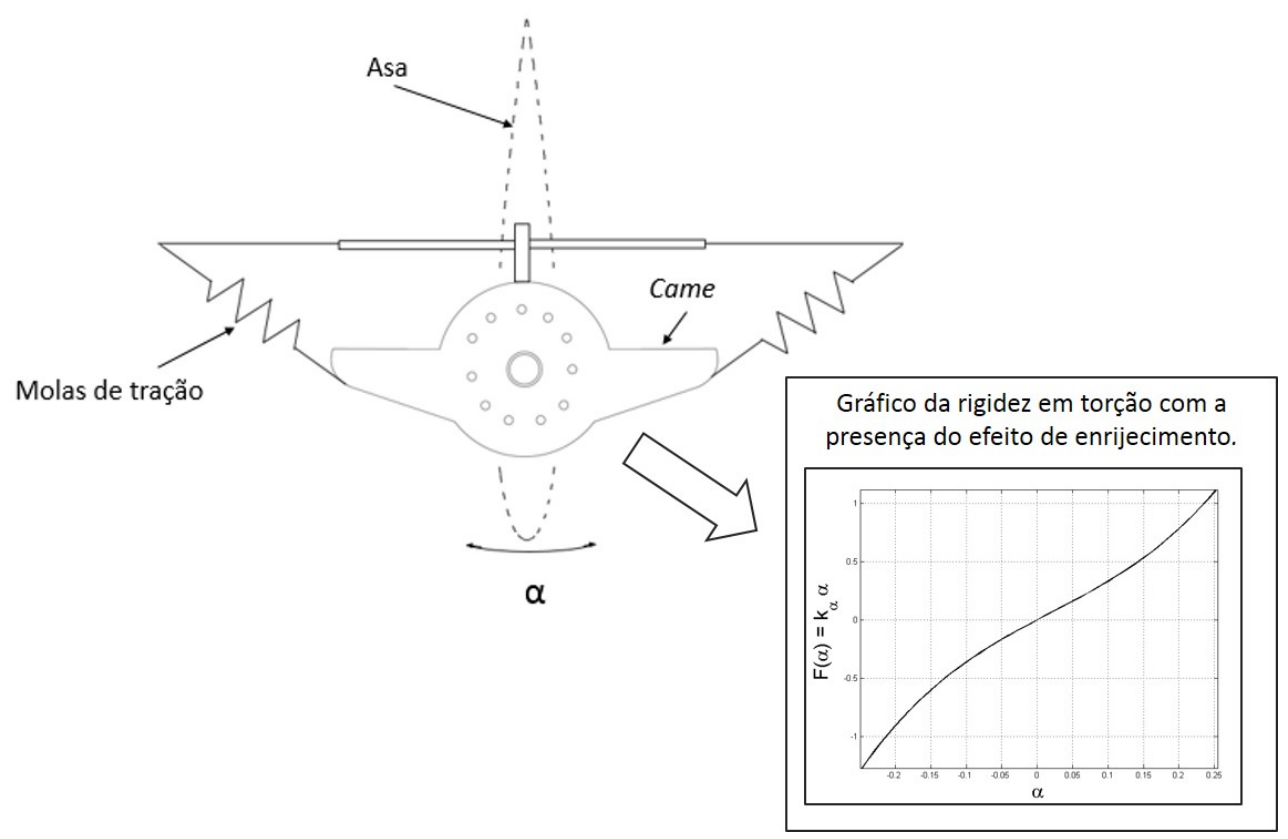

Figura 2.7: Detalhes do dispositivo responsável pela rigidez não linear em torção

As Figuras 2.8 e 2.9 mostram com detalhes os sistemas que apresentam as não linearidades estruturais: $(i)$ do tipo enrijecimento em pitch, no qual o came não linear induz as molas de tração a terem deslocamentos maiores do que os lineares com o aumento do ângulo de ataque, resultando assim no aparecimento do efeito de enrijecimento, (ii) do tipo folga na superfície de controle, a qual possui um dispositivo para controle do tamanho da folga $(2 \delta$, conforme o modelo numérico (ver Figura 2.3(b)). Esse dispositivo consiste em um fio mola e em duas batentes, o fio mola é responsável pela rigidez estrutural e as batentes podem variar o tamanho da folga através de dois parafusos. 


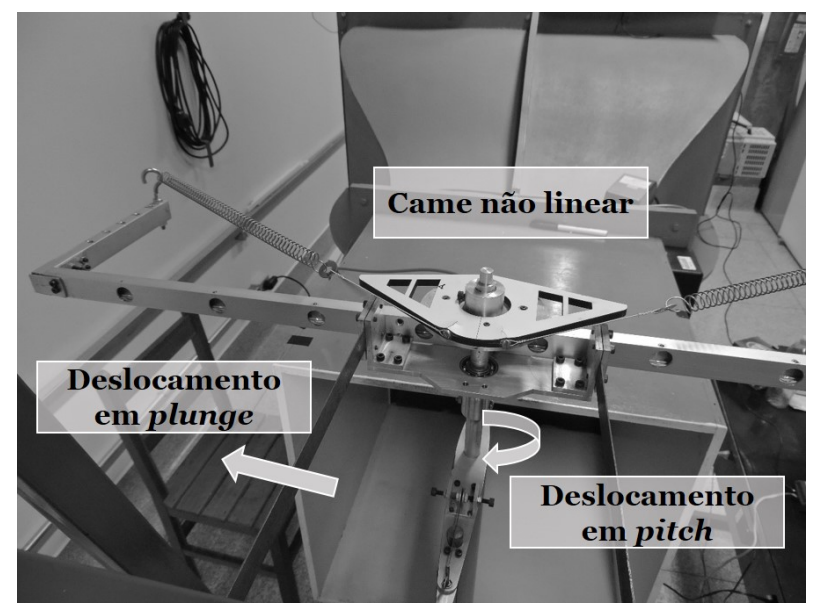

(a) Vista superior/traseira

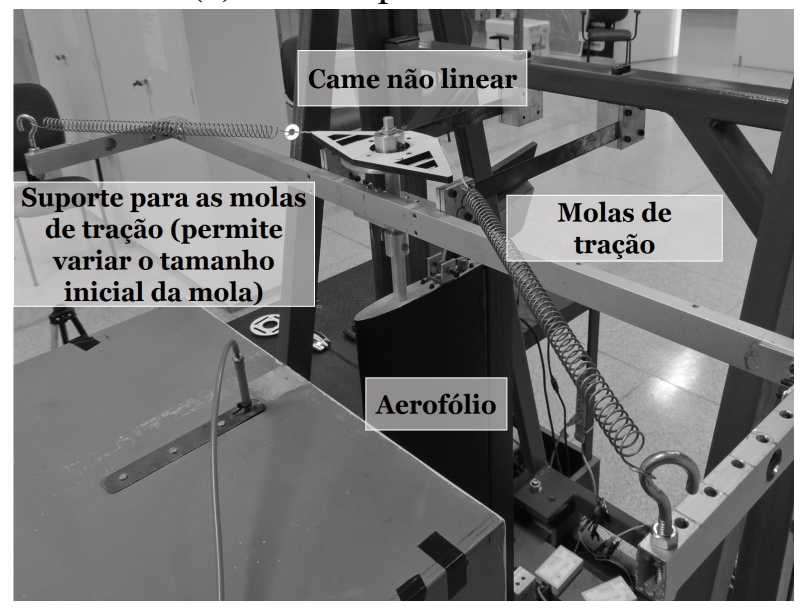

(b) Vista lateral

Figura 2.8: Detalhes do dispositivo da não linearidade de enrijecimento presente no momento de torção (pitch).

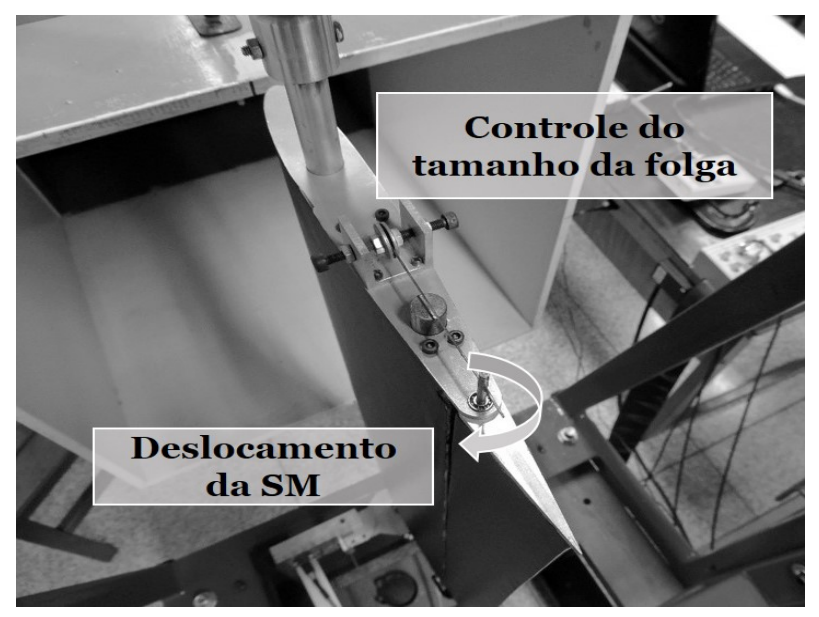

Figura 2.9: Detalhes do aparato experimental responsável pelo aparecimento da não linearidade do tipo folga. 


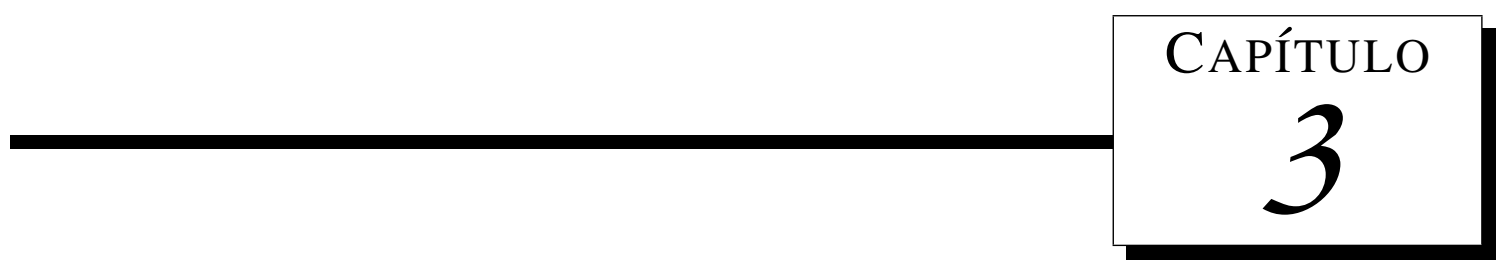

\section{ANÁLISE DE SÉRIES TEMPORAIS}

\subsection{Introdução}

Nesse capítulo, serão explicados com detalhes os métodos utilizados para técnicas de identificação e análise das séries temporais não lineares no domínio do tempo chamado reconstrução no espaço de estados e no domínio da frequência chamado análise por espectros de ordem mais alta. Também será explicado a forma utilizada para a obtenção dos diagramas de bifurcação.

\subsection{Análise da bifurcação de Hopf}

A bifurcação de Hopf é típica em sistemas aeroelásticos não lineares, nos quais, em determinadas condições de escoamento, ocorre o aparecimento de movimentos autossustentados chamados de oscilações em ciclo limite (NAYFEH; BALACHANDRAN, 1995). A condição de início crítico da bifurcação, velocidade na qual o sistema entra em LCO independentemente da condição inicial, pode ser obtida experimentalmente ou através de simulações numéricas.

A bifurcação de Hopf foi obtida através das séries temporais variando a velocidade do túnel de vento, ou seja, para cada série temporal foram obtidos, através do valor eficaz (do inglês, root mean square-RMS), os valores da medida estatística do máximo e mínimo deslocamento de cada LCO, obtém-se, assim, um valor médio chamado de RMS 1 e RMS 2, que estão presentes nas Figuras 3.1(a) e (b). Esses pontos são colocados num gráfico $x-y$, no qual $x$ representa 
a velocidade normalizada e $y$ as amplitudes dos deslocamentos em flexão, torção e torção da SC. Desse modo, pode-se analisar a evolução do sistema bem como a sua característica sub ou supercrítica. A Figura 3.1 mostra com detalhes como foi obtido o diagrama de bifurcação. Vale ressaltar que o diagrama não é necessariamente simétrico em relação ao eixo $U / U_{c}$.

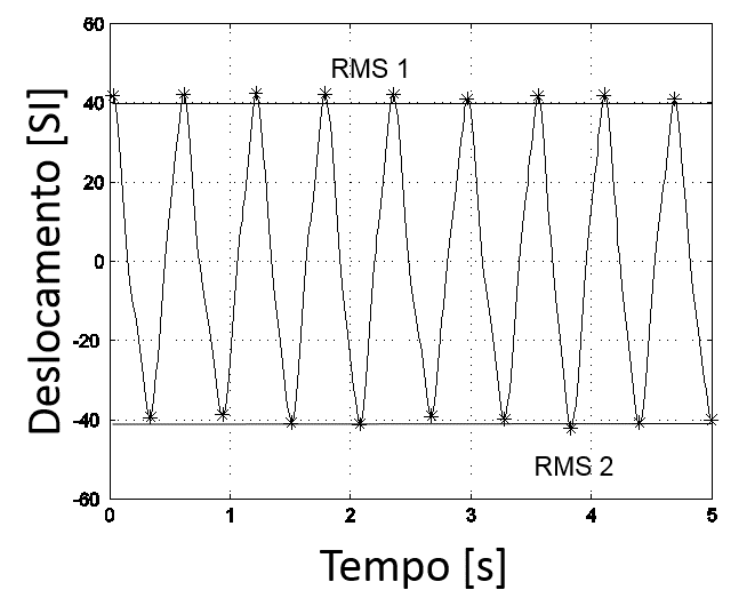

(a) Série temporal.

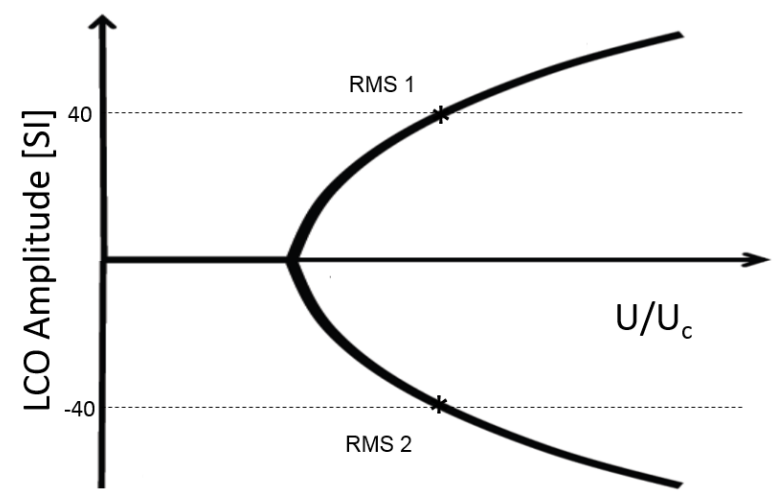

(b) Diagrama de bifurcação.

Figura 3.1: Obtenção do diagrama de bifurcação.

\subsection{Reconstrução do espaço de estados}

Num experimento não são medidas todas as variáveis de estado envolvidas na dinâmica de um sistema. Geralmente, têm-se disponível a evolução no tempo de apenas algumas variáveis representadas por séries temporais. Assim, torna-se necessário analisar o sistema a partir dessas séries temporais, sendo que o principal método disponível é o da reconstrução do espaço de 
estados (SIMONI, 2008).

A técnica de reconstrução do espaço de estados é usada para extrair informações da dinâmica do sistema presentes em variáveis de estados que não foram medidas experimentalmente. A técnica tem base no teorema de imersão de Takens (1981) e Mañé (1981) (do ingles, Takens embedding theorem), no qual é possível reconstruir um espaço de fases $m$-dimensional similar ao espaço de fases original uma vez que toda série temporal guarda informações sobre todos os estados não observáveis. Esse espaço reconstruído apresenta uma pequena variação de coordenadas em relação ao espaço original, preservando os invariantes geométricos do sistema, tais como os expoentes de Lyapunov.

Existem três métodos utilizados na reconstrução do espaço de estado: (i) método das derivadas (PACKARD et al., 1980), no qual as coordenadas são aproximações numéricas das derivadas de ordem sucessivamente superiores de uma variável medida, (ii) o método da decomposição em valores singulares (BROOMHEAD; KING, 1986), no método da decomposição em valores singulares não há a necessidade de escolher a defasagem, esse método utiliza-se das propriedades da matriz de covariância-variância para gerar coordenadas não correlacionadas. E, por fim, o (iii) método das coordenadas defasadas (PACKARD et al., 1980; TAKENS, 1981), que tem sido o mais explorado na literatura. Desse modo, a técnica usada nesse trabalho para a reconstrução é baseado no método das coordenadas defasadas (do inglês, Method of Delays MOD).

Chamando $x(t)$ como a série temporal medida, o resultado da aproximação do MOD segue o novo vetor,

$$
\mathbf{y}_{t}=\left[\begin{array}{lllll}
x(t) & x(t+\tau) & x(t+2 \tau) & \ldots & x(t+\tau(d-1))
\end{array}\right]^{\mathrm{T}}
$$

onde o espaço reconstruído usando os vetores $\mathbf{y}_{k}$ é chamado de espaço de estados reconstruído, o parâmetro $\tau$ é o atraso no tempo e $d$ a dimensão imersa. A dimensão imersa $d$ foi obtida usando a metodologia de saturação das invariantes do sistema (GRASSBERGER; PROCACCIA, 1983). A ideia desse método é que se o atrator é reconstruído usando uma dimensão de imersão $d$ suficientemente grande, então as propriedades dos invariantes do atrator, tais como 
o expoente de Lyapunov, calculadas na trajetória reconstruída não mudarão se aumentarmos $d$. Calcula-se a fração média do número de pontos do atrator com distâncias menores que $r$ através da integral de correlação $C(r)$ (NAYFEH; BALACHANDRAN, 1995).

$$
C(r)=\frac{1}{M^{2}} \sum_{\substack{i, j=0 \\ i \neq j}}^{M} H\left(r-\left|\mathbf{y}_{i}-\mathbf{y}_{j}\right|\right)
$$

onde $M=N_{0}-T(d-1)$ e $H(t)$ é a função de Heaviside, a qual é dada por

$$
H(u)=\begin{aligned}
& 1 \text { if } u \geq 0 \\
& 0 \text { if } u<0
\end{aligned}
$$

A função |.| é a distância Euclidiana.

$$
\left|\mathbf{y}_{i}-\mathbf{y}_{j}\right|=\sqrt{\sum_{k=1}^{d}\left(s_{i+T(k-1)}-s_{j+T(k-1)}\right)^{2}}
$$

A integral de correlação $C(r)$ é uma função de $r$ e da dimensão de imersão $d$. A inclinação da curva é dada por $\log _{10} C(r) / \log _{10} r$. Quando a inclinação dessa curva deixa de variar significa que o valor da dimensão $d$ do sistema foi encontrado. A Figura 3.2 mostra que a variação da inclinação entre a dimensão $d=3$ e $d=4$ é pequena, desse modo esse é o valor da dimensão imersa do sistema (SIMONI, 2008).

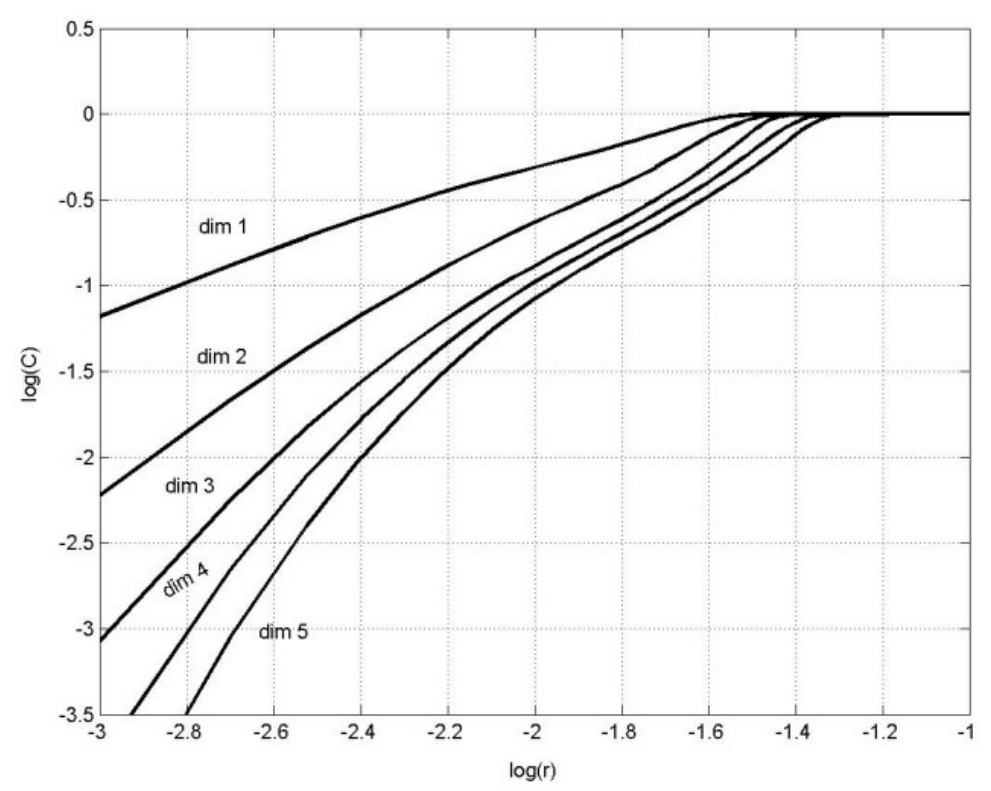

Figura 3.2: Curva para determinação da dimensão imersa $d$. 
A dimensão imersa é definida como 3, o que leva a uma reconstrução do espaço de estados como sendo $\mathbf{y}_{t}=[x(t) x(k+\tau) x(t+2 \tau)]^{\mathrm{T}}$ (reconstrução imersa em $\mathscr{R}^{3}$ ) para todas as medidas aeroelásticas. O atraso no tempo, entretanto, depende do conteúdo da frequência do sinal e deve ser determinado para todas as séries temporais (MARQUES et al., 2006). O atraso no tempo foi calculado através da função de autocorrelação, da forma que quando a autocorrelação do sinal analisado cruza o eixo zero pela primeira vez, esse é o valor assumido como $\tau$. A Figura 3.3 mostra esse procedimento e o valor da defasagem obtido.

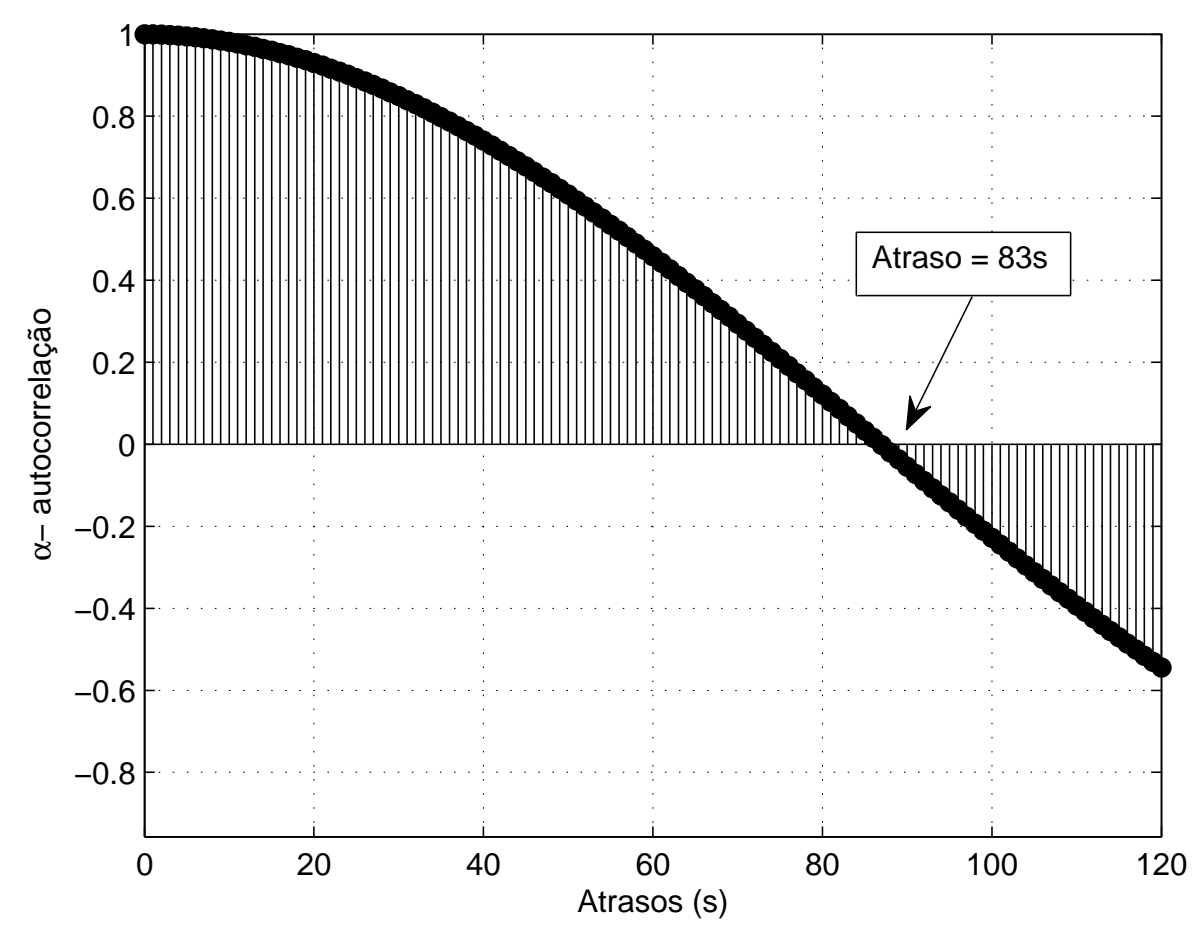

Figura 3.3: Gráfico de autocorrelação para obtenção da defasagem no tempo.

A Figura 3.4 mostra um exemplo de reconstrução do espaço de estados de uma série temporal característica associada à oscilações em ciclo limite induzidos por uma não linearidade do tipo enrijecimento. O gráfico tridimensional do espaço reconstruído está imerso num espaço $\mathscr{R}^{3}$. A Figura 3.4 também apresenta três projeções dos subespaços, os quais podem ser usados para observar dinâmicas complexas. 


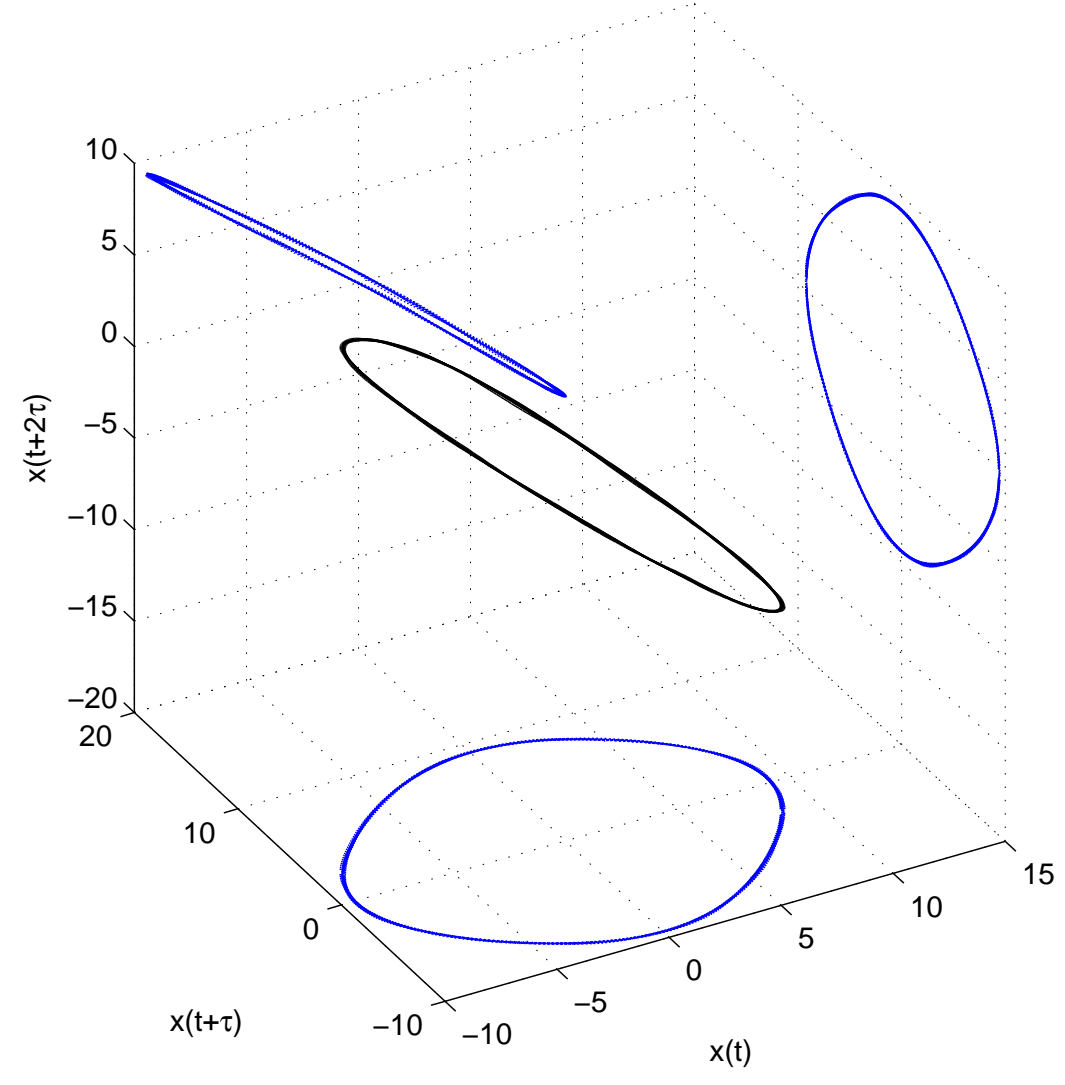

Figura 3.4: Reconstrução do espaço de estados e suas respectivas projeções para um sistema apresentando LCO, as projeções nos planos estão representados em azul.

\subsection{Espectros de ordem mais alta}

Espectros de ordem mais alta (do ingles, higher-order spectralanalysis, HOS) são transformadas de Fourier das funções de correlação de ordem mais alta, com os quais é possível acessar mais informações entre as frequências do sistema, mostrando, assim, se elas possuem ou não determinados tipos de acoplamentos não lineares. Por exemplo, o bispectro (medida de terceira ordem) é sensível a acoplamentos quadráticos, enquanto que o trispectro, a acoplamentos cúbicos e assim por diante. No entanto, não é viável obter estimativas de ordem maior que quatro (FACKRELL et al., 1994). Esta seção apresenta os aspectos teóricos básicos para a análise do HOS baseados nas seguintes referências: Nayfeh e Balachandran (1995), Hajj, Miksad e Powers (1993, 1997), Hajj e Beran (2008).

Uma das ferramentas mais utilizas para analisar a resposta de sistemas cujos processos 
são aleatórios (estocásticos), ou seja, que são dependentes do tempo, é a análise pelo domínio da frequência obtida através da transformada de Fourier. A transformada de Fourier de uma função temporal $x(t)$ é definida como

$$
X(f)=\int_{-\infty}^{+\infty} x(t) e^{-i 2 \pi f t} d t
$$

onde $f$ representa a frequência em $\mathrm{Hz}$.

Em teoria a transformada de Fourier pode ser usada para determinar as frequências presentes no sinal $x(t)$ no intervalo $-\infty<t<+\infty$, contudo sinais estocásticos dependem do tempo e existem por todo o intervalo de $t$ e, portanto, não são integráveis, por isso, devem-se utilizar junções generalizadas. Na realidade, usa-se uma faixa finita de comprimento no tempo $T$ conhecida como transforma finita de Fourier, a qual é dada por

$$
X(f)=\int_{0}^{T} x(t) e^{-i 2 \pi f t} d t
$$

No presente contexto, os sinais são obtidos através de séries temporais experimentais e através de integração numérica de um número finito de pontos determinados por uma frequência de amostragem (do inglês, sampling frequency- $F_{S}$ ), que deve ser no mínimo superior a duas vezes a frequência máxima analisada no experimento. Esse critério é conhecido como critério de amostragem de Nyquist. Essa escolha é importante para evitar o problema de subamostragem (do inglês, aliasing) que é um efeito indesejado na coleta de dados e ocorre quando um sinal é coletado a uma taxa menor que o dobro da maior frequência desejada, o que faz com que apareça frequências incorretas no sinal. A transformada de Fourier desses pontos discretizados de extensão finita (ver Figura 3.5 ) pode ser feita através da transforma de Fourier discreta (do inglês, discrete Fourier transform- DFT), na qual os resultados são números complexos. A DFT é obtida por

$$
X[k]=\sum_{n=0}^{N-1} x[n] e^{\frac{-i 2 \pi k n}{N}},
$$

onde $x[n]$ e $X[k]$ são os pontos no domínio do tempo e da frequência, respectivamente, $\mathrm{N}$ representa o número total de pontos presentes na série temporal discreta e $k=0,1,2 \cdots N-1$. 
O intervalo de amostragem da transformada de Fourier é obtida por $\Delta f=\frac{1}{T}$, onde T é o tamanho do sinal no tempo (SMITH, 2003). Algumas considerações devem ser tomadas: $\frac{1}{\Delta t}$ deve ser maior que a frequência de Nyquist e o número de pontos $\mathrm{N}$ da transformada deve ser pelo menos tão longo quanto a duração do seu sinal no tempo T. No presente trabalho será utilizada a transformada rápida de Fourier, conhecida como FFT, que nada mais é do que um algoritmo muito mais eficiente para o cálculo da DFT.

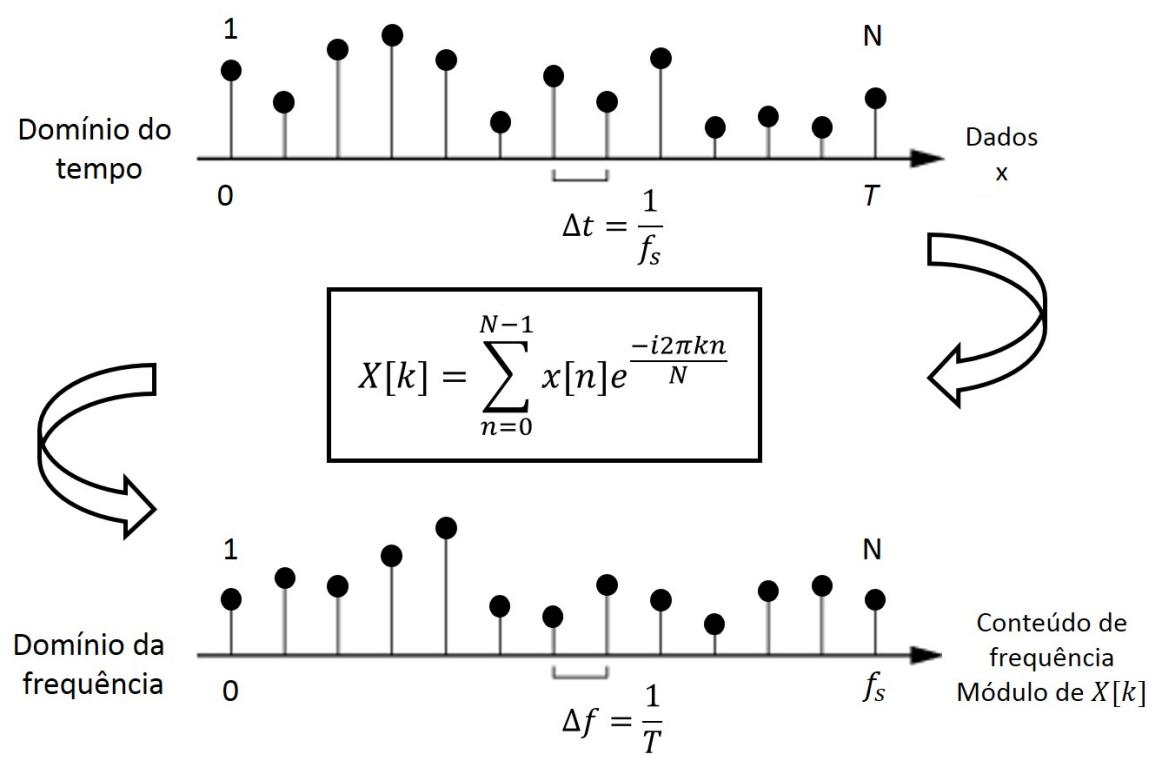

Figura 3.5: Transformada discreta de Fourier

Com a transformada de Fourier, pode-se calcular os espectros de potência, os quais descrevem como a energia de um sinal ou uma série temporal será distribuída com a frequência e é o primeiro passo para se entender os espectros de ordem mais alta (HOS). Desse modo, primeiramente define-se a função de autocorrelação $\left(R_{x x}\right)$, a qual é dada dividindo-se a série temporal em diferentes segmentos e relacionando cada segmento do sinal com ele mesmo atrasado no tempo (ver Figura 3.6). A função de correlação para um sinal estacionário é dada por

$$
R_{x x}(\tau)=E[x(t) x(t+\tau)]=\lim _{T \rightarrow \infty} \frac{1}{T} \int_{0}^{T} x(t) x(t+\tau) d t
$$

onde $\tau$ é o atraso no tempo e $E[$ ] é média do conjunto ou o valor esperado que representa o valor médio entre todos os sinais calculados para uma mesma condição experimental, o qual na 


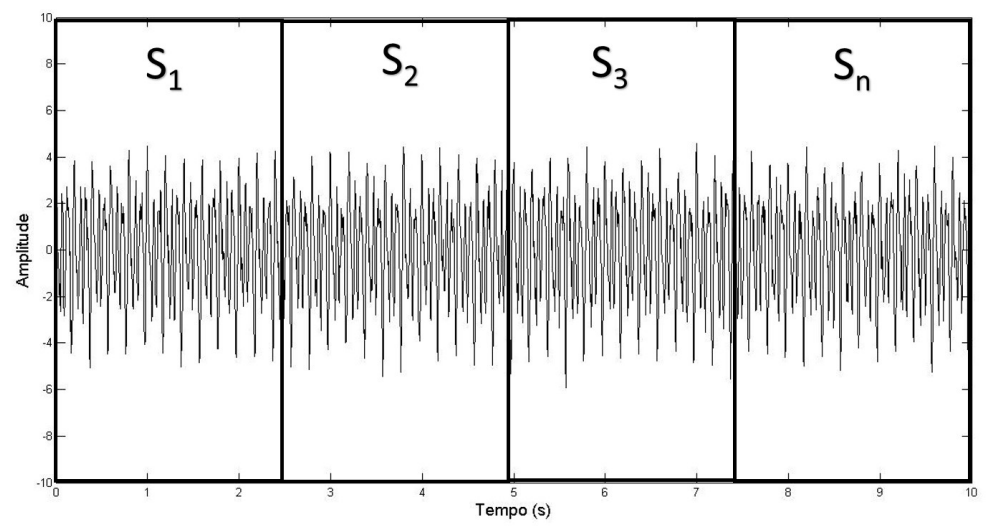

Figura 3.6: Série temporal dividida em $S_{n}$ segmentos.

forma integral é dado por

$$
E[X]=\int_{S_{n}} X d P
$$

onde $S_{n}$ são os espaços amostrais, $X$ é uma variável do experimento relacionada com $P$ que é a medida de probabilidade com que o resultado se repete nos diferentes segmentos da série temporal.

O espectro de potência $\left(S_{x x}\right)$, ou também chamado de autoespectro, é a transformada de Fourier da correlação de segunda ordem $R_{x x}$, o qual é dado por

$$
S_{x x}(f)=\lim _{T \rightarrow \infty} \frac{1}{T} E\left[X(f) X^{*}(f)\right]
$$

onde $X(f)$ é a transformada de Fourier (ver Eq. (3.6)) e o sobrescrito (*) denota o complexo conjugado.

Para séries temporais $x(t)$, cuja média é zero e possuem valores reais, as funções de correlação de ordem elevada $R_{n}\left(\tau_{1}, \ldots, \tau_{n-1}\right)$ podem ser definidas como

$$
R_{n}\left(\tau_{1}, \ldots, \tau_{n-1}\right)=E\left[x(t) x\left(t+\tau_{1}\right) \cdots x\left(t+\tau_{n-1}\right)\right]
$$

Seguindo a Eq. (3.11), as funções de correlação de terceira e quarta ordem, também chamadas de autobicorrelação e autotricorrelação (HAJJ; BERAN, 2008), são respectivamente:

$$
R_{x x x}=E\left[x(t) x\left(t+\tau_{1}\right) x\left(t+\tau_{2}\right)\right]
$$




$$
R_{x x x x}=E\left[x(t) x\left(t+\tau_{1}\right) x\left(t+\tau_{2}\right) x\left(t+\tau_{3}\right)\right] .
$$

O espectros de potência de terceira $\left(S_{x x x}\left(f_{1}, f_{2}\right)\right)$ e quarta ordem $\left(S_{x x x x}\left(f_{1}, f_{2}, f_{3}\right)\right)$ são obtidos pela transforma de Fourier das Eqs. (3.12) e (3.13), os quais são chamados de autobispectro e autotrispectro, respectivamente, e são dados por

$$
\begin{gathered}
S_{x x x}\left(f_{1}, f_{2}\right)=\lim _{T \rightarrow \infty} \frac{1}{T} E\left[X\left(f_{1}+f_{2}\right) X^{*}\left(f_{1}\right) X^{*}\left(f_{2}\right)\right] \\
S_{x x x x}\left(f_{1}, f_{2}, f_{3}\right)=\lim _{T \rightarrow \infty} \frac{1}{T} E\left[X\left(f_{1}+f_{2}+f_{3}\right) X^{*}\left(f_{1}\right) X^{*}\left(f_{2}\right) X^{*}\left(f_{3}\right)\right] .
\end{gathered}
$$

Para o cálculo do HOS utilizam-se os seguintes passos: $(i)$ o sinal é dividido em $S_{n}$ segmentos conforme a Figura 3.6, (ii) multiplica-se cada segmento por uma janela (por exemplo, janela hanning (SMITH, 2003)), (iii) calcula-se a sua FFT, (iv) relaciona-se cada segmento com ele mesmo usando as Eqs. 3.10, 3.14 e 3.15 para o autospectro, autobispectro e autotrispectro, respectivamente e $(i v)$ calcula-se o valor médio esperado dos resultados para todo o sinal amostral.

A técnica do janelamento consiste na multiplicação do sinal por uma função que "zera"os extremos da amostra, tornando o sinal "periódico", dessa forma, ela tenta melhorar o efeito de vazamento (do ingles, leakage), que consiste no vazamento da energia real de uma frequência do sinal para as frequências adjacentes. É importante salientar que o janelamento não elimina esse efeito, para isso deve-se calcular a média de diversas FFTs para um mesmo experimento.

A base da análise por espectros de ordem mais alta é detectar se há acoplamento não linear entre as frequências do sistema uma vez que sistemas que apresentam não linearidades podem ter suas frequências interagindo e formando novos componentes da suas somas ou de frequências diferentes (HAJJ; MIKSAD; POWERS, 1997). Ao interagir a fase do novo componente está relacionada com as fases dos modos de interação primários. Portanto, inspecionando a relação de fase é possível identificar qualquer acoplamento não linear. Desse modo, se dois componentes de frequência $\left(f_{1}\right.$ e $\left.f_{2}\right)$ e sua soma $\left(f_{1}+f_{2}\right)$ estão acoplados significa que o sistema possui não linearidade do tipo quadrática e terá um alto valor de autobispectro, conforme mostrado na Figura 3.7, onde $A^{n}\left(f_{1}, f_{2}\right)=X\left(f_{1}+f_{2}\right) X^{*}\left(f_{1}\right) X^{*}\left(f_{2}\right)$. Igualmente, se três com- 
ponentes de frequência estão relacionados $\left(f_{1}, f_{2}\right.$ e $\left.f_{3}\right)$ o mecanismo apresenta não linearidade cúbica e terá um alto valor de autotrispectro. A Tabela 3.1 apresenta um resumo da relação de fase e o tipo de não linearidade.

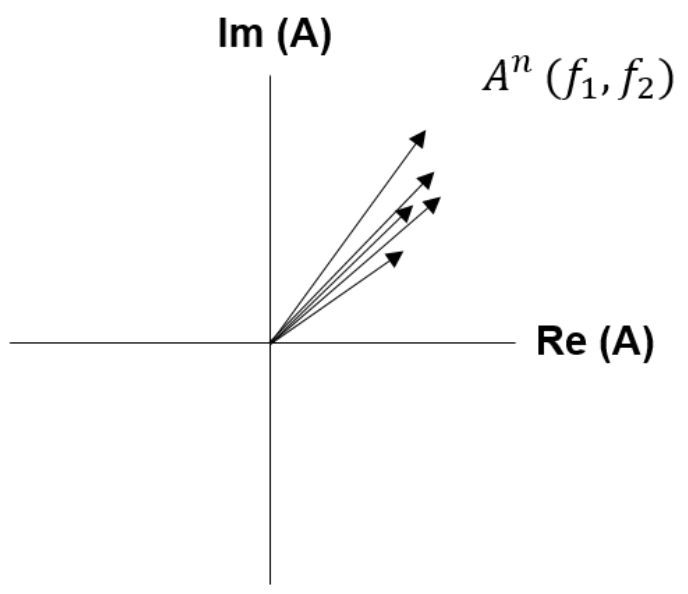

(a) Alta relação de fase

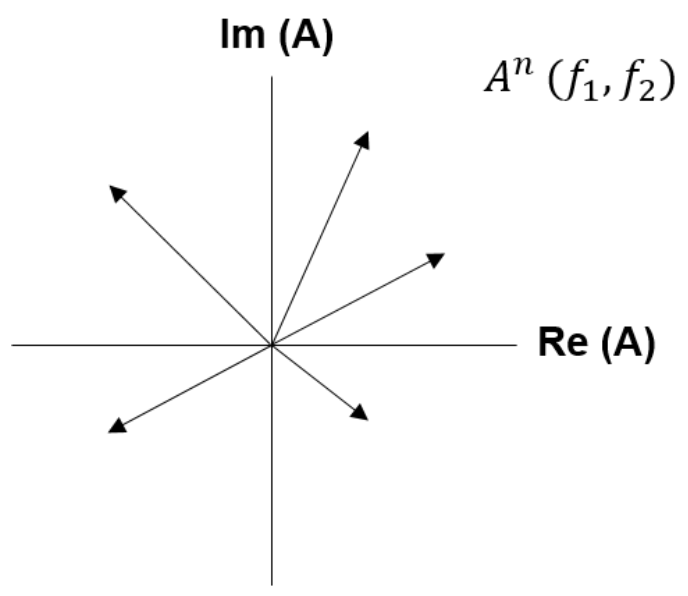

(b) sem relação de fase

Figura 3.7: Representação vetorial de $N$ estimativas de autobispectro (adaptado de (HAJJ; MIKSAD; POWERS, 1993)).

Tabela 3.1: Relação de fase e ferramenta espetral de identificiação.

\begin{tabular}{|c|c|c|c|}
\hline \multirow{2}{*}{ Característica do sistema } & \multirow{2}{*}{ Linear } & \multicolumn{2}{|c|}{ Não Linear } \\
\cline { 3 - 4 } & & Quadrática & Cúbica \\
\hline \hline Relação de fase entre as frequências & nenhuma & $\phi_{f_{1}+f_{2}}=\phi_{f_{1}}+\phi_{f_{2}}$ & $\phi_{f_{1}+f_{2}+f_{3}}=\phi_{f_{1}}+\phi_{f_{2}}+\phi_{f_{3}}$ \\
\hline Ferramenta de detecção & espectro de potência & autobispectro & autotrispectro \\
\hline
\end{tabular}

O autobispectro e autotrispectro são geralmente normalizados com as amplitudes dos componentes espectrais individuais para se obter a autobicoerência e autotricoerência, as quais, tendo por base a desigualdade de $S c h w a r t z$, são definidas respectivamente como

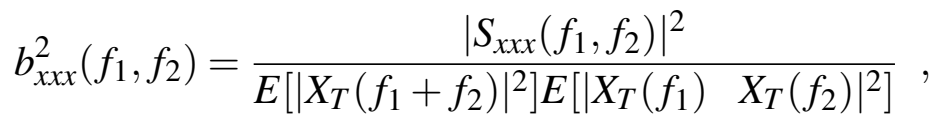

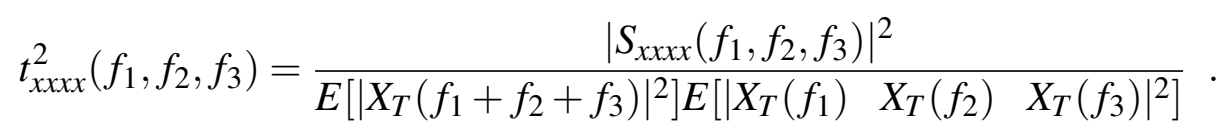

onde $0<b_{x x x}^{2}\left(f_{1}, f_{2}\right)<1$ e $0<t_{x x x x}^{2}\left(f_{1}, f_{2}, f_{3}\right)<1$.

Se $b_{x x x}^{2}\left(f_{1}, f_{2}\right)=1$, então as frequências $f_{1}, f_{2}$ e a sua soma $f_{1}+f_{2}$ são quadraticamente 
acopladas. Se $0<b_{x x x}^{2}\left(f_{1}, f_{2}\right)<1$ as frequências são parcialmente acopladas e, finalmente, se $b_{x x x}^{2}\left(f_{1}, f_{2}\right)=0$ as frequências não são acopladas, para observar o grau de acoplamento plotase um gráfico bidimensional. Similarmente, valor unitário na autotricoerência indica perfeito acoplamento cúbico, valores entre um e zero indicam acoplamento parcial e zero indica sem acoplamento. Nesse caso, observa-se o grau de acoplamento em um gráfico tridimensional. A Tabela 3.2 mostra um resumo da análise por espectros de ordem mais alta e as possíveis interações não lineares.

Tabela 3.2: Análise por espectros de ordem mais alta (VASCONCELLOS, 2012).

\begin{tabular}{|c|c|c|}
\hline \multicolumn{3}{|c|}{ Interação não linear } \\
\hline \hline \multirow{4}{*}{ Autobicoerência } & $b_{x x x}^{2}\left(f_{1}, f_{2}\right)=1$ & Acoplamento de fase quadrático \\
\cline { 2 - 4 } & $0<b_{x x x}^{2}\left(f_{1}, f_{2}\right)<1$ & Acoplamento quadrático parcial \\
\cline { 2 - 4 } & $b_{x x x}^{2}\left(f_{1}, f_{2}\right)=0$ & Sem acoplamento de fase \\
\hline \multirow{3}{*}{ Autotricoerência } & $t_{x x x x}^{2}\left(f_{1}, f_{2}, f_{3}\right)=1$ & Acoplamento de fase cúbico \\
\cline { 2 - 4 } & $0<t_{x x x x}^{2}\left(f_{1}, f_{2}, f_{3}\right)<1$ & Acoplamento cúbico parcial \\
\cline { 2 - 4 } & $t_{x x x x}^{2}\left(f_{1}, f_{2}, f_{3}\right)=0$ & Sem acoplamento de fase \\
\hline
\end{tabular}




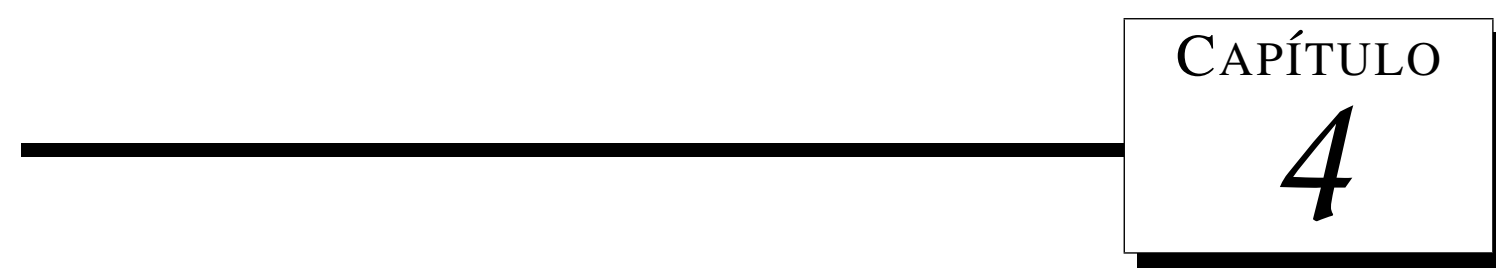

\section{RESULTADOS}

\subsection{Introdução}

Nesse capítulo, primeiramente discute-se a obtenção de todos os parâmetros necessários para a realização das análises computacionais. Em seguida são feitas as análises computacionais e experimentais para o sistema aeroelástico apresentando três intensidades diferentes da não linearidade estrutural do tipo enrijecimento, presente na curva de rigidez do movimento de torção $(\alpha)$. Segue-se com o estudo do efeito no diagrama de bifurcação da não linearidade do tipo folga, presente na junção da superfície de controle com a asa $(\beta)$, quando todo o sistema apresenta somente um tipo de enrijecimento. Também será feita uma comparação computacional entre os diagramas de bifurcação supercrítico versus subcrítico e o efeito exercido sobre eles pelos parâmetros lineares do sistema em conjunto com as não linearidades de enrijecimento e de folga. Além disso, será observado o comportamento das variáveis reconstruídas no tempo, através do MOD, na representação da dinâmica do sistema. Por fim, as não linearidades presentes no experimento serão identificadas usando os espectros de ordem mais alta.

\subsection{Determinação dos parâmetros do sistema}

Antes de realizar os testes aeroelásticos, foi feita uma investigação modal com o túnel de vento desligado a fim de avaliar as características dinâmico-estruturais do dispositivo experi- 
mental. A análise modal foi realizada usando o dispositivo $L M S^{\circledR}$ Scadas Mobile 5 system, micro acelerômetros modelo $\mathrm{PCB}^{\circledR}$ e um martelo de impacto modelo $\mathrm{PCB}^{\circledR}$ para excitações externas (ver Figura 4.1). As funções de resposta em frequência foram obtidas através da média de 5 impactos para cada simulação, com uma frequência de amostragem de $512 \mathrm{~Hz}$ e resolução de $0,25 \mathrm{~Hz}$. O método PolyMax do software $\mathrm{LMS}^{\circledR}$ foi usado para a estimativa dos parâmetros modais. Heylen e Sas (2006), Peeters et al. (2004) apresentam uma explicação sobre esse método.

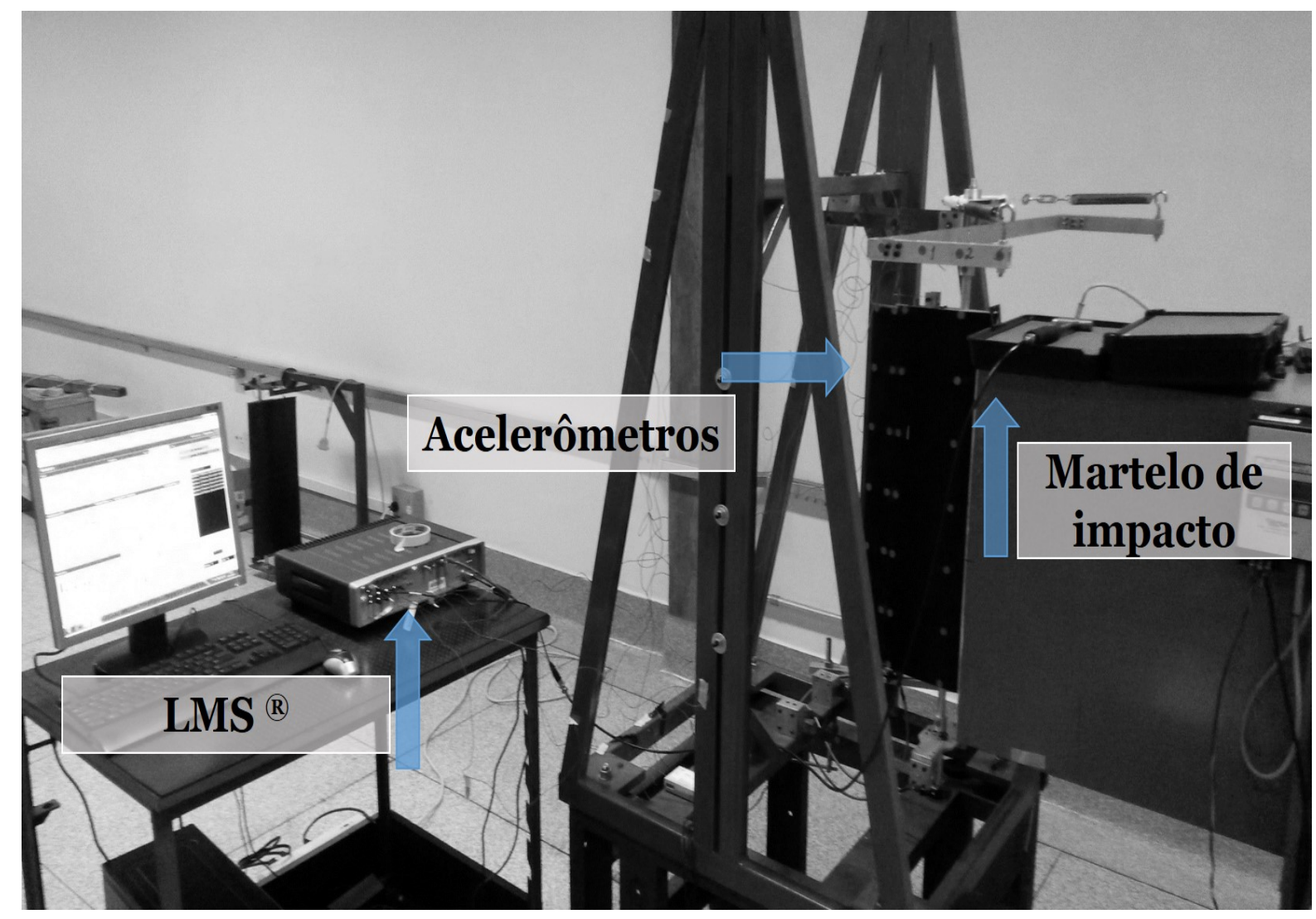

Figura 4.1: Dispositivos para análise modal.

Os resultados modais relevantes para os testes aeroelásticos estão presentes na Tabela 4.1. As frequências presentes nessa tabela são totalmente acopladas. Aqui o terceiro modo, chamado de segunda flexão, corresponde ao movimento de flexão dado pelo deslocamento da parte superior da asa com diferença de fase em relação ao deslocamento da parte inferior (ver Figura 4.2). Esse modo é atribuído pelo efeito de assimetria de massa entre os extremos da asa na direção vertical devido à presença do dispositivo responsável pela não linearidade do tipo enrijecimento, 
o qual apresenta uma massa de $0,7 \mathrm{~kg}$ equivalente a $46 \%$ da massa total da asa. Análises posteriores mostraram que esse modo não exerceu influência na dinâmica do sistema bidimensional, portanto não causando impacto no estudo sobre os efeitos não lineares no sistema através do diagramas de bifurcação.

Tabela 4.1: Frequências naturais do sistema acoplado com os primeiros quatro modos.

\begin{tabular}{l|c}
\hline MODO DE VIBRAR & FREQUÊNCIAS ACOPLADAS $(\mathrm{Hz})$ \\
\hline \hline Primeira flexão $(\mathrm{h})$ & 2,37 \\
\hline Torção $(\alpha)$ & 4,43 \\
\hline Segunda flexão - assimetria vertical & 6,87 \\
\hline Superfície de controle $(\beta)$ & 9,48 \\
\hline
\end{tabular}

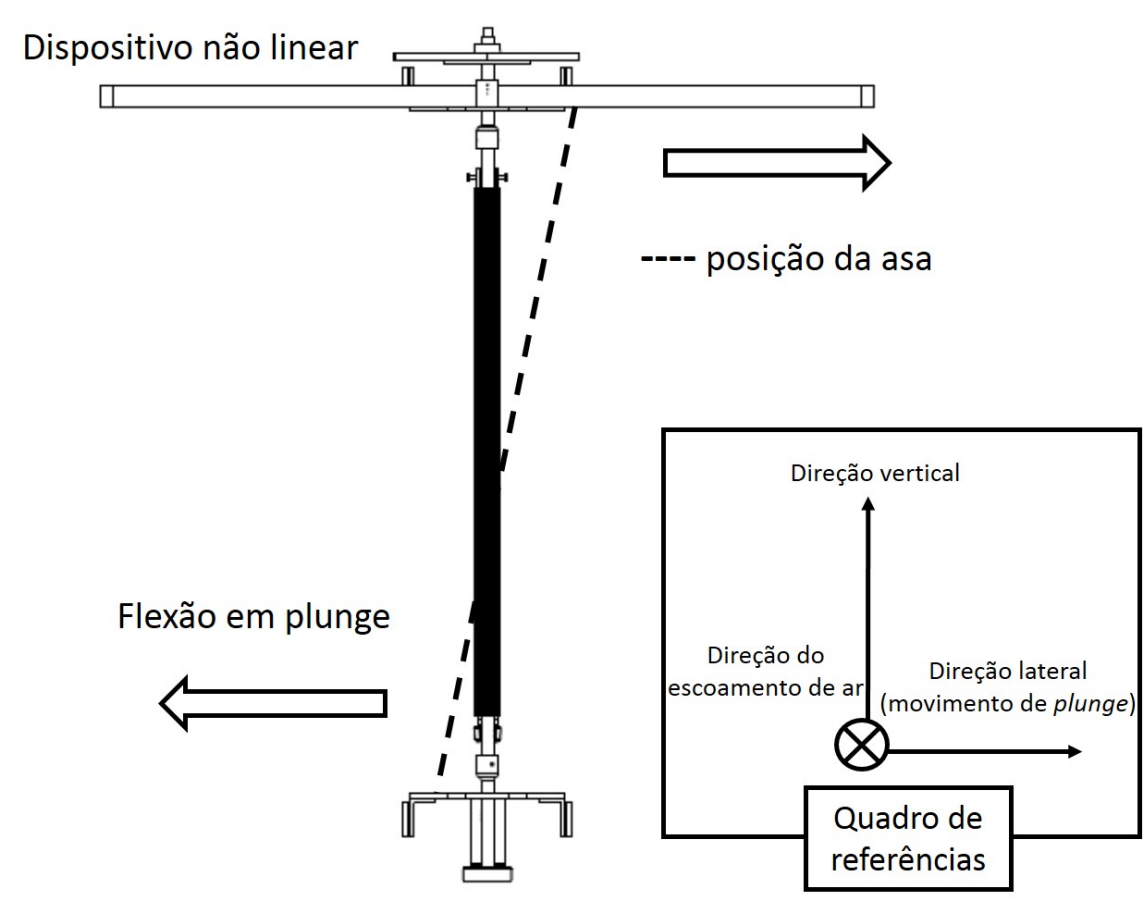

Figura 4.2: Representação do segunda flexão devido à assimetria de massa.

Para realizar as simulações numéricas, as frequências naturais de cada grau de liberdade presentes na Eq. (2.17) devem ser utilizadas. Desse modo, as frequências de flexão, de torção e da superfície de controle foram avaliadas restringindo individualmente dois graus de liberdade e realizando o teste modal para o movimento restante. As Figuras 4.3(b), (d) e (f) apresentam os espectros de potência de cada grau de liberdade das frequências desacopladas. Os valores são $2,54 \mathrm{~Hz}$ para flexão $(h), 1,92 \mathrm{~Hz}$ para torção $(\alpha)$ e $8,29 \mathrm{~Hz}$ para torção da $\mathrm{SC}(\beta)$ na primeira, segunda e terceira linha, respectivamente. A Tabela 4.3 mostra essas frequências em 
$\mathrm{rad} / \mathrm{s}$, ela apresenta o valor da frequência natural desacoplada de flexão corrigida pela fórmula $\omega_{h}=\left(2 \pi f_{h} \sqrt{m_{T} / m_{w}}\right)$, na qual $f_{h}$ é $2,54 \mathrm{~Hz}$. Na Tabela 4.3, também estão presentes todos os outros parâmetros da asa, como a massa, posição do CG e momento de inércia (necessário para obtenção dos raios de giração) obtidos através do desenho em CAD.

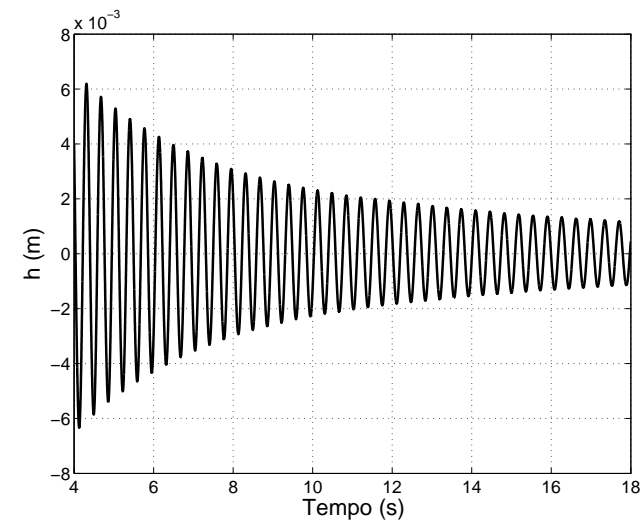

(a)

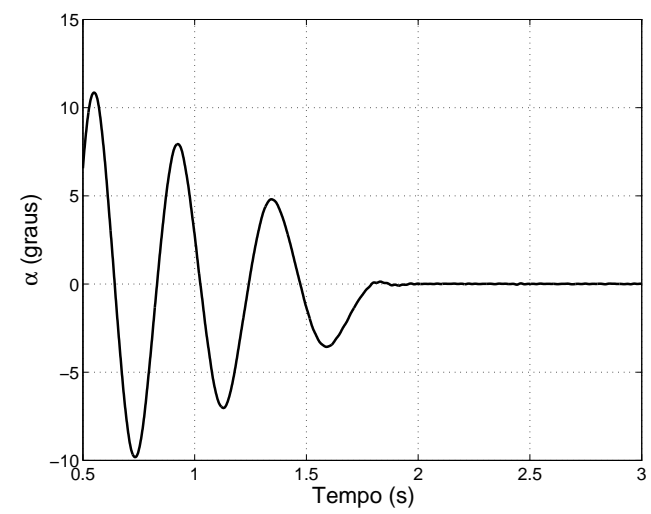

(c)

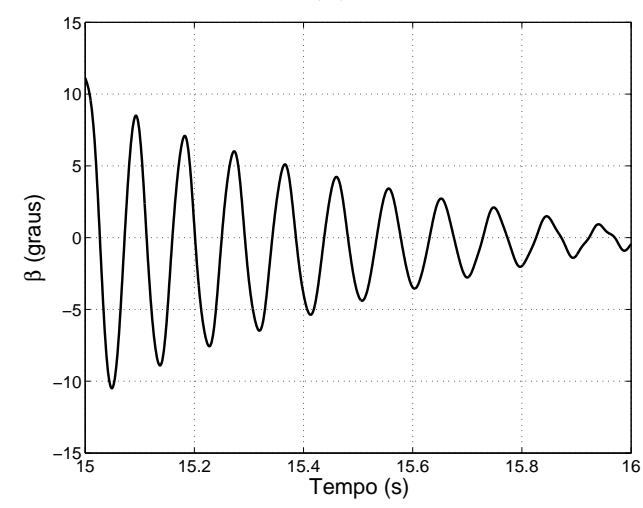

(e)

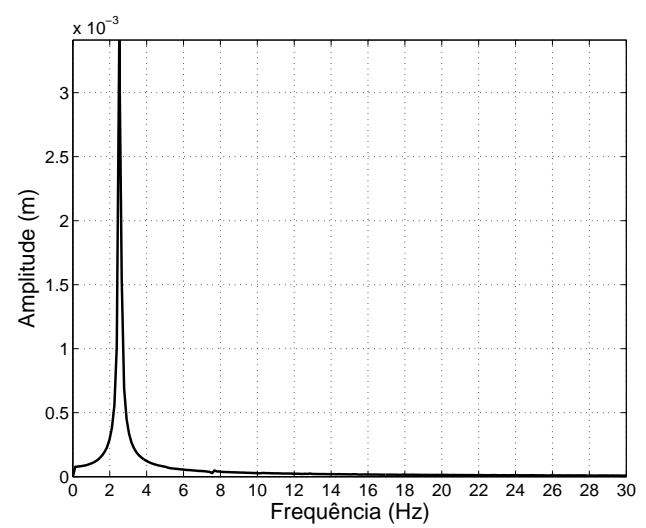

(b)

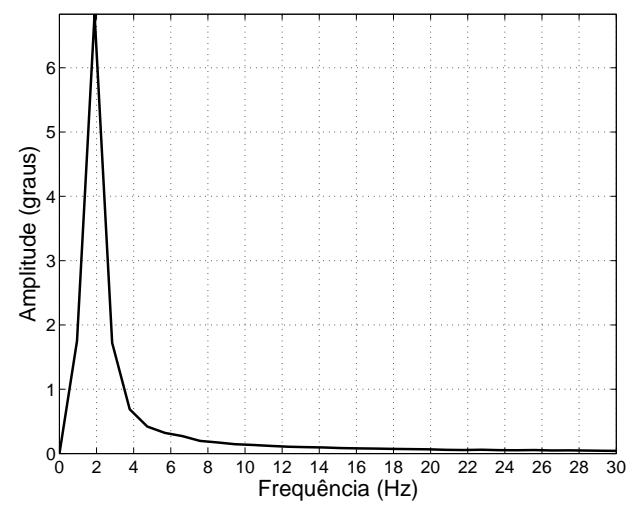

(d)

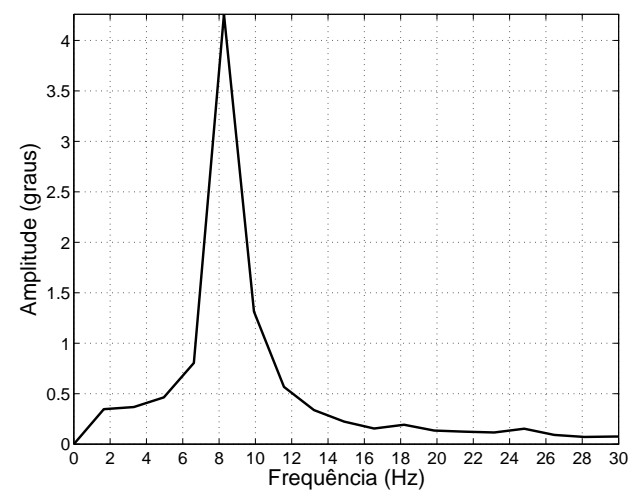

(f)

Figura 4.3: Séries temporais e espectros de potência das respostas dinâmicas indicando as frequências desacopladas de todos os graus de liberdade do sistema para flexão, torção e torção da SC, respectivamente.

O amortecimento estrutural é uma questão importante e de difícil análise, exercendo um 
impacto relevante nas simulações numéricas. Nesse trabalho, a matriz de amortecimento é representada pela aproximação linear de Rayleigh, obtida por

$$
[\mathbf{C}]=a_{0}[\mathbf{M}]+a_{1}[\mathbf{K}]
$$

onde $[\mathbf{C}],[\mathbf{M}]$ e $[\mathbf{K}]$ são as matrizes de amortecimento, de massa e de rigidez antes de ocorrer as deformações não lineares (ver Equação (2.17)), respectivamente, e os fatores $a_{0}$ e $a_{1}$ são chamados fatores de Rayleigh.

Os fatores de Rayleigh podem ser calculados pela solução de um par de equações simultâneas se as razões de amortecimento $\zeta_{m}$ e $\zeta_{n}$ associadas com duas frequências naturais desacopladas específicas $\omega_{m}$ e $\omega_{n}$ forem conhecidas, os quais são dados por

$$
\left\{\begin{array}{c}
a_{0} \\
a_{1}
\end{array}\right\}=2 \frac{\omega_{m} \omega_{n}}{\omega_{n}^{2}-\omega_{m}^{2}}\left[\begin{array}{cc}
\omega_{n} & -\omega_{m} \\
\frac{-1}{\omega_{n}} & \frac{1}{\omega_{m}}
\end{array}\right]\left\{\begin{array}{c}
\zeta_{m} \\
\zeta_{n}
\end{array}\right\}
$$

As razões de amortecimento da Tabela 4.3 foram obtidas usando dois métodos: o método da largura de meia banda de potência e método do decremento logarítmico (CLOUGH; PENZIEN, 2003). Para calcular a matriz $[\mathbf{C}]$ com a Eq. (4.1), admitiu-se $\zeta_{m}=\zeta_{\alpha}, \zeta_{n}=\zeta_{\beta}, \omega_{m}=\omega_{\alpha}$ e $\omega_{n}=$ $\omega_{\beta}$, o que resultou na matriz de amortecimento,

$$
\left[\begin{array}{lll}
d_{1,1} & d_{1,2} & d_{1,3} \\
d_{2,1} & d_{2,2} & d_{2,3} \\
d_{3,1} & d_{3,2} & d_{3,3}
\end{array}\right]=\left[\begin{array}{ccc}
25,0423 & 6,2304 & 0,0264 \\
6,2304 & 4,7756 & 0,0784 \\
0,0264 & 0,0784 & 0,0059
\end{array}\right]\left(\frac{N s}{m}\right)
$$

Obtém-se a velocidade linear crítica de flutter substituindo os parâmetros da Tabela 4.3 na Equação (2.17) linear do sistema aeroelástico, nesse caso as forças não lineares $F(\alpha)$ e $F(\beta)$ são iguais a zero. Para cada velocidade obtêm-se os respectivos autovalores da matriz $[\mathbf{A}]$ do espaço de estados (ver Equação 2.42) e quando a parte real se torna nula tem-se a condição crítica para flutter. A Figura 4.4 (a) ilustra a velocidade de flutter encontrada em 11,465m/s. A Figura 4.4 (b) apresenta os valores das frequências naturais acopladas computacionais que são os valores absolutos da parte imaginária dos autovalores. Observa-se que as frequência 
são $1,54 \mathrm{~Hz}, 3,26 \mathrm{~Hz}$ e $8,01 \mathrm{~Hz}$ quando a velocidade do escoamento é igual a zero para $h, \alpha$ e $\beta$, respectivamente. A diferença entre os valores computacionais e experimentais presentes na Tabela 4.2, deve-se possivelmente ao valor de amortecimento estimado pela aproximação linear.

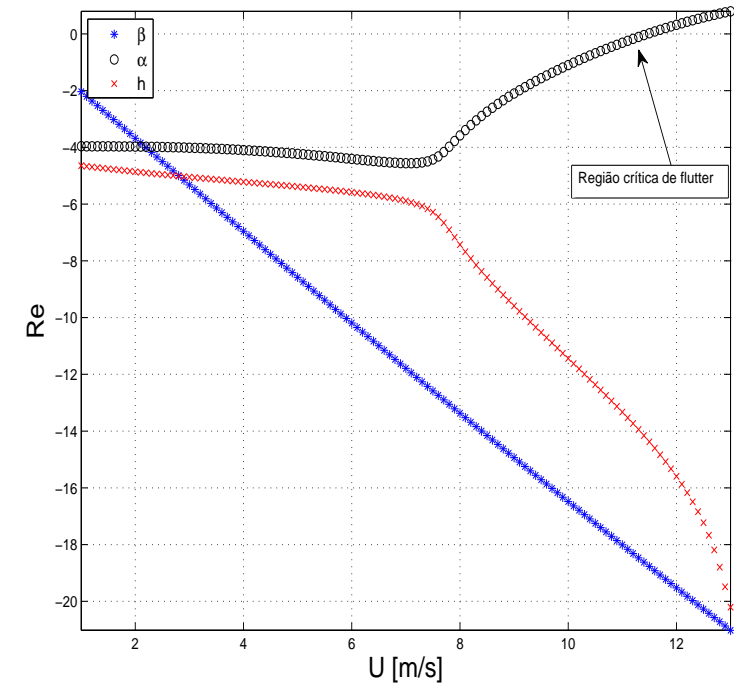

(a) Parte real dos autovalores.

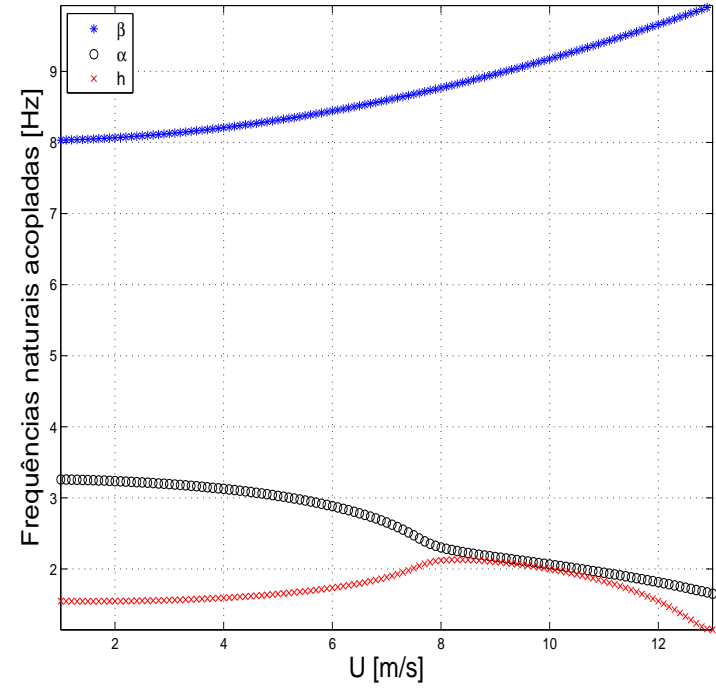

(b) Parte imaginária dos autovalores.

Figura 4.4: Evolução aeroelástica do modelo linear.

Tabela 4.2: Comparação entre as frequência acopladas e velocidade de flutter.

\begin{tabular}{l|c|c|c}
\hline FREQUÊNCIAS ACOPLADAS & EXPERIMENTAL & NUMÉRICO & ERRO RELATIVO (\%) \\
\hline \hline Flexão $(h)$ & $2,27 \mathrm{~Hz}$ & $1,54 \mathrm{~Hz}$ & 32.1 \\
\hline Torção $(\alpha)$ & $4,43 \mathrm{~Hz}$ & $3,26 \mathrm{~Hz}$ & 26.4 \\
\hline Torção da SC $(\beta)$ & $9,48 \mathrm{~Hz}$ & $8,01 \mathrm{~Hz}$ & 15.5 \\
\hline Velocidade de flutter & $12,10 \mathrm{~m} / \mathrm{s}$ & $11,465 \mathrm{~m} / \mathrm{s}$ & 5.2 \\
\hline
\end{tabular}

O experimento aeroelástico e as simulações numéricas foram feitas considerando a possibilidade de não linearidade de enrijecimento em torção e a não linearidade de folga na articulação da superfície de controle. Combinações das não-linearidades foram admitidas com base em três intensidades diferentes de enrijecimento (Figura 4.5) e dois tamanhos de folga (2,0 e 4,0 graus).

As três intensidades da não linearidade de enrijecimento em torção foram obtidas ajustando as molas de tração (ver Figura 2.8(b)). O aumento no efeito de enrijecimento, variando com três níveis de intensidade, no momento restaurador da rigidez em torção é chamado neste trabalho de enrijecimento 3, 2 e 1, respectivamente, no qual o mais intenso é o enrijecimento 3. A curva de momento restaurador foi obtida através da aproximação por razão de polinômios 
Tabela 4.3: Valores experimentais utilizados no modelo numérico.

\begin{tabular}{clc}
\hline Variáveis & Especificações & Valores \\
\hline $\mathrm{b}$ & Semi-corda $(\mathrm{m})$ & 0,125 \\
$\mathrm{a}$ & Distância da semi-corda até o eixo elástico (adimensional) & $-0,5$ \\
$\mathrm{c}$ & Posição da dobradiça da SC em relação a semi-corda (adimensional) & 0,5 \\
$\rho$ & Densidade do ar $\left(\mathrm{kg} / \mathrm{m}^{3}\right)$ & 1,078 \\
$m_{W}$ & Massa da asa $(\mathrm{kg})$ & 1,5 \\
$m_{T}$ & Massa da asa e suportes $(\mathrm{kg})$ & 4,3723 \\
$\omega_{h}$ & Frequência desacoplada de flexão $(\mathrm{rad} / \mathrm{s})=\left(2 \pi f_{h} \sqrt{\mathrm{m}_{T} / \mathrm{m}_{w}}\right)$ & 27,3266 \\
$\omega_{\alpha}$ & Frequência desacoplada de torção $(\mathrm{rad} / \mathrm{s})$ & 12,1108 \\
$\omega_{\beta}$ & Frequência desacoplada da superfície de controle $(\mathrm{rad} / \mathrm{s})$ & 52,1065 \\
$x_{\alpha}$ & Distância entre o CG e o eixo elástico (adimensional) & 0,66 \\
$x_{\beta}$ & Distância entre o CG e o eixo da superfície de controle (adimensional) & 0,0028 \\
$r_{\alpha}$ & Raio de giração (torção) & 0,7303 \\
$r_{\beta}$ & Raio de giração (SC) & 0,0742 \\
$\mu$ & Razão de massa adimensional & 28,3467 \\
$\zeta_{h}$ & Fator de amortecimento de flexão & 0,0106 \\
$\zeta_{\alpha}$ & Fator de amortecimento de torção & 0,3697 \\
$\zeta_{\beta}$ & Fator de amortecimento da SC & 0,1275 \\
$U_{f}$ & Velocidade crítica de flutter $($ numérico) $(\mathrm{m} / \mathrm{s})$ & 11,465 \\
$U_{f}^{*}$ & Velocidade crítica de flutter $($ experimental $)(\mathrm{m} / \mathrm{s})$ & $12,0 \leq U_{f}^{*} \leq 12,20$ \\
\hline
\end{tabular}

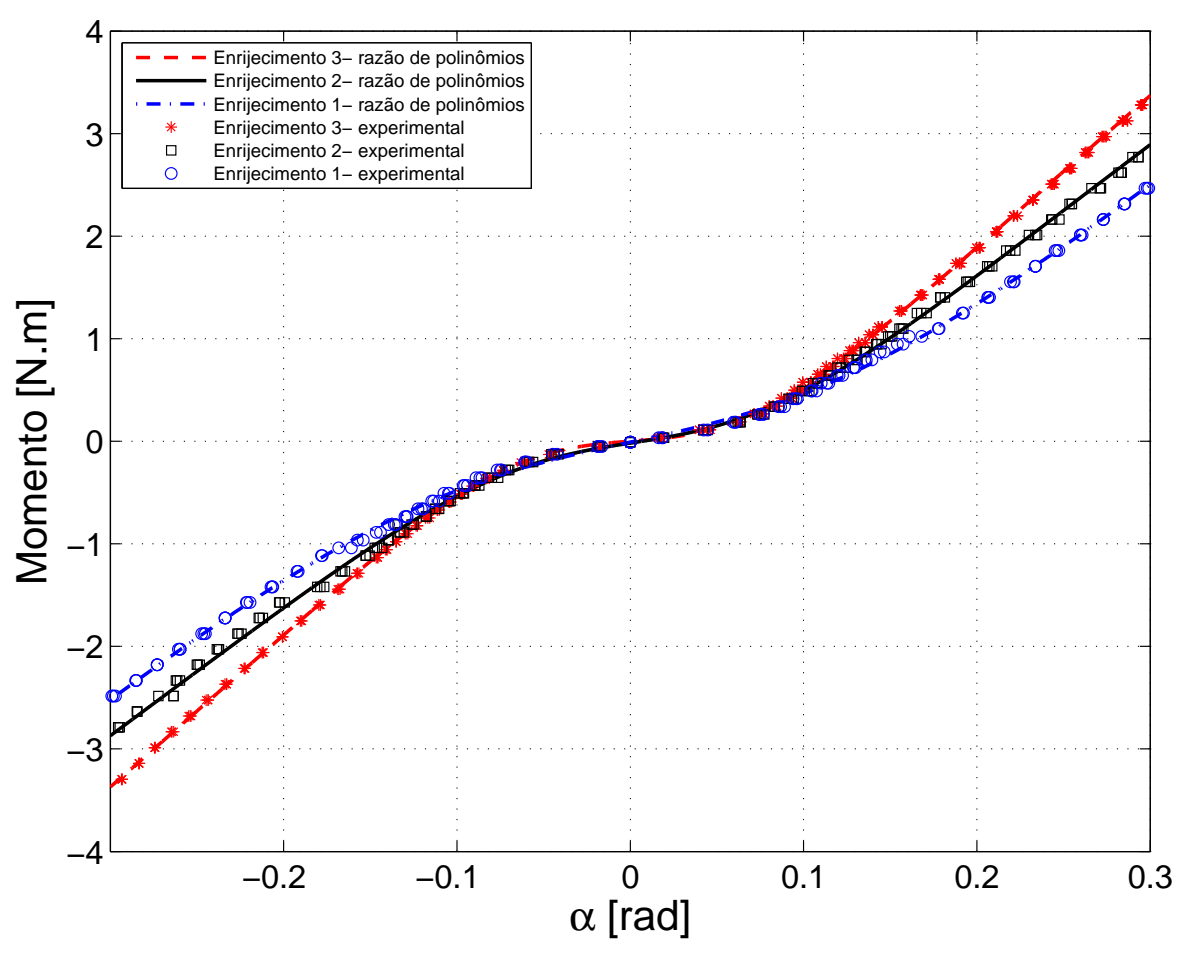

Figura 4.5: Momento restaurador da rigidez em torção sujeito a efeitos de enrijecimento das três intensidades.

dos resultados experimentais, conforme apresentado na Figura 4.5. A Tabela 4.4 apresenta os respectivos coeficientes das aproximações por RP para cada intensidade de enrijecimento, (Eq. 2.46). 
Tabela 4.4: Coeficientes da curva de aproximação por razão de polinômios para três intensidades diferentes de não linearidades do tipo enrijecimento.

\begin{tabular}{c|c|c|c|c|c|c|c}
\hline Não linearidade & $a_{3}$ & $a_{2}$ & $a_{1}$ & $a_{0}$ & $b_{2}$ & $b_{1}$ & $b_{0}$ \\
\hline \hline Enrijecimento 3 & 7,281 & $3,01 \times 10^{-2}$ & $1,33 \times 10^{-2}$ & $1,44 \times 10^{-4}$ & 1,0 & $6,39 \times 10^{-3}$ & $1,91 \times 10^{-2}$ \\
\hline Enrijecimento 2 & 6,313 & $-4,58 \times 10^{-2}$ & $3,64 \times 10^{-2}$ & $-2,48 \times 10^{-4}$ & 1,0 & $-1,06 \times 10^{-2}$ & $2,54 \times 10^{-2}$ \\
\hline Enrijecimento 1 & 6,403 & $-4,76 \times 10^{-3}$ & $1,26 \times 10^{-1}$ & $-3,03 \times 10^{-4}$ & 1,0 & $2,61 \times 10^{-7}$ & $6,37 \times 10^{-2}$ \\
\hline
\end{tabular}

\subsection{Análise através das séries temporais}

Nesse trabalho, para comparar os resultados não lineares experimentais e numéricos, é tomada como referência a velocidade prevista de flutter computacional de um comportamento estrutural linear. A velocidade de flutter numérica, chamada de $U_{f}$, é $11,465 \mathrm{~m} / \mathrm{s}$, já a velocidade de flutter experimental, $U_{f}^{*}$, está entre o intervalo $12,0<U_{f}^{*}<12,2 \mathrm{~m} / \mathrm{s}$, o que representa um erro de $4,45 \%$ a $6,0 \%$. Os resultados que serão apresentados consideram as velocidades normalizadas, tanto as computacionais quanto experimentais. Para isso normalizou-se todos os intervalos de velocidade por $11,465 \mathrm{~m} / \mathrm{s}$ para as velocidades numéricas e por $12,10 \mathrm{~m} / \mathrm{s}$ para as velocidades experimentais, ou seja, para se obter as velocidades reais numéricas e experimentais, a normalizada deve ser multiplicada por $11,465 \mathrm{~m} / \mathrm{s}$ e $12,10 \mathrm{~m} / \mathrm{s}$, respectivamente. Desse modo, cria-se uma velocidade chamada de velocidade crítica $U_{c}$, a qual será usada para comparar os resultados experimentais e computacionais.

A Figura 4.6 apresenta a relação entre o resultado computacional e experimental para os três graus de liberdade (flexão, torção e superfície de controle) quando a não linearidade do tipo enrijecimento 3 está presente e a velocidade de escoamento é de $U=1,18 U_{c}$. As séries temporais são representadas nas Figuras 4.6 (a), (c) e (e) (coluna da esquerda) e os espectros de potência nas Figuras 4.6 (b), (d) e (f) (coluna da direita). Cada espectro de potência foi calculado através de uma média de vinte amostras de séries temporais, com frequência de amostragem de $F_{s}=520 \mathrm{~Hz}$ cada uma. As Figuras 4.7 e 4.8 apresentam análises através das séries temporais e espctros de potência variando a intensidade do efeito de enrijecimento e da velocidade do 
ar. A Figura 4.7 apresenta a relação entre os resultados para o enrijecimento 2 e velocidade de $U=1,08 U_{c}$ e a Figura 4.8 para o enrijecimento 1 e velocidade de $U=1,0 U_{c}$. A Tabela 4.5 apresenta a comparação entre os valores da frequências fundamentais experimentais e numéricas para diferentes tipos de enrijecimento e velocidades de escoamento.

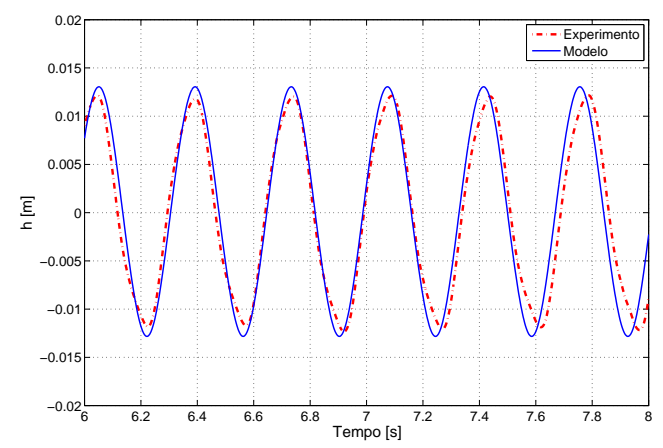

(a)

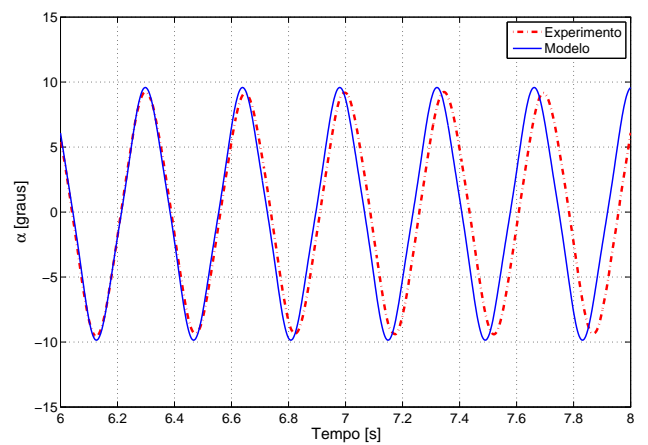

(c)

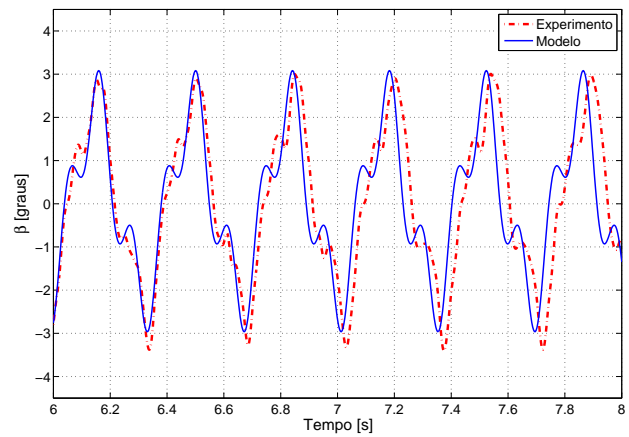

(e)

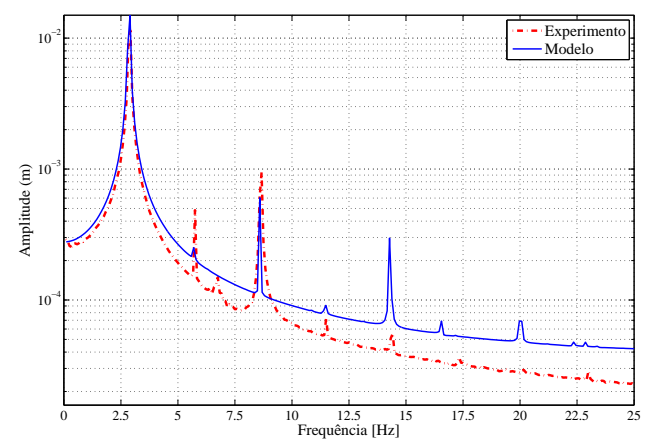

(b)

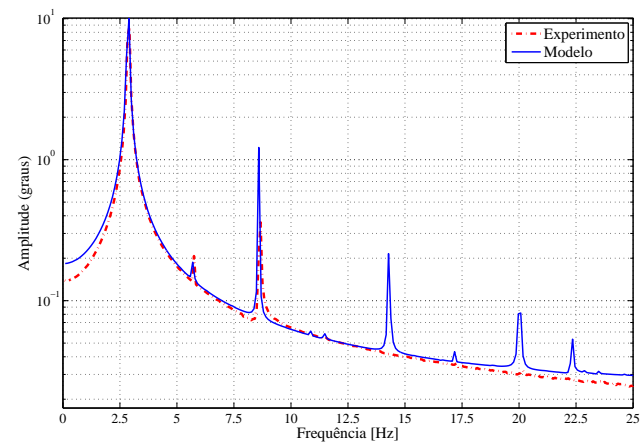

(d)

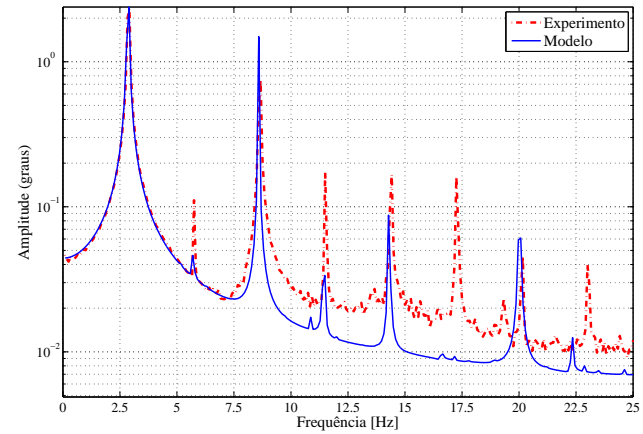

(f)

Figura 4.6: Série temporal e espectros de potência para o sistema com não linearidade do tipo enrijecimento 3 e velocidade de escoamento de $U=1,18 U_{c}$.

Tabela 4.5: Comparação entre os valores das frequências fundamentais experimentais e numéricas no LCO.

\begin{tabular}{l|c|c|c}
\hline NÃO LINEARIDADE & EXPERIMENTAL $\left(\Omega_{e x p}\right)$ & NUMÉRICO $\left(\Omega_{\text {num }}\right)$ & ERRO RELATIVO (\%) \\
\hline \hline Enrijecimento $3\left(U=1,18 U_{c}\right)$ & $2,87 \mathrm{~Hz}$ & $2,93 \mathrm{~Hz}$ & 2.1 \\
\hline Enrijecimento $2\left(U=1,08 U_{c}\right)$ & $2,80 \mathrm{~Hz}$ & $2,80 \mathrm{~Hz}$ & 0 \\
\hline Enrijecimento $1\left(U=1,0 U_{c}\right)$ & $2,68 \mathrm{~Hz}$ & $2,63 \mathrm{~Hz}$ & 1.9 \\
\hline
\end{tabular}




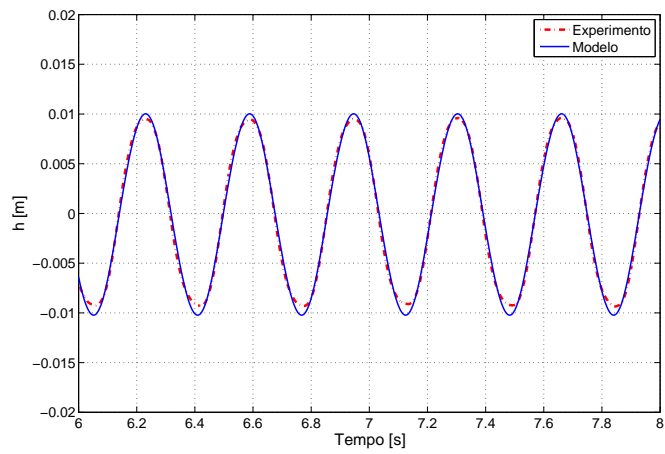

(a)

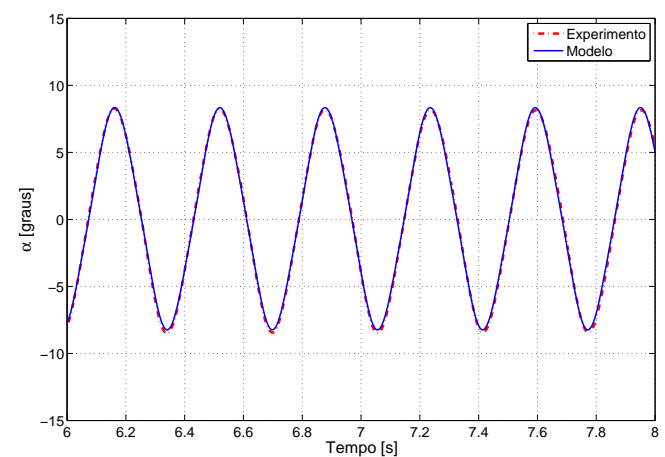

(c)

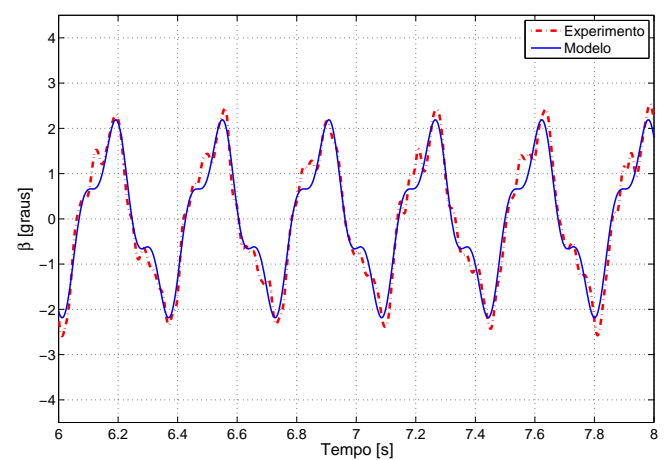

(e)

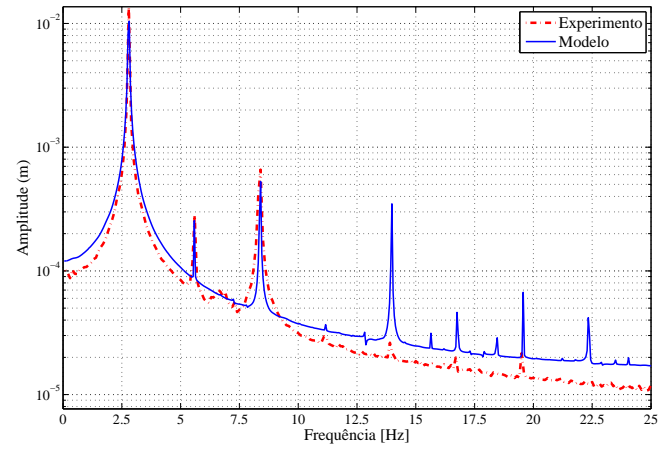

(b)

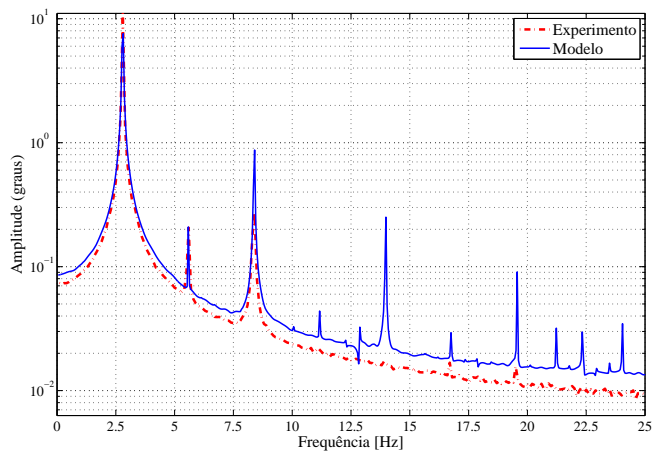

(d)

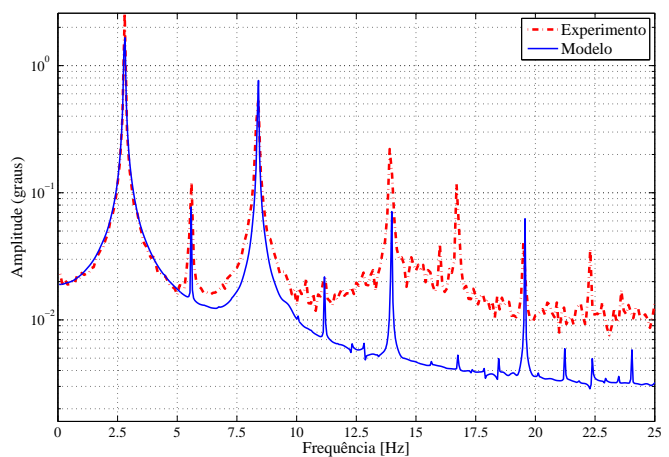

(f)

Figura 4.7: Série temporal e espectros de potência para o sistema com não linearidade do tipo enrijecimento 2 e velocidade de escoamento de $U=1,08 U_{c}$.

Essa pequena diferença deve-se ao fato de que a frequência do primeiro harmônico aumenta com o aumento da velocidade de ar e as flutuações do escoamento do túnel de vento não permitem tomar exatamente a velocidade crítica experimental naquele momento. Qualquer harmônico acima do primeiro harmônico, o qual coincide com a frequência fundamental de oscilação, é chamado nesse trabalho de super harmônico. Em todos os casos é possível observar que o modelo numérico representa bem os super harmônicos ímpares $(3 \Omega, 5 \Omega, 7 \Omega$ e $9 \Omega)$, que têm origem na não linearidade de enrijecimento e os super harmônicos pares $(2 \Omega$, $4 \Omega, \ldots)$, que em grande parte deve-se a presença de assimetria na curva não linear de rigidez 


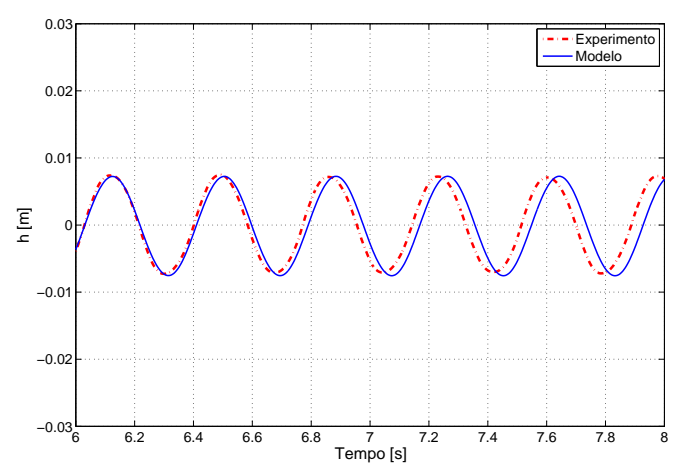

(a)

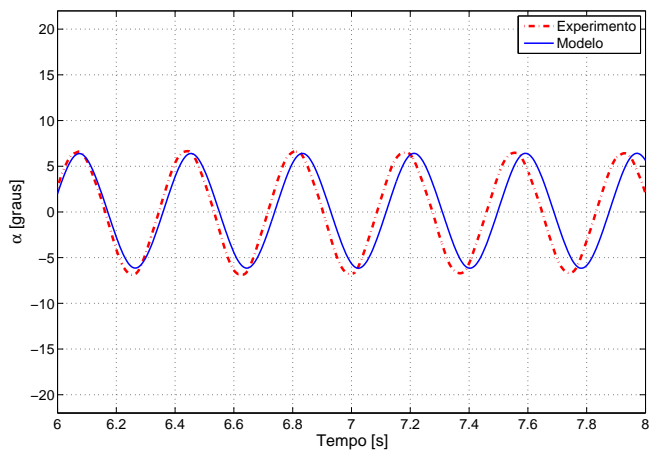

(c)

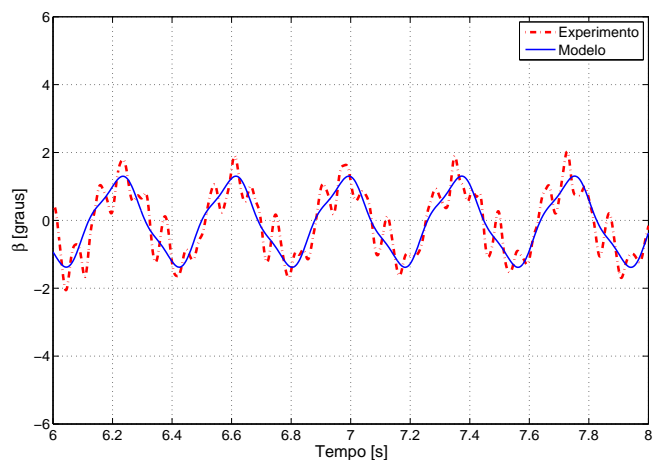

(e)

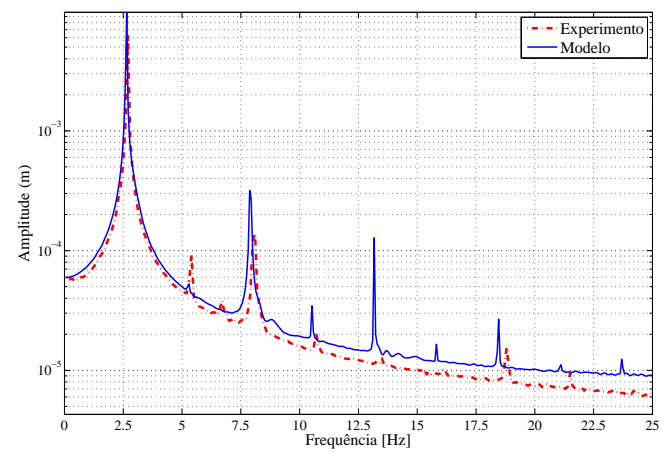

(b)

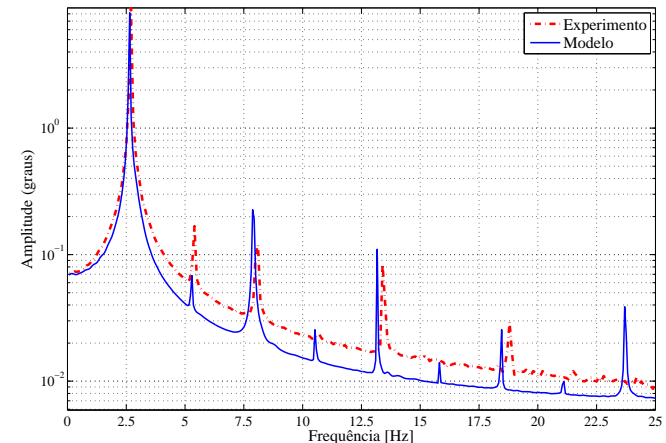

(d)

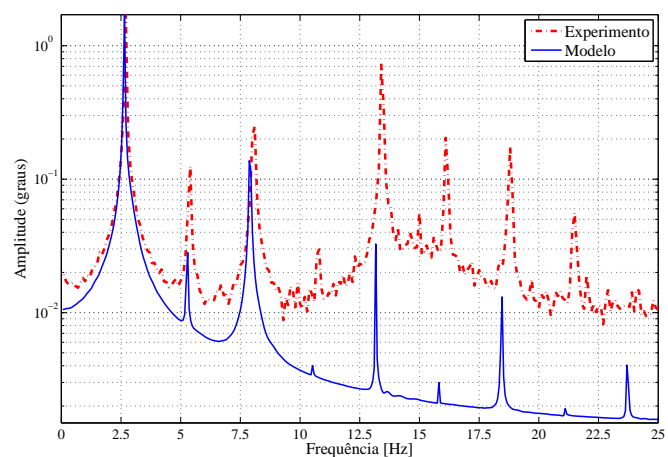

(f)

Figura 4.8: Série temporal e espectros de potência para o sistema com não linearidade do tipo enrijecimento 1 e velocidade de escoamento de $U=1,0 U_{c}$.

em torção. Observa-se que os resultados computacionais representam bem as dinâmicas experimentais obtidas para as três intensidades de enrijecimento, mostrando boa concordância com as amplitudes e frequências dos deslocamentos dos graus de liberdade de flexão, torção e da superfície de controle.

A Figura 4.9 apresenta os resultados da projeção $(x(t), x(t+\tau))$ usando o método de coordenadas defasadas para todos os graus de liberdade do sistema: flexão, torção e da superfície de controle. As análises pelo método de coordenadas defasadas foram feitas para o sistema 
aeroelástico quando há não linearidade de enrijecimento 3 (coluna da esquerda) e enrijecimento 3 e folga de 4 graus (coluna da direita) para uma velocidade de $1,18 U_{c}$.

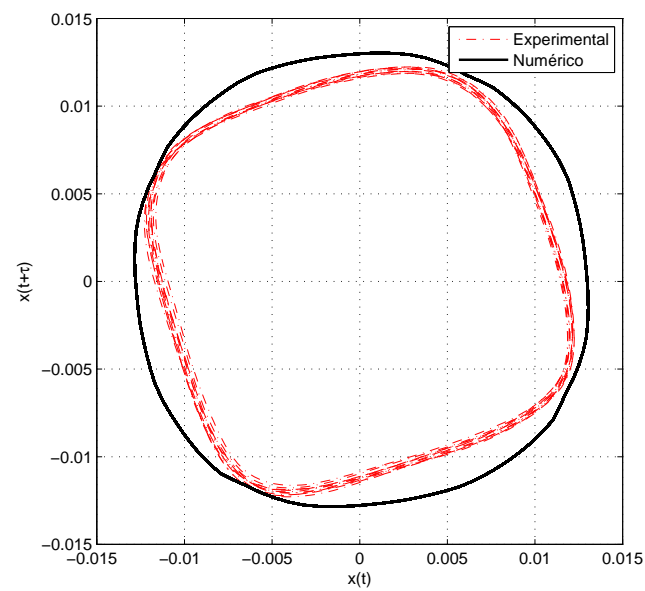

(a) Flexão

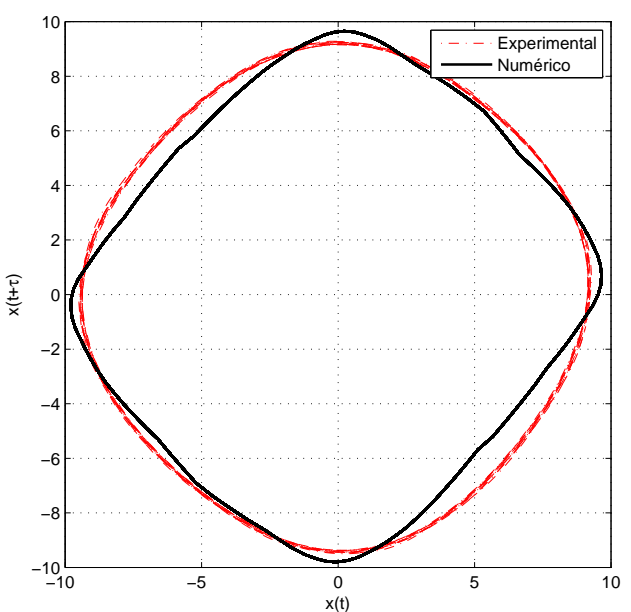

(c) Torção

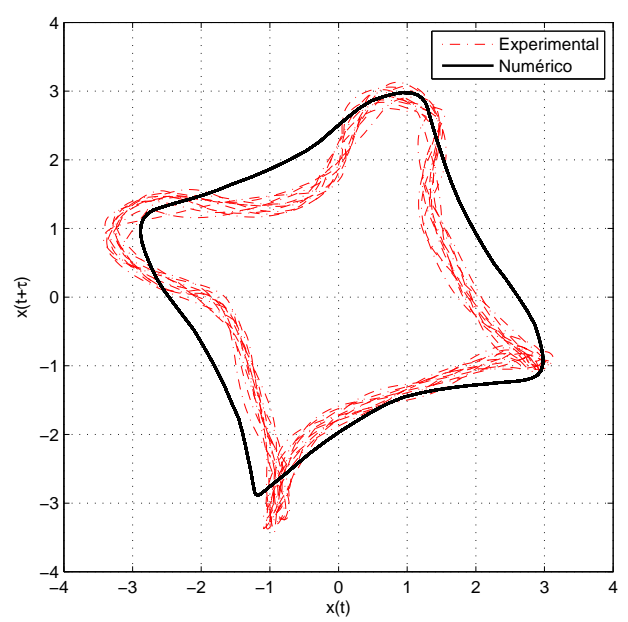

(e) $\mathrm{SC}$

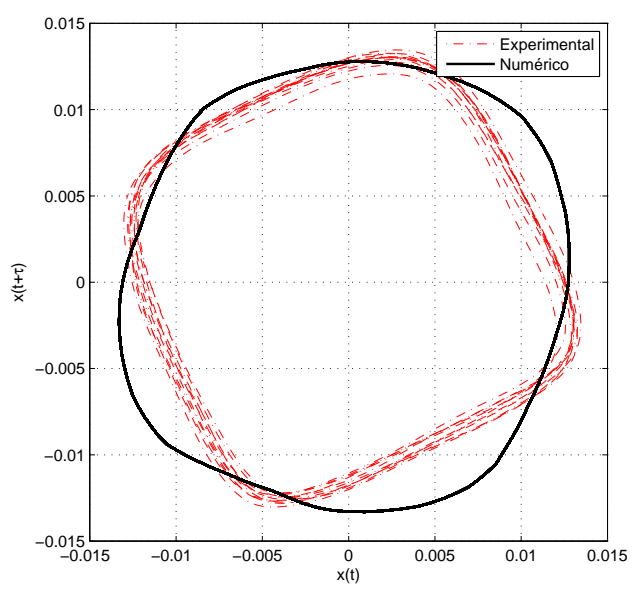

(b) Flexão

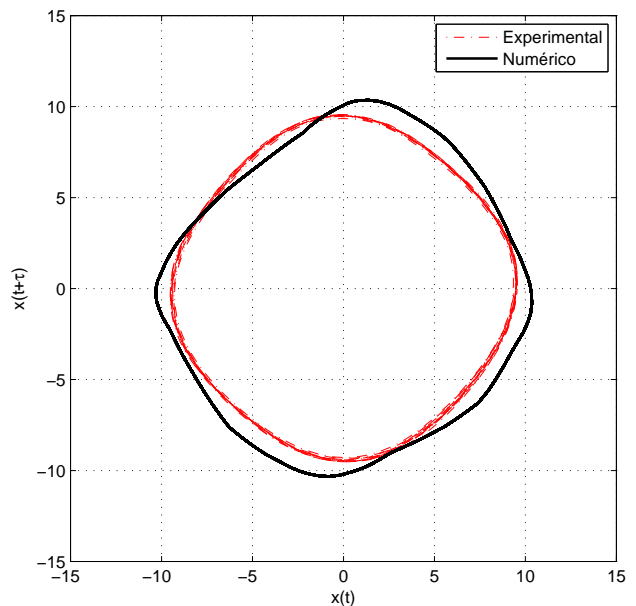

(d) Torção

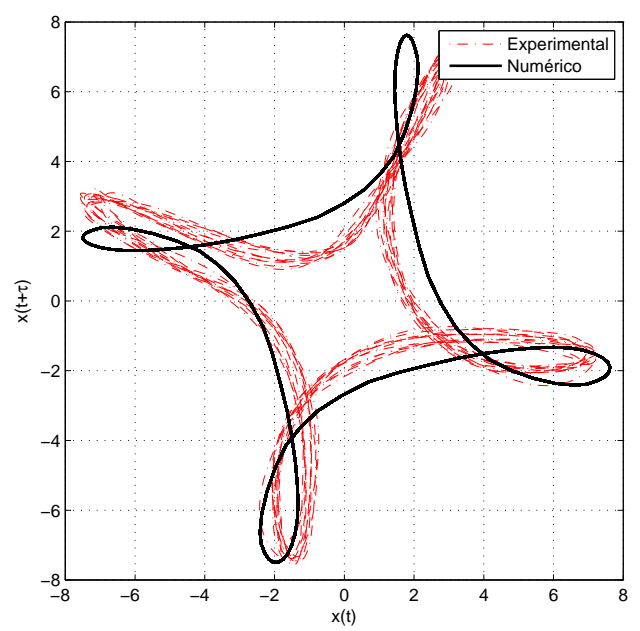

(f) SC

Figura 4.9: Análise por pseudo retratos de fase para o sistema aeroelástico quando (a) apresenta enrijecimento 3 e (b) apresenta enrijecimento 3 e folga de 4 graus, para uma velocidade de $1,18 U_{c}$. 
O valor da defasem foi calculado através das curvas de autocorrelação para cada série temporal conforme explicado no Capítulo 3. Os valores de $\tau$ utilizados na Figura 4.9 são apresentados na Tabela 4.6.

Tabela 4.6: Atraso no tempo usado para a reconstrução do espaço de estados.

\begin{tabular}{|l|c|c|c|c|}
\cline { 3 - 5 } \multicolumn{2}{c|}{} & Flexão $(h)$ & Torção $(\alpha)$ & Torção da SC $(\beta)$ \\
\hline \multirow{2}{*}{ Enrijecimento 3} & Experimental $(\tau)$ & $87 \mathrm{~s}$ & $86 \mathrm{~s}$ & $86 \mathrm{~s}$ \\
\cline { 2 - 5 } & Computacional $(\tau)$ & $26 \mathrm{~s}$ & $25 \mathrm{~s}$ & $23 \mathrm{~s}$ \\
\hline \hline \multirow{2}{*}{$\begin{array}{l}\text { Enrijecimento 3 } \\
\text { e folga de 4 graus }\end{array}$} & Experimental $(\tau)$ & $84 \mathrm{~s}$ & $84 \mathrm{~s}$ & $82 \mathrm{~s}$ \\
\cline { 2 - 5 } & Computacional $(\tau)$ & $23 \mathrm{~s}$ & $23 \mathrm{~s}$ & $26 \mathrm{~s}$ \\
\hline
\end{tabular}

O retrato de fase é uma ótima ferramenta para analisar a complexidade das oscilações em ciclo limite. Neste caso, tanto o movimento de flexão quando o de torção tiveram uma dinâmica de LCO sem movimentos complexos. Contudo, analisando as Figuras 4.9 (e) e (f), observa-se que a superfície de controle possui um movimento complexo em virtude do acoplamento dos outros movimentos. Esse comportamento se agrava na presença da folga (ver Figura 4.9 (f)). Dessa forma, conclui-se que os resultado computacionais apresentaram boa concordância na simulação da dinâmica do sistema físico. Segue-se, assim, com a análise da bifurcação de Hopf para diferentes faixas de velocidade (diagrama de bifurcação).

\subsection{Bifurcações de Hopf}

\subsubsection{Influência da não linearidade de enrijecimento}

A Figura 4.10 apresenta a amplitude das oscilações do sistema aeroelástico de cada grau de liberdade para as simulações numéricas e para os resultados experimentais, ambos apresentando somente o efeito não linear de enrijecimento em torção. Três intensidades diferentes de enrijecimento foram consideradas como anteriormente apresentado.

Os resultados revelam um comportamento subcrítico do sistema, no qual o sistema salta de um ponto estável para começar a oscilar em ciclo limite com alta amplitude antes de atingir a velocidade crítica de flutter $\left(U=U_{c}\right)$, chamado aqui de início crítico da bifurcação. Nos resultados numéricos as amplitudes iniciais de LCO dos deslocamentos são: flexão igual a 0,4cm, 


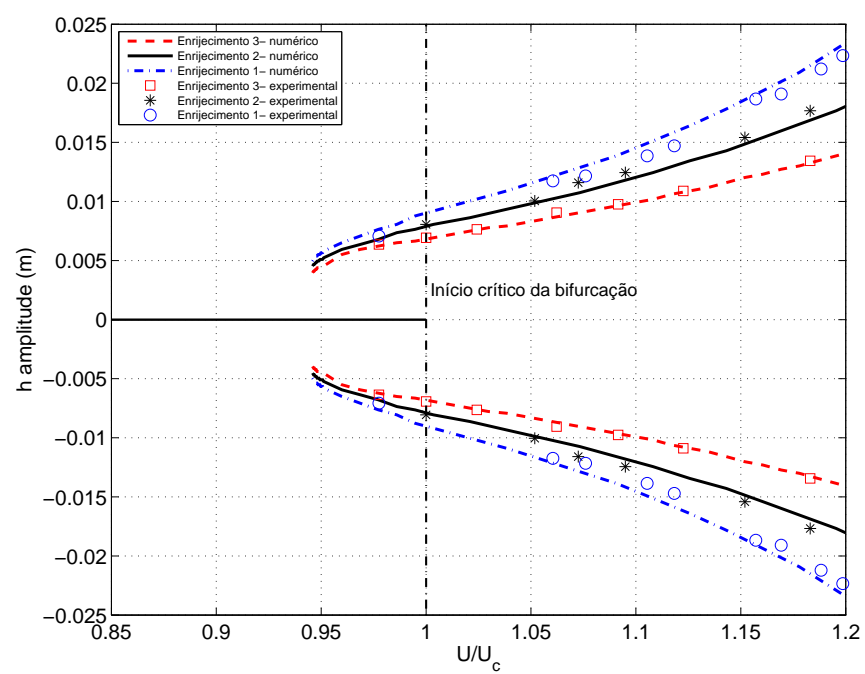

(a)

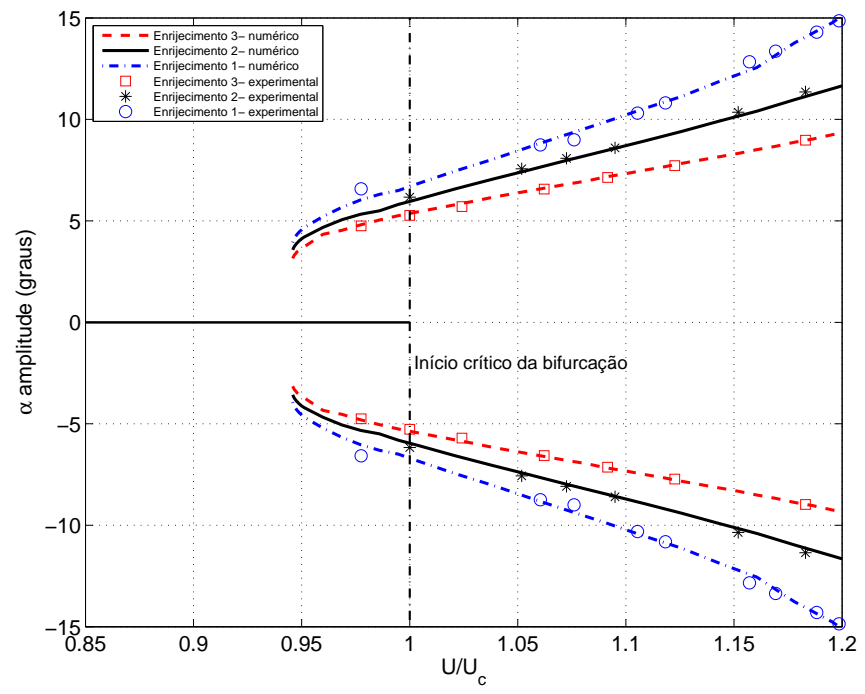

(b)

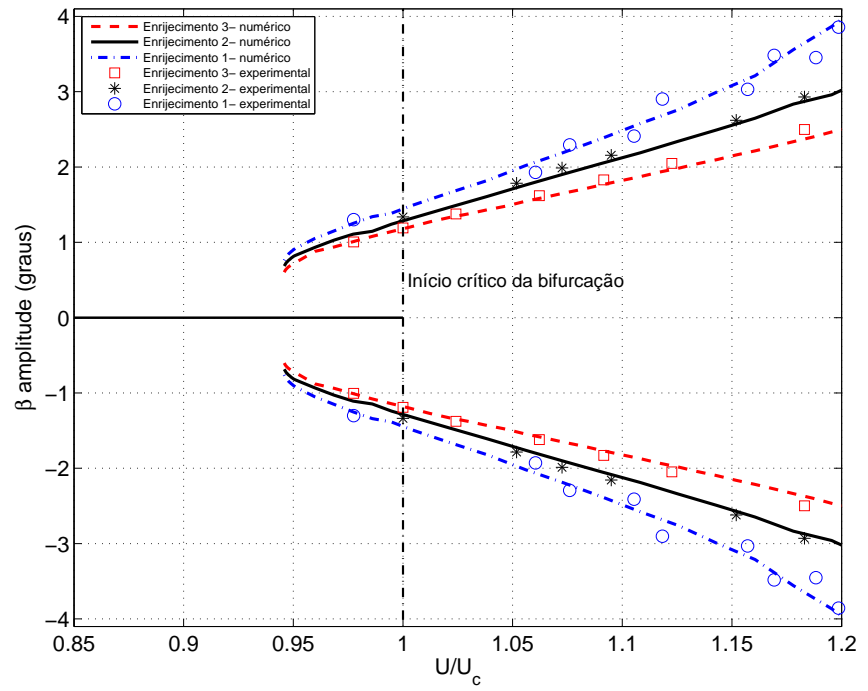

(c)

Figura 4.10: Diagrama de bifurcação de Hopf quando três diferentes intensidades da não linearidade do tipo enrijecimento estão presentes. 
$0,45 \mathrm{~cm}$ e $0,5 \mathrm{~cm}$ para a curva de enrijecimento 3,2 e 1 , respectivamente, torção igual a $3,2^{\circ}$, $3,6^{\circ}$ e $3,9^{\circ}$, e superfície de controle igual a $0,6^{\circ}, 0,68^{\circ}$ e $0,76^{\circ}$. Devido às flutuações do escoamento não foi possível capturar exatamente o ponto de início de LCO. Desse modo os primeiros resultados experimentais estão a $U=0,97 U_{c}$. Em todas as curvas obtidas computacionalmente a instabilidade começa em $U=0,945 U_{c}$, o que mostra que, de fato, a não linearidade de enrijecimento não altera a velocidade crítica de flutter e nem o ponto inicial da bifurcação.

Embora a não linearidade estrutural de enrijecimento seja responsável pelo aparecimento das oscilações em ciclo limite, ela não altera o comportamento da bifurcação do sistema de subcrítico para supercrítico ou vice-versa. Além disso, a velocidade crítica de flutter para todos os LCOs começa e termina na mesma velocidade de escoamento, ou seja, $U=1,0 U_{c}$ e $U=0,945 U_{c}$, respectivamente, demonstrando que a característica subcrítica é a mesma. Os resultados numéricos mostraram boa aproximação com os experimentais, nos quais é possível observar uma não linearidade forte de enrijecimento gerar menores amplitudes de LCO, quando a velocidade do ar é aumentada e diminuída.

\subsubsection{Influência da não linearidade de folga}

Admitindo a não linearidade de enrijecimento 3 na rigidez de torção, a não linearidade de folga é incluída na dobradiça da superfície de controle. Foram considerados dois diferentes tamanhos de folga nas análises $\left(2 \delta=2^{\circ}\right.$ e $\left.2 \delta=4^{\circ}\right)$. A Figura 4.11 mostra o diagrama de bifurcação dos resultados numéricos e computacionais para os três graus de liberdade, flexão, torção e SC, respectivamente. A bifurcação subcrítica pode ser vista em todos os casos observados, porém com diferentes níveis de oscilações em ciclo limite. As Figuras 4.11 (a) e (b) mostram que a folga não altera consideravelmente a amplitude de oscilação desses graus de liberdade. Contudo, a Figura 4.11(c), como esperado, mostra que a amplitude de oscilação da superfície de controle é muito maior quando ela apresenta folga.

Observa-se que a instabilidade da bifurcação de Hopf obtida numericamente começa em $U=0,946 U_{c}, U=0,927 U_{c}$, e $U=0,917 U_{c}$, para o sistema sem folga, com folga de dois 


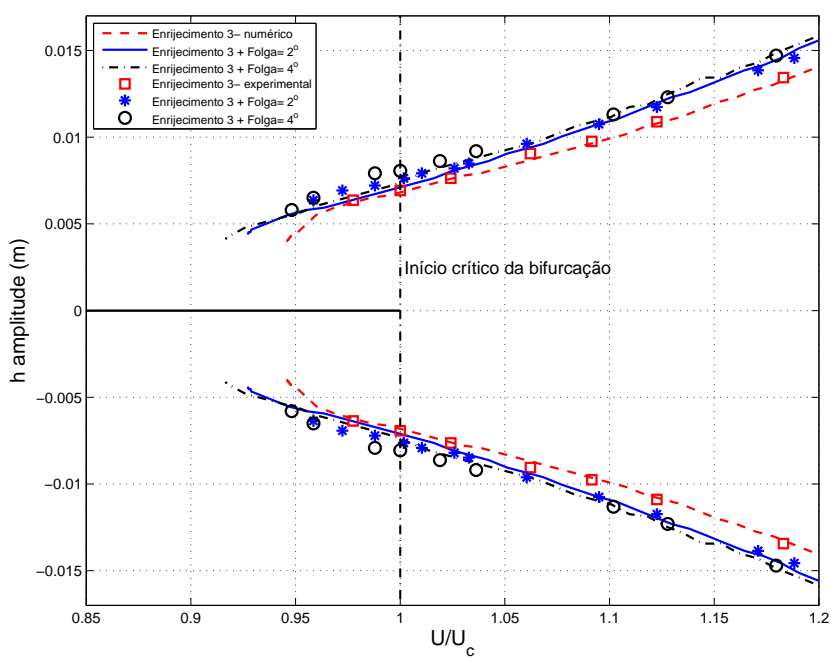

(a)

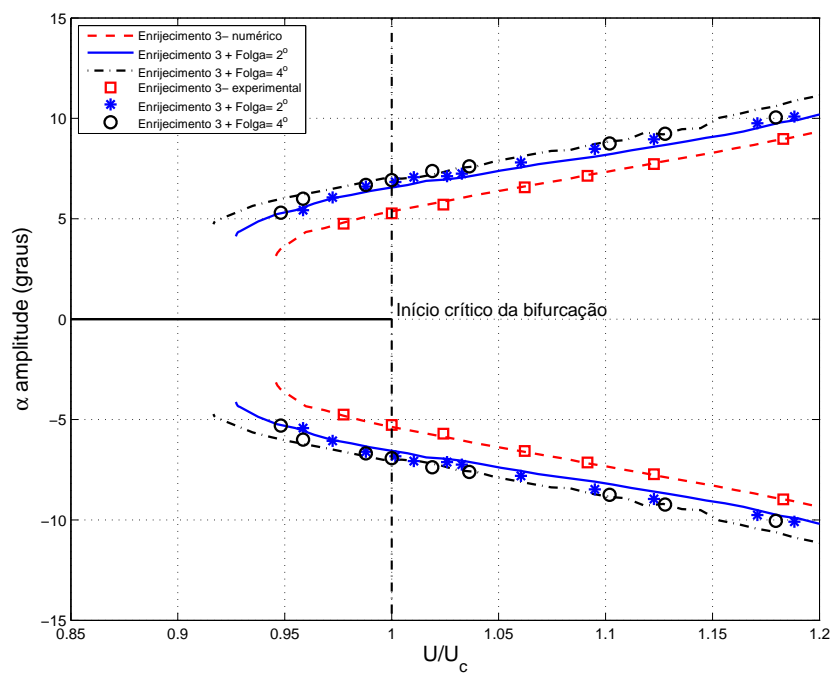

(b)

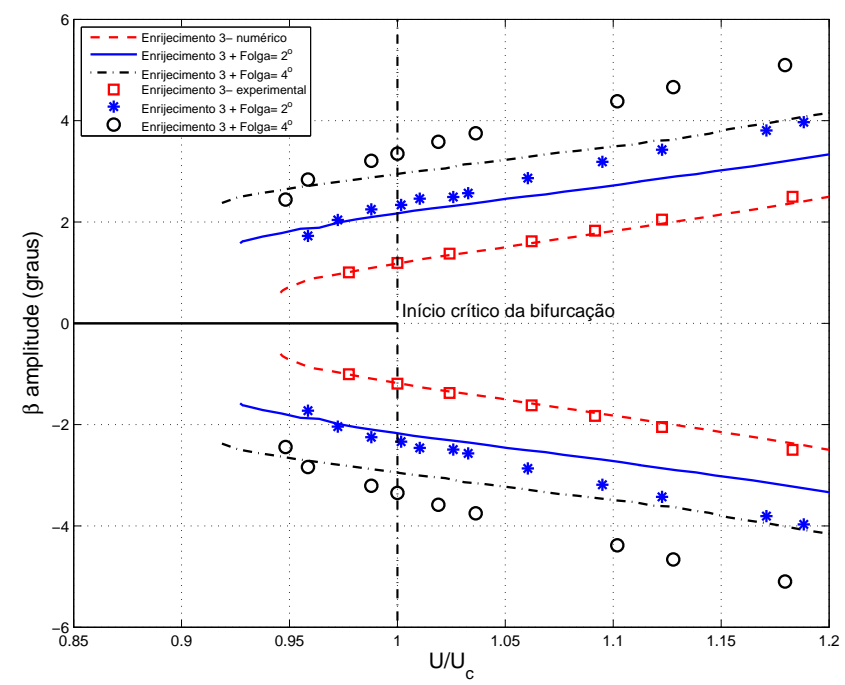

(c)

Figura 4.11: Diagrama de bifurcação de Hopf quando há o efeito combinado das não linearidades de enrijecimento 3 e de dois tamanhos de folga. 
graus e quatro graus, respectivamente. Isso demostra que a bifurcação subcrítica aumenta com o aumento do tamanho da folga tornando, desse modo, o sistema mais instável. Já a instabilidade da bifurcação dos resultados experimentais começa em $U=0,977 U_{c}, U=0,958 U_{c}$ e $U=0,948 U_{c}$. Observa-se na Figura 4.11(c) que os resultados da amplitude de oscilação do movimento da superfície de controle são maiores no experimento do que no modelo computacional, ou seja, a superfície de comando precisa ser ajustada, ou mesmo, há a necessidade de uma investigação complementar sobre as possíveis causas desse efeito.

Conclui-se através das Figuras 4.10 e 4.11 que a não linearidade de enrijecimento controla a amplitude do sistema, não alterando significativamente sua dinâmica sub ou supercrítica. Já a folga, mesmo na presença da maior intensidade de enrijecimento, é responsável por alterar esse comportamento. Nota-se que ambos os casos possuem bifurcações com oscilações simétricas em torno do eixo $U / U_{c}$. Outro fator relevante foi a máxima velocidade experimental de $14,27 \mathrm{~m} / \mathrm{s}$. Valores maiores não puderam ser medidos uma vez que a asa passa a atingir ângulos de incidência muito altos e os fenômenos aerodinâmicos não lineares (efeito de escoamento separado, por exemplo) passam a exercer grande influência na dinâmica do sistema, o que faz com que a bifurcação salte para uma nova dinâmica. Além disso, o modelo numérico usado nesse trabalho não consegue prever qualquer efeito aerodinâmico não linear.

\subsubsection{Bifurcações subcríticas versus supercríticas}

Embora haja alterações na dinâmica do sistema aeroelástico em virtude das não-linearidades estruturais, tem sido observado que o comportamento linear é o responsável por determinar se a bifurcação será subcrítica ou supercrítica quando o sistema apresenta não linearidade do tipo enrijecimento. A fim de demonstrar essas características, a rigidez da mola de torção teve seu valor aumentado arbitrariamente levando a um novo valor de $\omega_{\alpha}=17,1261 \mathrm{rad} / \mathrm{s}$ (o qual corresponde a um aumento de $100 \%$ na rigidez em torção). Todos os outros parâmetros foram deixados iguais aos apresentados na Tabela 4.3. A Figura 4.12 apresenta o diagrama de bifurcação do novo sistema aeroelástico (linha sólida) comparado com o antigo (linha ponti- 
lhada) para os movimentos de flexão, de torção e da superfície de controle, respectivamente, os quais apresentam uma nova velocidade crítica de flutter $U_{c}=10,98 \mathrm{~m} / \mathrm{s}$.

Nota-se que embora a rigidez em torção tenha sido aumentada, o resultado foi uma diminuição na velocidade de $f l u t t e r($ de $11,465 m / s$ para $10,98 m / s$ ), demostrando que esse ponto de instabilidade depende do acoplamento de todos os graus de liberdade e de todos os parâmetros do sistema.Esse sistema, mesmo com a não linearidade de enrijecimento 1 (vermelho) e 3 (preto) em torção, apresenta bifurcação supercrítica, diferentemente do que foi obtido experimentalmente quando o sistema apresentava bifurcação subcrítica para o valor de $\omega_{\alpha}=12,11 \mathrm{rad} / \mathrm{s}$. Isso mostra que os parâmetros do sistema e suas relações com as não linearidades são muito importantes e devem ser analisados cuidadosamente.

A Figura 4.13 apresenta a comparação do sistema descrito anteriormente quando nele é introduzido a não linearidade de folga (linha pontilhada) na superfície de controle Esse sistema possui a frequência de $\omega_{\alpha}=17,1261 \mathrm{rad} / \mathrm{s}$. Vale ressaltar que os sistemas supercríticos, para as mesmas intensidades de não linearidades, apresentam oscilações com amplitude bem controladas e não dependem da condição inicial, sempre começando na região chamada de início crítico da bifurcação.

Novamente há uma comparação entre a não linearidade de enrijecimento 1 e 3. Observa-se que a folga é responsável por alterar o comportamento do sistema de supercrítico para subcrítico conforme discutido na Seção 3.3.2, ou seja, essa não linearidade força o aparecimento de LCO instável, o qual é dependente da condição inicial e existe antes da velocidade crítica. Além disso, quando o sistema atinge a velocidade de flutter, abaixo da velocidade crítica linear, a não linearidade de enrijecimento é responsável por controlar a amplitude de oscilação do sistema dando margens de segurança para o mecanismo voltar a condição estável. Quando não há essa não linearidade o sistema pode atingir grandes e perigosos deslocamentos abaixo da velocidade crítica de flutter. 


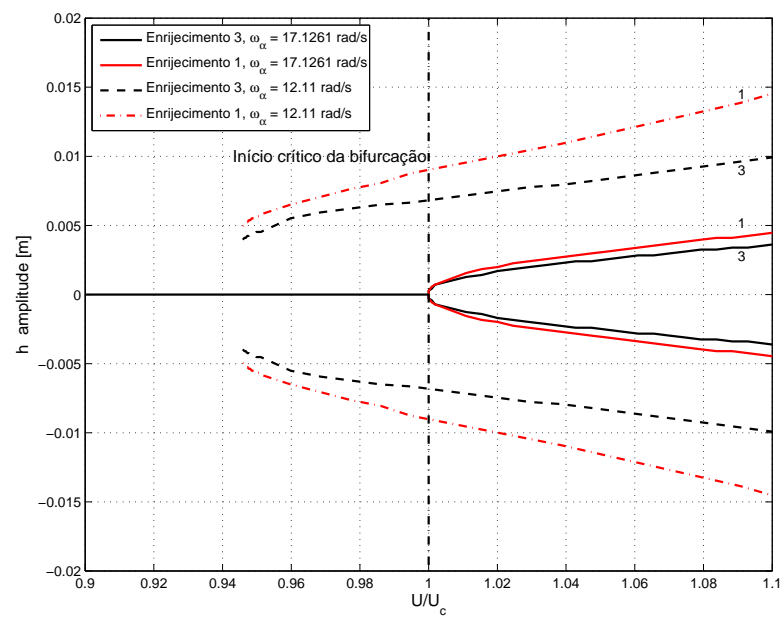

(a)

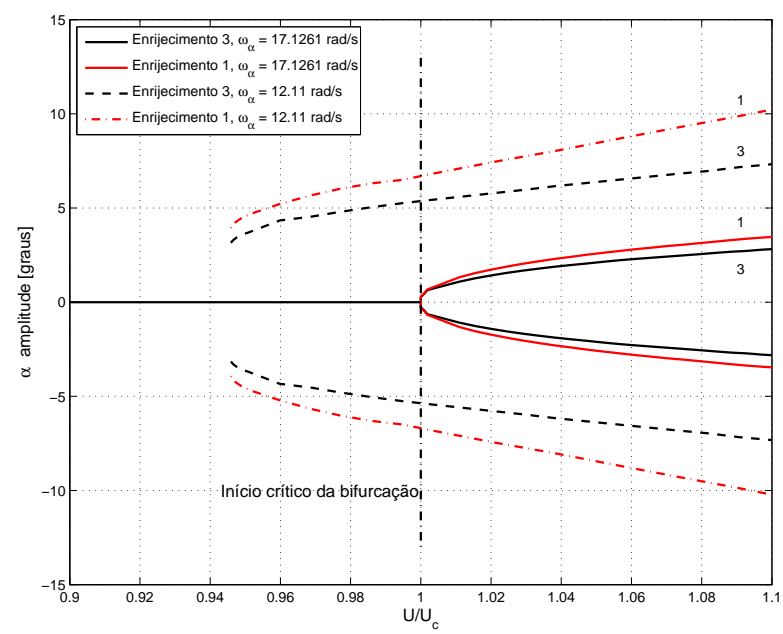

(b)

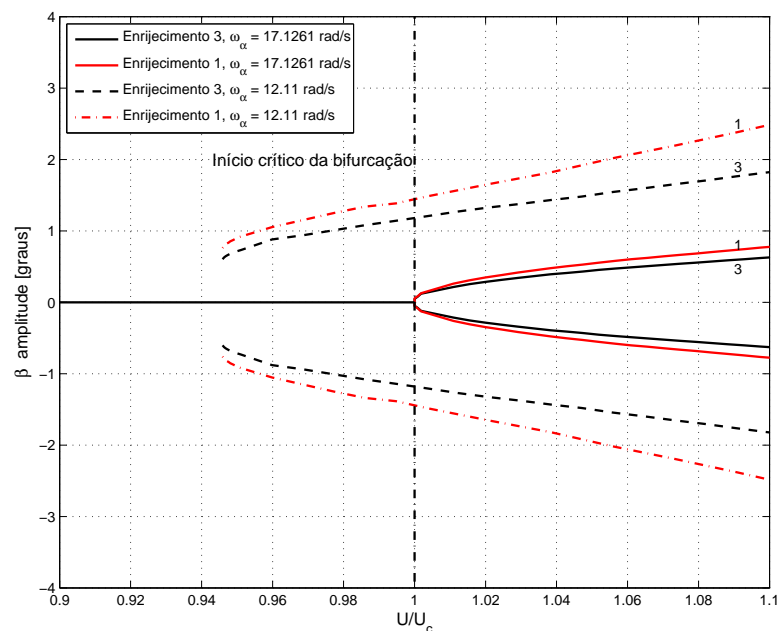

(c)

Figura 4.12: Diagrama de bifurcação de Hopf computacional quando há um comportamento supercrítico devido a um aumento na rigidez de torção. 


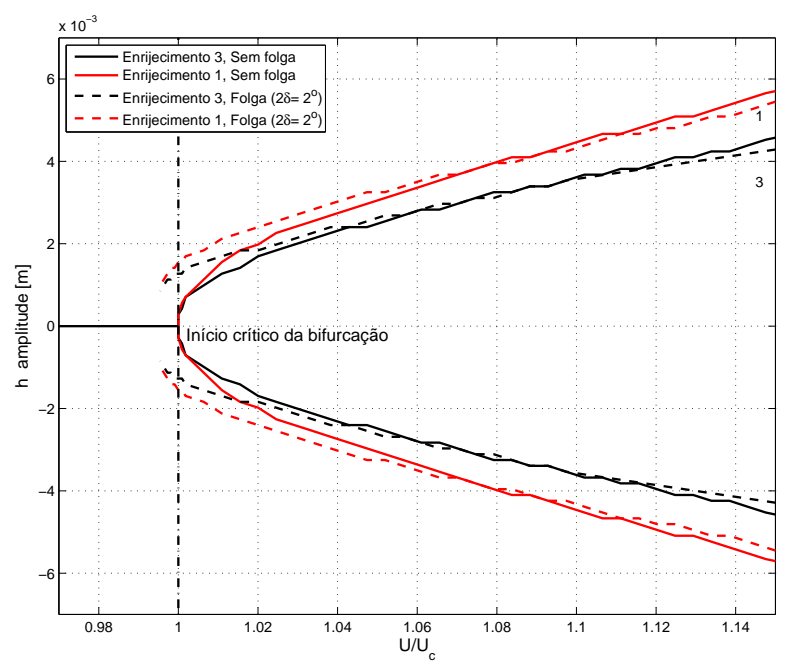

(a)

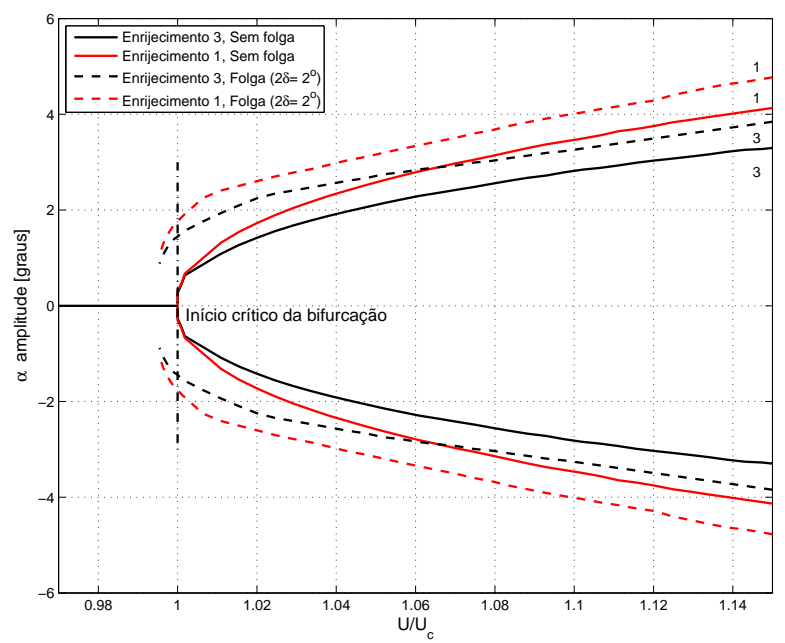

(b)

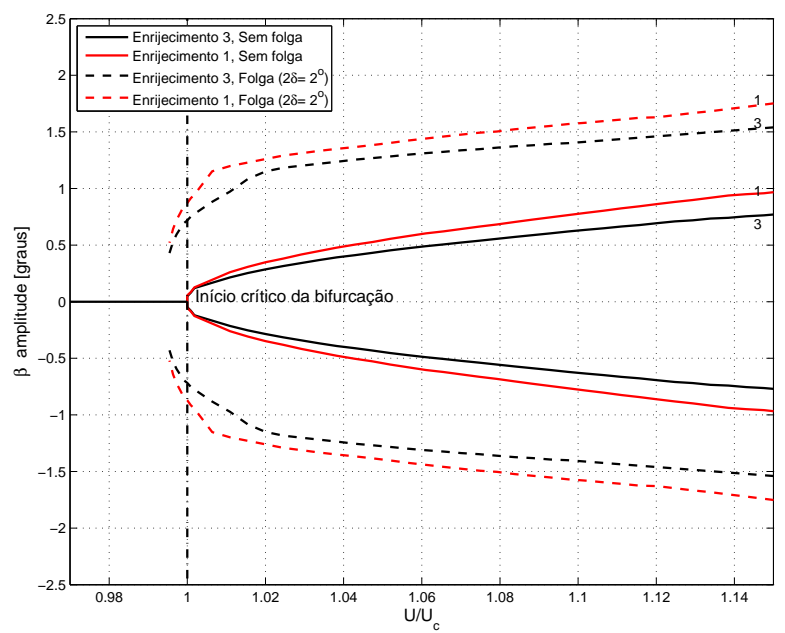

(c)

Figura 4.13: Diagrama de bifurcação de Hopf quando há o efeito combinado da não linearidade chamada de enrijecimento 3 e da não linearidade de folga com o tamanho de 2 graus. 


\subsection{Análise por espectros de ordem mais alta}

Para entender como as não linearidades influenciam um sistema e identificar as suas fontes, a análise por espectros de ordem mais alta é aplicada aos resultados experimentais e computacionais em todos os graus de liberdade. $\mathrm{O}$ autospectro foi usado para identificar as frequências presentes no sistema, a autobicoerência foi usada para analisar se há não linearidade quadrática e, finalmente a autotricoerência para analisar se há não linearidade cúbica.

Considerando o dispositivo criado para introduzir o efeito de não linearidade em torção, é razoável concluir que é pouco provável construir um modelo experimental sem assimetrias. De fato, o dispositivo apresenta uma pequena assimetria na curva de momento restaurador, o que pode ser observado no gráfico de densidade espectral (ver Figuras 4.6, 4.7 e 4.8 - através da presença dos harmônicos pares). A autobicoerência pode ser usada para confirmar o acoplamento de fase entre a frequência fundamental e os seus super harmônicos pares, ou seja, verificar se há o efeito não linear quadrático. A Figura 4.14 apresenta a densidade espectral de potência e o gráfico de contorno da autobicoerência para os sinais experimentais quando há uma não linearidade cúbica de enrijecimento 3, a qual é responsável pelo aparecimento LCO na velocidade de escoamento de $U=1,18 U_{c}$.

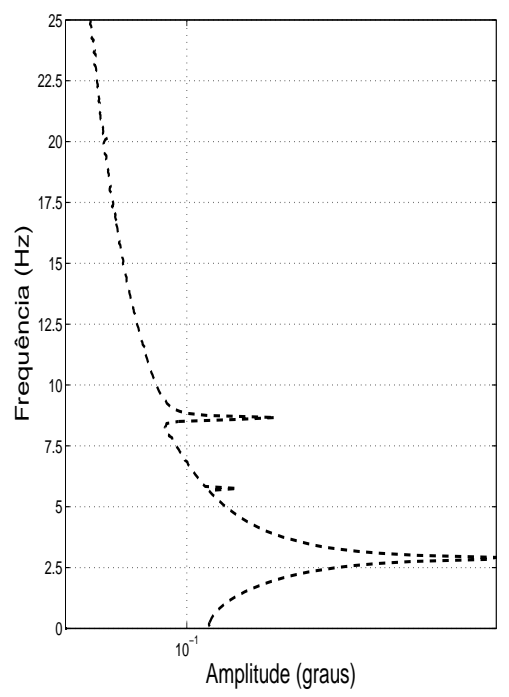

(a) Densidade espectral de potência.

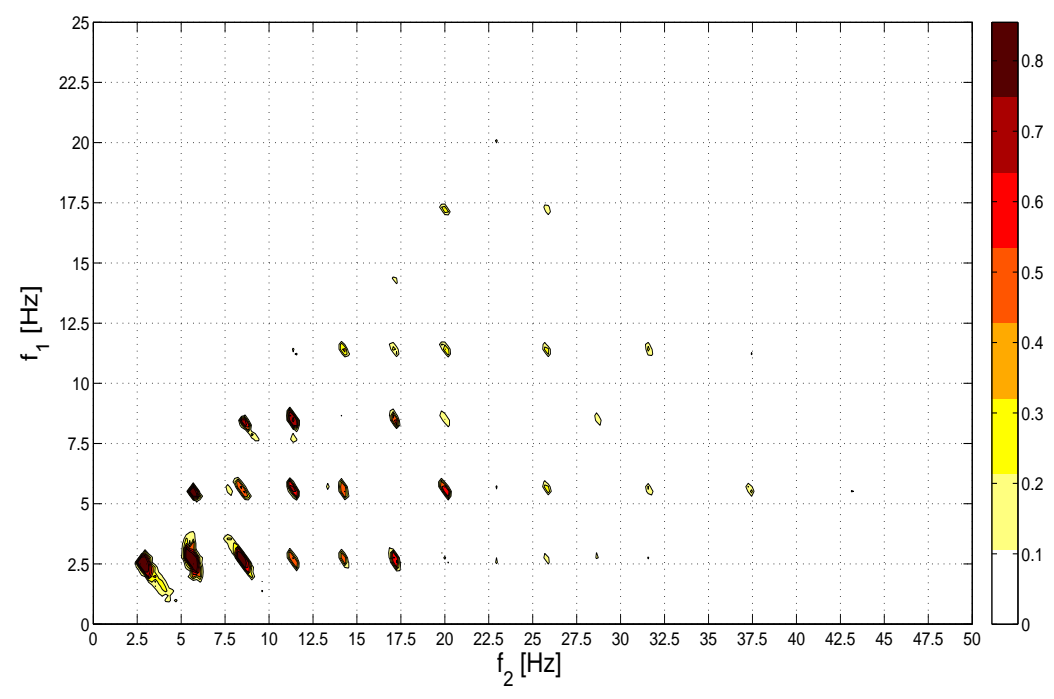

(b) Autobicoerência.

Figura 4.14: Análise experimental por autobicoerência para o deslocamento em torção em uma velocidade de $1,18 U_{c}$ com a não linearidade de enrijecimento 3. 
Esses resultados revelam o acoplamento de fase quadrático com níveis de bicoerência de até 0,85 . É possível observar na Figura 4.14(b) que esse acoplamento é mais forte para baixas frequências, como ocorre entre o harmônico fundamental $(2,73 \mathrm{~Hz})$ com ele mesmo gerando o primeiro super harmônico $(2,73 \mathrm{~Hz}+2,73 \mathrm{~Hz}=5,46 \mathrm{~Hz})$. Além disso, todos os outros super harmônicos são afetados, concluindo, assim, que a assimetria contamina todas as frequência do sistema, inclusive as ímpares $(2,73 \mathrm{~Hz}+5,46 \mathrm{~Hz}=8,19 \mathrm{~Hz})$. Vale salientar que a energia envolvida nos deslocamentos obtidos experimentalmente não é suficientemente grande para envolver os super harmônicos de frequência muito alta como os acima de $25 \mathrm{~Hz}$, os quais são quase dez vezes maiores que a frequência fundamental.

A Figura 4.15 apresenta a análise por autobicoerência dos sinais experimentais quando há uma não linearidade cúbica de enrijecimento 3 e uma folga de 4 graus na superfície de comando para uma velocidade de escoamento de $1,18 U_{c}$. Observa-se que o acoplamento de fase quadrático não sofre alteração considerável, ou seja, não se pode concluir acerca do efeito da presença da folga na análise por HOS nesse caso.

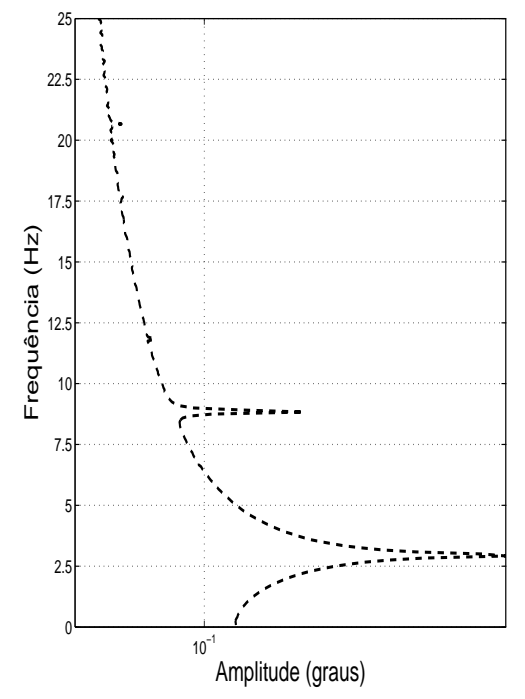

(a) Densidade espectral de potência.

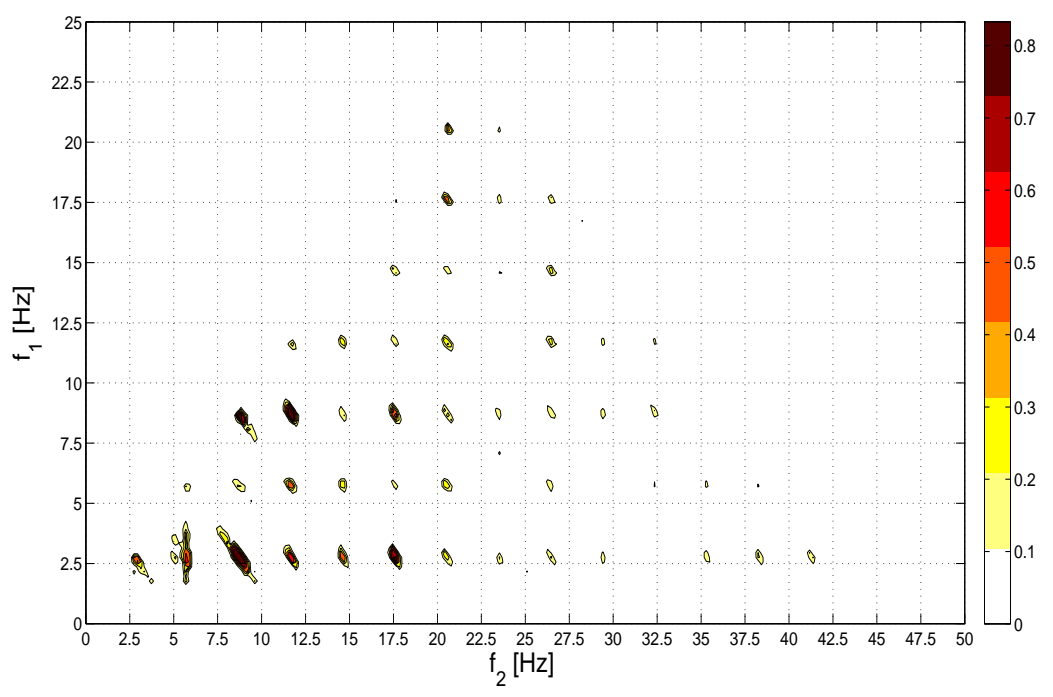

(b) Autobicoerência.

Figura 4.15: Análise experimental por autobicoerência para o deslocamento em torção em uma velocidade de $1,18 U_{c}$ com a não linearidade de enrijecimento 3 e folga de $4^{o}$.

Vale salientar que qualquer outra assimetria presente no sistema também poderia interferir nessa análise, ou seja, o HOS não consegue determinar com exatidão onde esse efeito está 
ocorrendo, mas sim determinar a intensidade das interações entre as frequências envolvidas. Desse modo, realizando a análise dos resultados computacionais com e sem essa assimetria na curva de rigidez de torção, pode-se concluir se ela é realmente a causadora dessa não linearidade quadrática.

A Figura 4.16 mostra as mesmas análises apresentadas na Figura 4.14, porém nesse caso para os sinais computacionais. A curva não linear de momento restaurador em torção é a aproximação dos resultados obtidos experimentalmente com a assimetria presente. Observase que novamente as frequências possuem uma relação de fase entre elas (nível de acoplamento até 0,85 ), indicando que é forte esse efeito quadrático, principalmente nas frequências relacionadas com o segundo super harmônico $(5,46 \mathrm{~Hz})$.

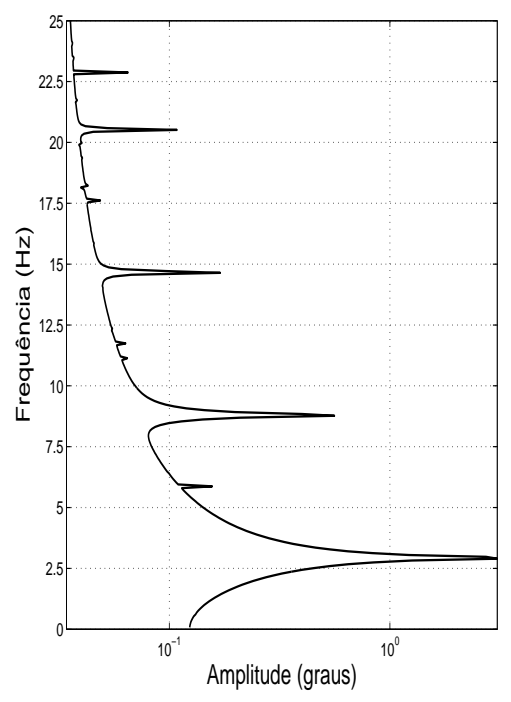

(a) Densidade espectral de potência.

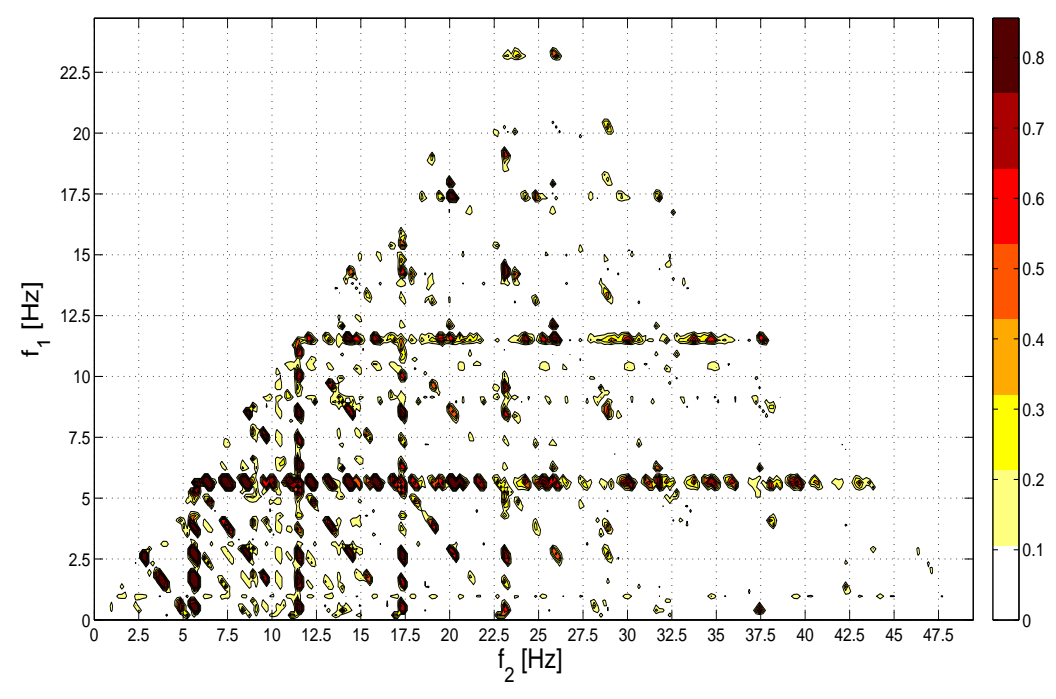

(b) Autobicoerência.

Figura 4.16: Análise computacional por autobicoerência para o deslocamento em torção em uma velocidade de $1,18 U_{c}$ com assimetria na rigidez não linear.

Conclui-se que o modelo matemático e a aproximação por razão de polinômios da não linearidade cúbica representam bem a dinâmica não linear quadrática envolvida. Desse modo, para comprovar o efeito da assimetria, realizam-se novamente as análises computacionais para as mesmas condições da Figura 4.16. Contudo, com a curva não linear de enrijecimento 3 simétrica em relação ao zero. 
A Figura 4.17 mostra que a não linearidade quadrática realmente vem da assimetria presente na curva de rigidez em torção, uma vez que nesse caso a relação de fase não atinge 0,2 no gráfico de autobicoerência, o que, de fato, representa baixa presença não linear do tipo quadrática.

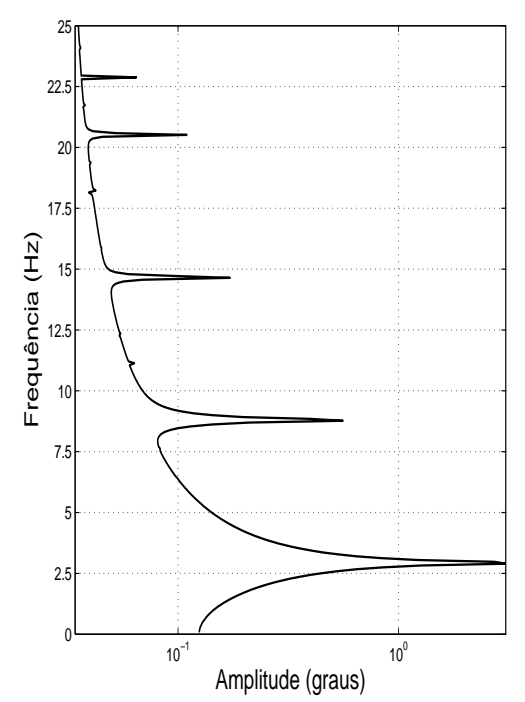

(a) Densidade espectral de potência.

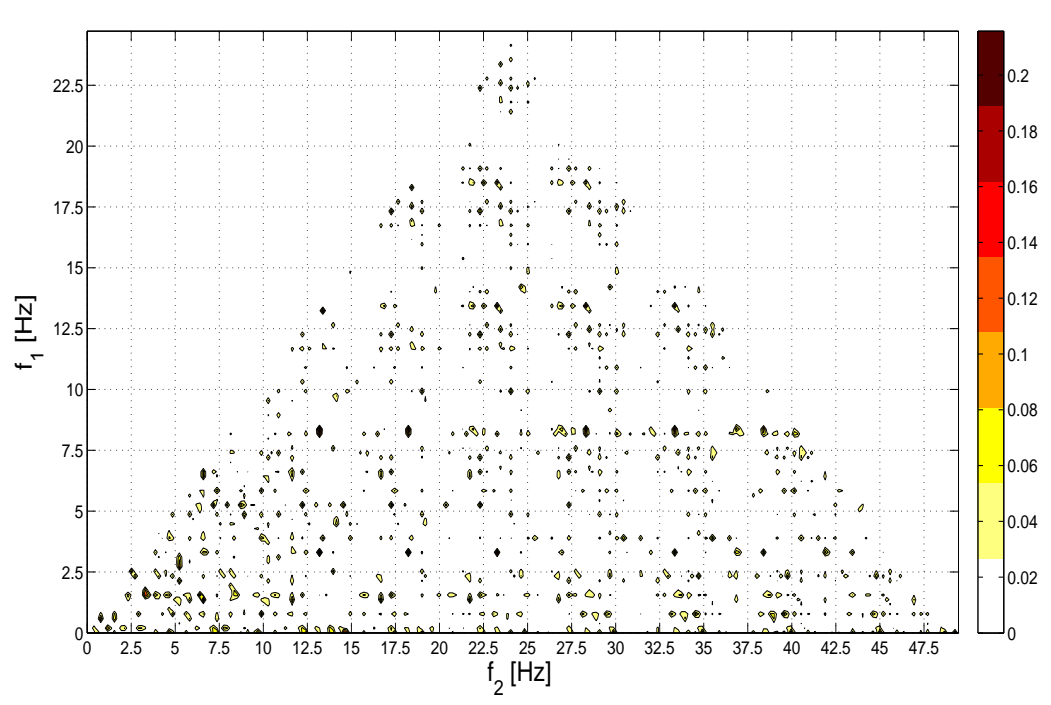

(b) Autobicoerência.

Figura 4.17: Análise computacional por autobicoerência para o deslocamento em torção em uma velocidade de $1,18 U_{c}$ com a curva de rigidez não linear simétrica.

A Figura 4.18 apresenta os gráficos de contorno da autotricoerência (nível de contorno definido em 0,8 ) para os resultados experimentais do deslocamento em torção na velocidade de vento igual a $U=1,16 U_{c}$. As Figuras 4.18 (a) e (b) mostram os resultados para o sistema com as não linearidades de enrijecimento 3 e 1, respectivamente. O acoplamento não linear entre a frequência fundamental com ela mesma gera os harmônicos ímpares $(2,73 \mathrm{~Hz}+2,73 \mathrm{~Hz}+$ $2,73 \mathrm{~Hz}=8,18 \mathrm{~Hz}$ ), o que pode ser observado através do número de círculos e suas projeções nos três eixos, representadas por triângulos. De fato, já era esperado um alto nível de acoplamento de fase, uma vez que o dispositivo experimental foi desenvolvido para apresentar não linearidade do tipo cúbica. Observa-se também que na Figura 4.18 (a) a não linearidade cúbica é mais acentuada para o enrijecimento 3 do que o enrijecimento 1 presente na Figura 4.18 (b), como era o esperado uma vez que a curva de enrijecimento 3 é mais intensa que a 1 . As Figuras 4.19 (a) e (b) representam as mesmas análises anteriores para os resultados computacionais. Conclui-se que o modelo por aproximação de polinômios representa bem a dinâmica 
não linear presente na curva de rigidez em torção, já que para maiores intensidades do efeito de enrijecimento maior é o nível de autotricoerência.

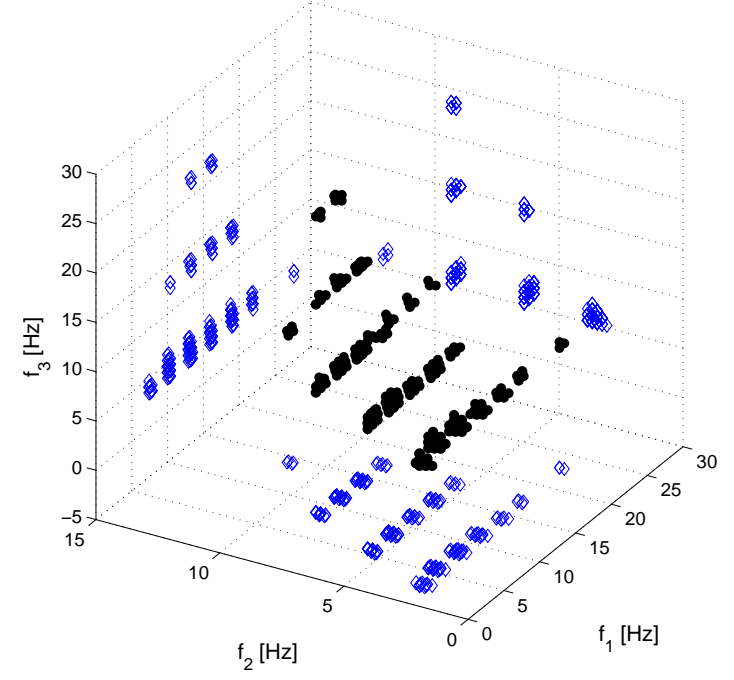

(a) Enrijecimento 3.

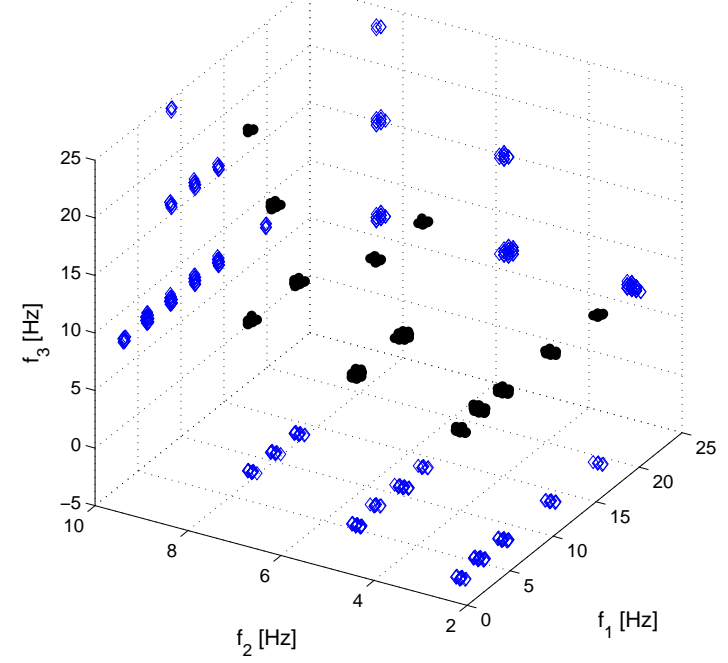

(b) Enrijecimento 1.

Figura 4.18: Análise da autotricoerência experimental e suas respectivas projeções para o movimento de torção quando $\mathrm{U}=1,18 U_{c}$. $\bullet$ - Autotricoerência $($ corte $=0,8)$, $\diamond$ - projeções.

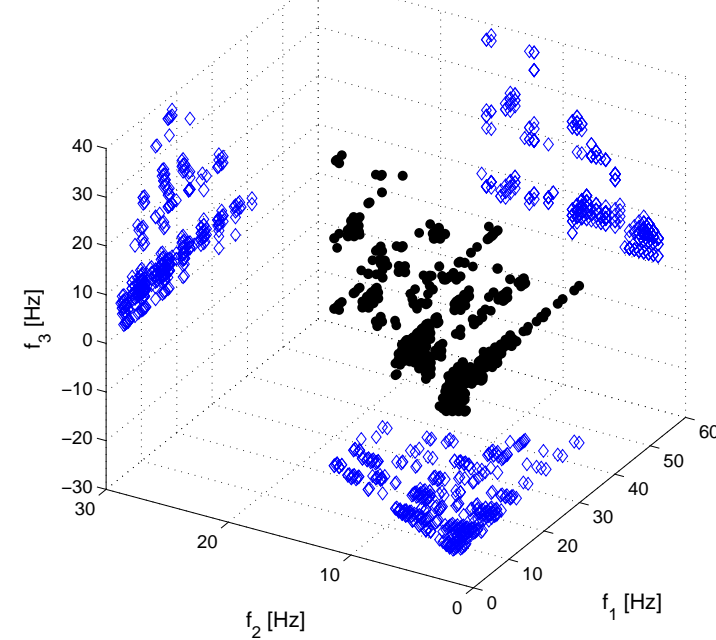

(a) Enrijecimento 3

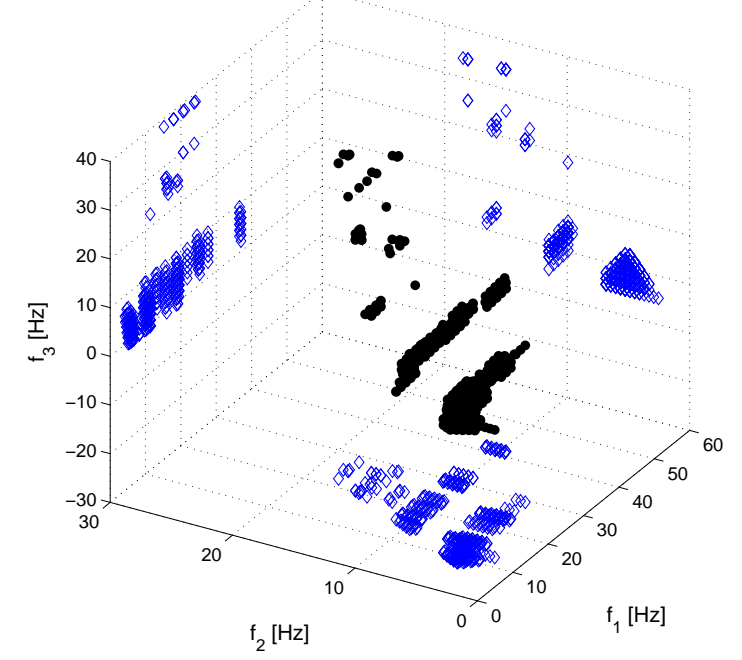

(b) Enrijecimento 1

Figura 4.19: Análise da autotricoerência computacional e suas respectivas projeções para o movimento de torção quando $U=1,18 U_{c}$. • - Autotricoerência $($ corte= 0,8$)$, $\diamond$ - projeções. 


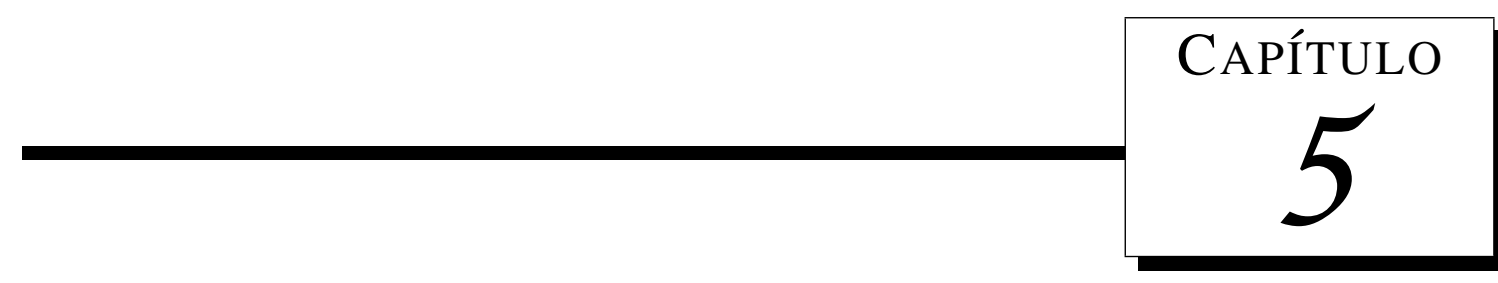

\section{CONCLUSÃO}

Esse trabalho apresentou um estudo experimental e computacional sobre a influência das não linearidades estruturais de enrijecimento e folga combinadas em um modelo de seção típica aeroelástico com três graus de liberdade. A não linearidade de enrijecimento foi aplicada no movimento de torção e a de folga no movimento da superfície de controle. Todos os resultados foram caracterizados e identificados utilizando diagramas de bifurcação de Hopf e análises espectrais.

O modelo numérico utilizado nesse trabalho segue o princípio do sistema aeroelástico de seção típica, cuja formação se dá pela relação entre a dinâmica estrutural e a aerodinâmica não-estacionária de um determinado sistema mecânico. As equações estruturais foram obtidas através da decomposição das equações da energia potencial e cinética pela equação de Lagrange. A não linearidade de enrijecimento e de folga foram introduzidas na matriz de rigidez através de razões de polinômio e funções de tangente hiperbólica, respectivamente. A aerodinâmica não estacionária utilizou o modelo proposto por Theodorsen (1935) com aproximações para movimentos arbitrários de um aerofólio. Os resultados experimentais foram obtidos nos três graus de liberdade através de sensores ópticos para deslocamento linear e angular. O dispositivo não linear experimental permitiu a variação da intensidade do enrijecimento e do tamanho entre as batentes da rigidez da superfície de controle, variando, assim, o tamanho da folga.

Os resultados computacionais foram validados através dos gráficos das séries temporais e 
dos espectros de potência como as transformadas rápidas de Fourier. Os resultados mostraram boa concordância uma vez que a velocidade de flutter linear computacional apresentou um erro de aproximadamente $4,45 \%$ a $6,0 \%$. Para validação também foi utilizada a reconstrução dos espaço de estados através do método de coordenadas defasadas, os quais mostraram experimentalmente e computacionalmente uma dinâmica complexa para os resultados das oscilações da superfície de comando, acentuando-se com a presença da folga. Sendo assim, conclui-se que os resultados computacionais apresentaram boa concordância com os experimentais para prever as respostas não lineares. Os resultados mais relevantes desse trabalho estão divididos em quatro tópicos: (I) Efeitos não lineares de enrijecimento e folga variando suas intensidades. (II) Influência das não linearidades de enrijecimento e folga combinadas na dinâmica do sistema. (III) Análise do efeito dos parâmetros lineares na bifurcação de Hopf. (IV) Aplicação da ferramenta de HOS e identificação não linear.

(I) Como esperado na literatura, a não linearidade de enrijecimento induziu oscilações em ciclo limite. Ela não muda a característica subcrítica ou supercrítica do sistema, mas leva ao aparecimento e também ao controle das amplitudes de oscilações em ciclo limite quando se varia a intensidade dessa não linearidade. Vale ressaltar que o experimento apresentou uma leve assimetria na rigidez não linear de torção, levando o sistema a apresentam não linearidade quadrática. Esse efeito foi introduzido no modelo matemático através da aproximação da curva de enrijecimento por razões de polinômios. Em contrapartida, a não linearidade de folga levou ao aparecimento do comportamento subcrítico e aumentou a região de instabilidade do diagrama de bifurcação de Hopf. Esses resultados apresentaram boa concordância com a literatura.

(II) Quando as duas não linearidades combinadas foram analisadas variando a suas intensidades, constatou-se que o enrijecimento não altera o comportamento do diagrama de Hopf de supercrítico para subcrítico, já a folga torna o sistema cada vez mais instável com seu aumento. O enrijecimento no sistema com folga mostrou-se, contudo, capaz de controlar as amplitudes de oscilações em ciclo limite. Essa conclusão pode ser tomada 
como importante pelo fato de a não linearidade de enrijecimento amenizar os resultados instáveis e indesejáveis gerados pela não linearidade do tipo folga.

(III) Alterou-se a rigidez computacional a fim de obter um sistema supercrítico. Constatou-se que os parâmetros lineares são responsáveis por alterar o comportamento do diagrama quando há alguma não linearidade envolvida. Desse modo torna-se importante o estudo dos parâmetros da asa e como eles se comportam na reposta subcrítico vs supercrítico do diagrama de bifurcação. Observou-se, também, que a folga faz o sistema supercrítico se tornar subcrítico instável, e o enrijecimento controla a amplitude de oscilação para oscilações instáveis antes da velocidade de flutter.

(IV) As análises por espectros de ordem mais alta confirmaram a presença das não linearidades quadráticas e cúbicas. Através dos gráficos de bicoerência experimental e computacional descobriu-se que a assimetria da curva de rigidez em torção foi a responsável por gerar a não linearidade quadrática. As tricoherencias mostraram que de fato a não linearidade cúbica influência todas as frequências do sistema gerando superharmônicos ímpares e que a intensidade dessas frequências aumenta com o aumento da velocidade do escoamento de ar.

Pontanto, como contribuições, tem-se o estudo detalhado dessas não linearidades estruturais separadas, utilizado aqui como revisão dos efeitos não lineares e validação do modelo computacional. Além disso, tem-se o estudo dessas duas não linearidades combinadas alterando o comportamento do sistema. Ademais, descobriu-se que os parâmetros lineares influenciam a dinâmica do sistema. Finalmente, mostrou-se que as análises por espectros de ordem mais alta são uma forte ferramenta na análise não linear espectral, podendo ser estendida para diversas outras áreas de engenharia. Por fim, esse trabalho de dissertação gerou três publicações:

1. Pereira, D. A., Marques, F. D. Supercritical and Subcritical Bifurcation in Typical Aeroelastic Section with Structural Nonlinearities. In: 23nd International Congress of Mechanical Engineering, 2015, Rio de Janeiro, SP, Brazil. 
2. Pereira, D. A., Vasconcellos, R. M., Hajj, M. R., Marques, F. D. Bifurcation Phenomena and Frequency Coupling in Nonlinear Typical Aeroelastic Sections. Submetido para Aerospace Science and Technology Journal.

3. Pereira, D. A., Vasconcellos, R. M., Hajj, M. R., Marques, F. D. Insights on Aeroelastic Bifurcation Phenomena in Airfoils with Structural Nonlinearities. Mathematics in Engineering, Science and Aerospace (MESA), 6(3), 2015.

\section{Sugestões para trabalhos futuros}

Em trabalhos futuros, espera-se analisar os parâmetros lineares do sistema e como as não linearidades estruturais se relacionam com eles. Também espera-se ampliar o modelo computacional através da utilização de modelos aerodinâmicos que levem em conta a não linearidade resultante da separação da camada limite, os quais serão uteis para analisar determinados tipos de voos como o bater da asa de pássaros (flapping wings). Finalmente, estuda-se a possibilidade de unificar as técnicas de análise não linear em um único modelo computacional, o qual facilitaria outros trabalhos futuros. 


\section{Funções $T$ de Theodorsen}

Mais detalhes sobre essas funções podem ser encontrados em Theodorsen (1935).

$$
\begin{aligned}
& T_{1}=-\frac{2+c^{2}}{3} \sqrt{1-c^{2}}+c \cos ^{-1} c \\
& T_{3}=-\frac{1-c^{2}}{8}\left(5 c^{2}+4\right)+\frac{1}{4} c\left(7+2 c^{2}\right) \sqrt{1-c^{2}} \cos ^{-1} c-\left(\frac{1}{8}+c^{2}\right)\left(\cos ^{-1} c\right)^{2} \\
& T_{4}=c \sqrt{1-c^{2}}-\cos ^{-1} c \\
& T_{5}=-\left(1-c^{2}\right)-\left(\cos ^{-1} c\right)^{2}+2 c \sqrt{1-c^{2}} \cos ^{-1} c \\
& T_{7}=c\left(\frac{7+2 c^{2}}{8}\right) \sqrt{1-c^{2}}-\left(\frac{1}{8}+c^{2}\right) \cos ^{-1} c \\
& T_{8}=-\frac{1}{3}\left(1+2 c^{2}\right) \sqrt{1-c^{2}}+c \cos ^{-1} c \\
& T_{9}=\frac{1}{2}\left[\frac{\sqrt{1-c^{2}}\left(1-c^{2}\right)}{3}+a T_{4}\right] \\
& T_{10}=\sqrt{1-c^{2}}+\cos ^{-1} c \\
& T_{11}=(2-c) \sqrt{1-c^{2}}-(1-2 c) \cos ^{-1} c \\
& T_{12}=(2+c) \sqrt{1-c^{2}}-(1+2 c) \cos ^{-1} c \\
& T_{13}=-\frac{1}{2}\left[T_{7}+(c-a) T_{1}\right]
\end{aligned}
$$




\section{Bibliografia}

ABDELKEFI, A.; VASCONCELLOS, R.; MARQUES, F.; HAJJ, M. Bifurcation analysis of an aeroelastic system with concentrated nonlinearities. Nonlinear Dynamics, Springer Netherlands, v. 69, n. 1-2, p. 57-70, 2012.

ALIGHANBARI, H.; PRICE, S. The post-hopf-bifurcation response of an airfoil in incompressible two-dimensional flow. Nonlinear Dynamics, Springer, v. 10, n. 4, p. 381-400, 1996.

BARBARINO, S.; BILGEN, O.; AJAJ, R. M.; FRISWELL, M. I.; INMAN, D. J. A review of morphing aircraft. Journal of Intelligent Material Systems and Structures, Sage Publications, v. 22, n. 9, p. 823-877, 2011.

BENDAT, J. S.; PIERSOL, A. G. Random data: analysis and measurement procedures. [S.1.]: John Wiley \& Sons, 2011.

BERAN, P. S.; STRGANAC, T. W.; KIM, K.; NICHKAWDE, C. Studies of store-induced limit-cycle oscillations using a model with full system nonlinearities. Nonlinear Dynamics, Springer, v. 37, n. 4, p. 323-339, 2004.

BISPLINGHOFF, R. L.; ASHLEY, H.; HALFMAN, R. L. Aeroelasticity. [S.1.]: Dover Publications, 1996.

BROOMHEAD, D. S.; KING, G. P. Extracting qualitative dynamics from experimental data. Physica D: Nonlinear Phenomena, Elsevier, v. 20, n. 2, p. 217-236, 1986.

CHEN, P.; SARHADDI, D.; LIU, D. Limit-cycle-oscillation studies of a fighter with external stores. In: Proceedings of the 39th AIAA Structures, Structural Dynamics and Materials Conference. Long Beach, CA: [s.n.], 1998. (AIAA Paper 98-1727), p. 258-266.

CLOUGH, R. W.; PENZIEN, J. Dynamics of Structures. [S.1.]: Computers \& Structures, Inc, 2003.

COLLAR, A. The expanding domain of aeroelasticity. Journal of the Royal Aeronautical Society, v. 50, n. 428, p. 613-636, 1946.

CUNNINGHAM, J.; ATLEE, M.; GEURTS, E. G. Analysis of limit cycle oscillation/transonic high alpha flow visualization. [S.1.], 1997.

DENEGRI, C. M. Limit cycle oscillation flight test results of a fighter with external stores. Journal of Aircraft, v. 37, n. 5, p. 761-769, 2000. 
DENEGRI, C. M.; CUTCHINS, M. A. Evaluation of classical flutter analyses for the prediction of limit cycle oscillations. In: Proceedings of the 38th AIAA Structures, Structural Dynamics and Materials Conference. Orlando, Florida: [s.n.], 1997. (AIAA Paper 97-1021).

DENEGRI, C. M.; JOHNSON, M. R. Limit cycle oscillation prediction using artificial neural networks. Journal of Guidance, Control, and Dynamics, v. 24, n. 5, p. 887-895, 2001.

DOBBS, S.; MILLER, G.; STEVENSON, J. Self-induced oscillation wind tunnel test of a variable sweep wing. AIAA Paper, v. 85, p. 86-92, 1985.

DOWELL, E. Panel flutter-a review of the aeroelastic stability of plates and shells. AIAA Journal, v. 8, n. 3, p. 385-399, 1970.

DOWELL, E. H. Nonlinear aeroelasticity. In: Proceedings of the 31st AIAA, Structures, Structural Dynamics and Materials Conference. [S.1.: s.n.], 1990. (AIAA Paper 90-1031), p. 1497-1509.

DOWELL, E. H. A modern course in aeroelasticity. [S.1.]: Springer, 2014.

DOWELL, E. H.; CURTISS, J. H. C.; CRAWLEY, E. F.; PETERS, D. A.; SCALAN, R. H.; SISTO, F. A modern course in aeroelasticity. 3. ed. [S.1.]: Kluwer Academic Publishers, 1995.

DOWELL, E. H.; EDWARDS, J.; STRGANAC, T. W. Nonlinear aeroelasticity. Journal of Aircraft, v. 40, n. 5, p. 857-874, 2003.

DOWELL, E. H.; TANG, D. Nonlinear aeroelasticity and unsteady aerodynamics. AIAA Journal, p. 40, v. 9, pp:1187-1196, 2002.

DOWELL, E. H.; THOMAS, J. P.; HALL, K. C. Transonic limit cycle oscillation analysis using reduced order aerodynamic models. Journal of Fluids and Structures, Elsevier, v. 19, n. 1, p. 17-27, 2004.

FACKRELL, J.; MCLAUGHLIN, S.; COLLIS, W.; WHITE, P. Non-linearity detection for condition monitoring using higher order statistics. Proc. COMADEM 96, Citeseer, p. 519-528, 1994.

FOX, R. W.; MCDONALD, A. T.; PRITCHARD, P. J. Introduction to fluid mechanics. [S.1.]: John Wiley \& Sons New York, 1985.

FRAZER, R. A. The flutter of aeroplane wings. [S.1.]: HM Stationery Off., 1929.

FRIEDMANN, P. P. Renaissance of aeroelasticity and its future. Journal of Aircraft, v. 36, n. 1, p. 105-121, 1999.

FUNG, Y. Some recent contributions to panel flutter research. AIAA Journal, v. 1, n. 4, p. 898-909, 1963.

FUNG, Y. C. An Introduction to the Theory of Aeroelasticity. New York: Dover Publications, 1993.

GARRICK, I.; REED-III, W. H. Historical development of aircraft flutter. Journal of Aircraft, v. 18, n. 11, p. 897-912, 1981. 
GRASSBERGER, P.; PROCACCIA, I. Measuring the strangeness of strange attractors. Physica D, v. 9, p. 189-208, 1983.

HAJJ, M.; MIKSAD, R.; POWERS, E. Fundamental-subharmonic interaction: effect of phase relation. Journal of Fluid Mechanics, Cambridge Univ Press, v. 256, p. 403-426, 1993.

HAJJ, M.; MIKSAD, R.; POWERS, E. Perspective: Measurements and analyses of nonlinear wave interactions with higher-order spectral moments. Journal of fluids engineering, American Society of Mechanical Engineers, v. 119, n. 1, p. 3-13, 1997.

HAJJ, M. R.; BERAN, P. S. Higher-order spectral analysis of limit cycle oscillation of fighter aircraft. Journal of Aircraft, v. 45, n. 6, p. 1917-1923, NOV-DEC 2008.

HARTWICH, P. M.; DOBBS, S. K.; ARSLAN, A. E.; KIM, S. C. Navier-stokes computations of limit-cycle oscillations for a b-1-like configuration. Journal of aircraft, v. 38, n. 2, p. 239-247, 2001.

HENSHAW, M. d. C.; BADCOCK, K. J.; VIO, G.; ALLEN, C.; CHAMBERLAIN, J.; KAYNES, I.; DIMITRIADIS, G.; COOPER, J.; WOODGATE, M.; RAMPURAWALA, A. M. et al. Non-linear aeroelastic prediction for aircraft applications. Progress in Aerospace Sciences, Elsevier, v. 43, n. 4, p. 65-137, 2007.

HEYLEN, W.; SAS, P. Modal analysis theory and testing. [S.1.]: Katholieke Universteit Leuven, Departement Werktuigkunde, 2006.

HODGES, D. H.; PIERCE, G. A. Introduction to structural dynamics and aeroelasticity. [S.1.]: cambridge university press, 2011.

KATZ, J.; PLOTKIN, A. Low-speed aerodynamics: from wing theory to panel methods. 2nd. ed. New York: McGraw-Hill, 2006.

KOUSEN, K. A.; BENDIKSEN, O. O. Limit cycle phenomena in computational transonic aeroelasticity. Journal of Aircraft, v. 31, n. 6, p. 1257-1263, 1994.

LEE, B.; GONG, L.; WONG, Y. Analysis and computation of nonlinear dynamic response of a two-degree-of-freedom system and its application in aeroelasticity. Journal of Fluids and Structures, v. 11, n. 3, p. 225 - 246, 1997.

LEE, B.; JIANG, L.; WONG, Y. Flutter of an airfoil with a cubic restoring force. Journal of Fluids and Structures, v. 13, n. 1, p. 75 - 101, 1999.

LEE, B.; LIU, L.; CHUNG, K. Airfoil motion in subsonic flow with strong cubic nonlinear restoring forces. Journal of Sound and Vibration, v. 281, p. 699 - 717, 2005.

LI, D.; GUO, S.; XIANG, J. Aeroelastic dynamic response and control of an airfoil section with control surface nonlinearities. Journal of Sound and Vibration, v. 329, n. 22, p. 4756 4771, 2010.

LI, D.; GUO, S.; XIANG, J. Study of the conditions that cause chaotic motion in a two-dimensional airfoil with structural nonlinearities in subsonic flow. Journal of Fluids and Structures, v. 33, n. 0, p. 109 - 126, 2012. 
LIU, J.; CHEN, F.; CHEN, Y. Bifurcation analysis of aeroelastic systems with hysteresis by incremental harmonic balance method. Applied Mathematics and Computation, Elsevier, v. 219, n. 5, p. 2398-2411, 2012.

LIVNE, E. Future of airplane aeroelasticity. Journal of Aircraft, v. 40, n. 6, p. 1066-1092, 2003.

LIVNE, E.; WEISSHAAR, T. A. Aeroelasticity of nonconventional airplane configurationspast and future. Journal of Aircraft, v. 40, n. 6, p. 1047-1065, 2003.

MAñé, R. On the dimension of compact invariant sets of certain nonlinear maps. In: HAND, D.; YOUNG, L. (Ed.). Dynamical Systems and Turbulence. [S.1.]: Springer, 1981. p. 230-242.

MARQUES, F. D.; BELO, E. M.; OLIVEIRA, V. A.; ROSOLEN, J. R.; SIMONI, A. R. On the investigation of state space reconstruction of nonlinear aeroelastic response time series. Shock and Vibration, Hindawi Publishing Corporation, v. 13, n. 4-5, p. 393-407, 2006.

MARQUES, F. D.; VASCONCELLOS, R. M. G. de. Non-linear aeroelastic signals analysis using time series techniques. In: 20th International Congress of Mechanical Engineering-COBEM. [S.1.: s.n.], 2009.

NAYFEH, A. H.; BALACHANDRAN, B. Applied Nonlinear Dynamics: Analytical Computacional, and Experimental Methods. New York: John Wiley \& Sons, Inc, 1995. (Wiley Series in Nonlinear Sciences).

O'NEIL, T.; STRGANAC, T. W. Aeroelastic response of a rigid wing supported by nonlinear springs. Journal of Aircraft, v. 35, n. 4, p. 616-622, JUL-AUG 1998.

PACKARD, N. H.; CRUTCHFIELD, J. P.; FARMER, J. D.; SHAW, R. S. Geometry from a time series. Physical review letters, APS, v. 45, n. 9, p. 712, 1980.

PEETERS, B.; AUWERAER, H. Van der; GUILLAUME, P.; LEURIDAN, J. The polymax frequency-domain method: a new standard for modal parameter estimation? Shock and Vibration, Hindawi Publishing Corporation, v. 11, n. 3-4, p. 395-409, 2004.

PETERS, D. A. Two-dimensional incompressible unsteady airfoil theory - an overview. Journal of Fluids and Structures, Elsevier, v. 24, n. 3, p. 295-312, 2008.

PRICE, S.; ALIGHANBARI, H.; LEE, B. The aeroelastic response of a two-dimensional airfoil with bilinear and cubic structural nonlinearities. Journal of Fluids and Structures, v. 9, n. 2, p. $175-193,1995$.

REISSNER, E. Effect of Finite Span on the Airload Distributions for Oscillating Wings. 1-Aerodynamic Theory of Oscillating Wings of Finite Span. [S.1.], 1947.

SEARS, W. R. Operational methods in the theory of airfoils in non-uniform motion. Journal of the Franklin Institute, v. 230, p. 95-111, 1940.

SHETA, F.; HARRAND, V. J.; THOMPSON, D. E.; STRGANAC, T. W. Computation and experimental investigation of limit cicle oscillations of nonlinear aeroelastic systems. Journal of Aircraft, v. 39, n. 1, p. 133-141, 2002. 
SILVA, W.; BRENNER, M.; COOPER, J.; DENEGRI, C.; DUNN, S.; HUTTSELL, L.; KAYNES, I.; LIND, R.; POIREL, D.; YURKOVICH, R. Advanced flutter and lco prediction tools for flight test risk and cost reduction-an international collaborative program for t\&e support. AIAA Paper, v. 7630, 2005.

SIMONI, A. R. Análise de Séries Temporais Aeroelásticas Experimentais Não Lineares. Tese (Doutorado) - Universidade de Sao Paulo, 2008.

SMITH, S. W. Digital signal processing: a practical guide for engineers and scientists. [S.1.]: Newnes, 2003.

STOICA, P.; MOSES, R. L. Spectral analysis of signals. [S.1.]: Pearson/Prentice Hall Upper Saddle River, NJ, 2005.

TAKENS, F. Detecting strange attractors in turbulence. In: HAND, D.; YOUNG, L. (Ed.). Dynamical Systems and Turbulence. [S.1.]: Springer, 1981. p. 366-381.

TANG, D.; DOWELL, E. Flutter and stall response of a helicopter blade with structural nonlinearity. Journal of Aircraft, v. 29, n. 5, p. 953-960, 1992.

TANG, D.; KHOLODAR, D.; DOWELL, E. H. Nonlinear response of airfoil section with control surface freeplay to gust loads. AIAA journal, v. 38, n. 9, p. 1543-1557, 2000.

THEODORSEN, T. General theory of aerodynamic instability and the mechanism of flutter. NACA Report 496, n. 496, 1935.

TRICKEY, S.; VIRGIN, L.; DOWELL, E. The stability of limit-cycle oscillations in a nonlinear aeroelastic system. In: THE ROYAL SOCIETY. Proceedings of the Royal Society of London A: Mathematical, Physical and Engineering Sciences. [S.1.], 2002. v. 458, n. 2025, p. 2203-2226.

TRICKEY, S. T. Global and Local Dynamics of an Aeroelastic System with a Control Surface Freeplay Nonlinearity. Tese (Doutorado) - Department of Mechanical Engineering and Materials Science in the Graduate School of Duke University, 2000.

VASCONCELLOS, R.; ABDELKEFI, A.; MARQUES, F.; HAJJ, M. Representation and analysis of control surface freeplay nonlinearity. Journal of Fluids and Structures, v. 31, n. 6, p. $79-91,2012$.

VASCONCELLOS, R. M.; ABDELKEFI, A.; HAJJ, M. R.; ALMEIDA, D. P.; MARQUES, F. D. Airfoil control surface discontinuous nonlinearity experimental assessment and numerical model validation. Journal of Vibration and Control, published online before print, 2014.

VASCONCELLOS, R. M. G. Caracterização e detecção da não linearidade associada à folga em sistemas aeroelásticos. Tese (Doutorado) - Escola de Engenharia de São Carlos, Universidade de São Paulo., 2012.

VASCONCELLOS, R. M. G.; MARQUES, F. D.; PEREIRA, D. A. Time series and spectral analysis of nonlinear aeroelastic oscillations. In: 22nd International Congress of Mechanical Engineering. [S.1.: s.n.], 2013. 
VIRGIN, L.; DOWELL, E.; CONNER, M. On the evolution of deterministic non-periodic behavior of an airfoil. International journal of non-linear mechanics, Elsevier, v. 34, n. 3, p. 499-514, 1999.

WORDEN, K.; TOMLINSON, G. Nonlinearity in Structural Dynamics. [S.1.]: IOP Publishing, 2001.

XIANG, J.; YAN, Y.; LI, D. Recent advance in nonlinear aeroelastic analysis and control of the aircraft. Chinese Journal of Aeronautics, Elsevier, v. 27, n. 1, p. 12-22, 2014.

ZHAO, L.; YANG, Z. Chaotic motions of an airfoil with non-linear stiffness in incompressible flow. Journal of Sound and Vibration, v. 138, n. 2, p. 245 - 254, 1990. 